\title{
Pigments, Colours and Patterns - The contribution of eumelanin and pheomelanin to molluscan shell ornamentation with a special focus on the terrestrial snail Cepaea nemoralis
}

\author{
Dissertation \\ for award of the degree \\ "Doctor rerum naturalium" (Dr. rer. nat.) \\ of the Georg-August-Universität Göttingen \\ within the doctoral program Geosciences \\ of the Georg-August University School of Science (GAUSS) \\ submitted by \\ Susanne Affenzeller \\ from Linz a. d. Donau, Österreich
}

Göttingen 2019 
Thesis Commitee:

Prof. Dr. Daniel J. Jackson, Dept. Geobiology, Georg-August-University Göttingen

Prof. Dr. Gregor Bucher, Dept. Developmental Biology GZMB, Georg-August-University Göttingen

Dr. Klaus Wolkenstein, Dept. Geobiology, Georg-August-University Göttingen

Members of the Examination Board:

Reviewer: $\quad$ Prof. Dr. Daniel J. Jackson, Dept. Geobiology, Georg-AugustUniversity Göttingen

Second Reviewer: Prof. Dr. Gregor Bucher, Dept. Developmental Biology GZMB, Georg-August-University Göttingen

Further members of the Examination Board:

Dr. Klaus Wolkenstein, Dept. Geobiology, Georg-August-University Göttingen

Prof. Dr. Volker Thiel, Dept. Geobiology, Georg-August-University Göttingen

Prof. Dr. Christoph Bleidorn, Dept. Animal Evolution and Biodiversity, GeorgAugust-University Göttingen

Dr. Sven Bradler, Dept. Animal Evolution and Biodiversity, Georg-AugustUniversity Göttingen

Dr. Nico Posnien, Dept. Developmental Biology GZMB, Georg-August-University Göttingen

Tag der mündlichen Prüfung: 7.10.2019 


\section{Versicherung}

Hiermit versichere ich an Eides statt, dass die Dissertation mit dem Titel „Pigments,

Colours and Patterns - The contribution of eumelanin and pheomelanin to molluscan shell ornamentation with a special focus on the terrestrial snail Cepaea nemoralis" selbständig und nur mit den angeführten Hilfsmitteln und Quellen angefertigt wurde.

Göttingen, den 20.08.2019 


\section{TABLE OF CONTENTS}

CHAPTER 1: GENERAL INTRODUCTION

CHAPTER 2: IDENTIFICATION AND VALIDATION OF REFERENCE GENES FOR QPCR IN THE TERRESTRIAL GASTROPOD CEPAEA NEMORALIS.

CHAPTER 3: QUANTITATION OF EUMELANIN AND PHEOMELANIN MARKERS IN DIVERSE BIOLOGICAL SAMPLES BY HPLC-UV-MS FOLLOWING SOLID-PHASE EXTRACTION 38

CHAPTER 4: EUMELANIN AND PHEOMELANIN PIGMENTATION IN MOLLUSC SHELLS MAY BE LESS COMMON THAN EXPECTED: INSIGHTS FROM MASS SPECTROMETRY 60

CHAPTER 5: EUMELANIN IS NOT THE BANDED PIGMENT IN CEPAEA NEMORALIS. 80

CHAPTER 6: GENERAL DISCUSSION 88

APPENDIX A: SUPPLEMENTARY MATERIAL FOR CHAPTER 2 97

APPENDIX B: SUPPLEMENTARY MATERIAL FOR CHAPTER 4 105

APPENDIX C: SUPPLEMENTARY MATERIAL FOR CHAPTER 5

APPENDIX D 


\section{ABSTRACT}

In recent years interest into molluscan pigments increased. But a lot of techniques have to be adapted to be usable with often difficult molluscan tissues and shell material. A comprehensive approach needs to encompass both pigment chemistry and molecular biology. Here an improved method for testing molluscan shells for the presence of characteristic melanin oxidation products is presented. The established method of RT-qPCR relies heavily on sufficiently tested reference genes. Comprehensive testing was carried out for both established house keeping genes and novel reference genes in the terrestrial gastropod Cepaea nemoralis. Both of these techniques were used to test for melanin in mollusc shell pigmentation. Evidence for eumelanin could be found in three conchiferan classes: Nautilus pompilius (Cephalopoda), Mytilus edulis (Bivalvia), Clanculus pharaonius and Steromphala adriatica (Gastropoda). Both eumelanin and pheomelanin were detected in the gastropod C. nemoralis. In this species genes known to be involved in melanin synthesis in insects and mammals were screened for their quantitative expression rates in shell producing mantle tissue. It was found that Tyrosinase and Tyrosinase Related Protein are well expressed all over the mantle tissue, but show no differential expression in band building mantle tissue. Together with evidence of both eumelanin and pheomelanin oxidation products throughout the shell of $\mathrm{C}$. nemoralis, this finding leads to the conclusion that both types of melanin seem to be involved in shell colouration, but not band patterning, of this gastropod shell. A surprisingly large number of other bivalve and gastropod species tested for melanin show similar geometric patterns, that could not be verified as eumelanin. Future research will hopefully shed light onto this very structurally stable molluscan shell pigmentation. 


\section{CHAPTER 1: GENERAL INTRODUCTION}

Mollusca are the one of the most diverse and successful groups in the animal kingdom [1,2]. With an estimated 85,000 extant and over 60,000 fossil species in nine recognized classes they represent the second largest phylum of invertebrates[3,4]. Their rapid diversification during the Cambrian explosion yielded a wide range of variations on the general mollusc Bauplan [5-7]. Through these adaptations of their body plans and lifestyles they successfully conquered all regions of marine and limnic habitats, with some gastropod linages even managing to adapt to the challenges of terrestrial life [8]. On top of their many roles in recent ecosystems, the shell bearing Conchifera also play a major role as markers in the fossil record $[9,10]$.

Although less known mollusc classes like Solenogastres, Caudofoveates and Polyplacophora are fascinating in their own right, it is the shell bearing molluscs that are best known. Especially the shells of Gastropods and Bivalves have been collected and cherished for centuries by children as souvenirs and scientific collectors alike. Perceived as especially precious and interesting are shells with pigments and patterns. Some of them even play major cultural roles. Some cowrie species were used as currency for trade in many different cultures in Africa, Asia and Oceania [11-13]. Conchs and Tridacnas are not only used as symbols and building material in native cultures, but were also integrated in European architecture and art from the renaissance period onwards [11,14-16]. The colourful adornments of certain shells even dictate their value for use in jewellery, but also in commercial food species [17-19]. It is these pigments and patterns and their variations on mollusc shells that interest researches all around the globe [16]. Although the mathematical concepts of shell pattering are well understood and can be computer simulated, little is known on the pigments they use and the biological mechanisms employed [16,20-22]. What is the evolutionary purpose for these patterns? Is it driven by camouflage to escape predation pressure or is it used as an intraspecific communication tool? Why are the patterns of some species stable and useable as identification 
markers, and other species show polymorphisms in both colouration and patterning? Research over the last hundred years has given us some insights into possible answers to these questions. Molluscs were shown to employ a number of chemically different pigments in their shells [16,23,24]. First efforts were undertaken to understand how mollusc shells are built and in which way pigments could be laid down into them [1,25-28]. And a number of studies tried to understand the evolution of polymorphic shell patterns, prominently known from the terrestrial snail Cepaea nemoralis including research on different selection pressures, underlying genetics and heritability patterns [29-36].

\section{Pigments}

Colours in mollusc shells can range from very colourful blues, reds and yellows to monochromatic brown/black and white (Fig. 1). The responsible pigments are thought to be built into the shell as it is laid down by the molluscs mantle edge [37].

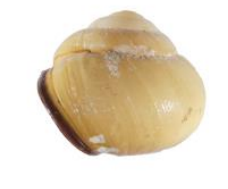

Cepaea nemoralis

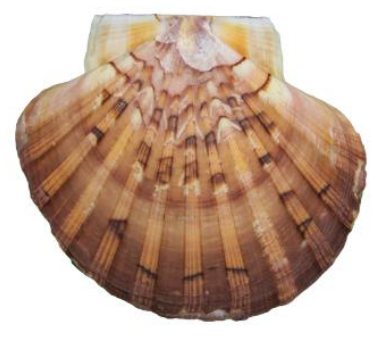

Pecten maximus

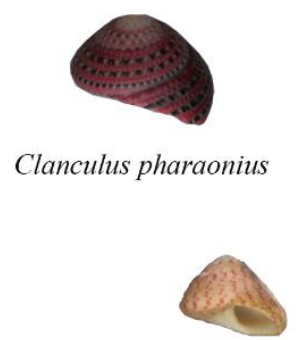

Steromphala rarilineata

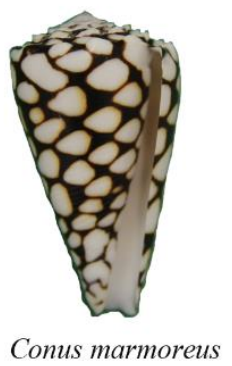

Mytilus edulis

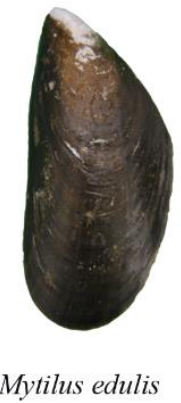

Figure 1.

Mollusc shells can range in colours from white and yellows to dark brown and black, sometimes showing geometrically fascinating patterns.

This leads to the assumption that mollusc mantle tissue is either able to produce these pigments or they are transported to the mantle edge after being taken up through food sources [16]. In some species (e.g. Cepaea nemoralis, Haliotis spp.) corresponding patterns can be observed in the mantle 
tissue directly beneath shell colouration $[25,37,38]$. But although molluses display a large amount of different colours, little is known about the chemical composition of their pigments. In one of the earliest comprehensive approaches Comfort [24,39-43] tested a range of conchiferan species for different pigment classes and indicated the widespread presence of pyrroles and melanins in these organisms. He found that tetrapyrroles, mainly as porphyrins and sometimes bile pigments, were commonly found in marine gastropods and bivalves $[24,39,40]$. This pigment class is easily dissolved in aqueous acids and shows a distinct reddish fluorescence [16]. Although Comforts' work is an invaluable basis to work from, one has to be aware that the methods available to him at the time were only rudimentary compared to modern chemical methods. Many of his works are based on solubility tests of these pigments and early chromatographic separations. While these investigations still yielded light on basic chemical properties of many mollusc pigments, more in depth and precise methods have to be applied to verify pigment classes. Efforts to that end were made in recent studies using high performance liquid chromatography and UV detection (HPLC-UV) to further characterise molluscan tetrapyrroles as uroporphyrins and protoporphyrins responsible for bright orange and red colourations $[23,44]$. Within this colour range another abundant pigment class are carotenoids, which are generally synthesised by plants and only secondarily taken up by animals for colouration $[16,18]$. Carotinoids are well known from plants, but also vertebrates and some Raman spectroscopy studies on shell material indicated their possible presence in gastropod and bivalve shells [18,45-50].

For dark geometric patterns, and generally darker colourations, melanins are often implicated as the responsible pigments [16,24,43]. Although melanins are well known in vertebrates, the term was used generically for most brown and black colourations in molluscs as well, often without chemically analysing the pigments in question [24,42,51]. More accurately melanins are defined as polymerisation products of DOPA (L-3,4-dihydroxyphenylalanine) subunits by enzymatic oxidation (Fig. 2) [51-57]. 


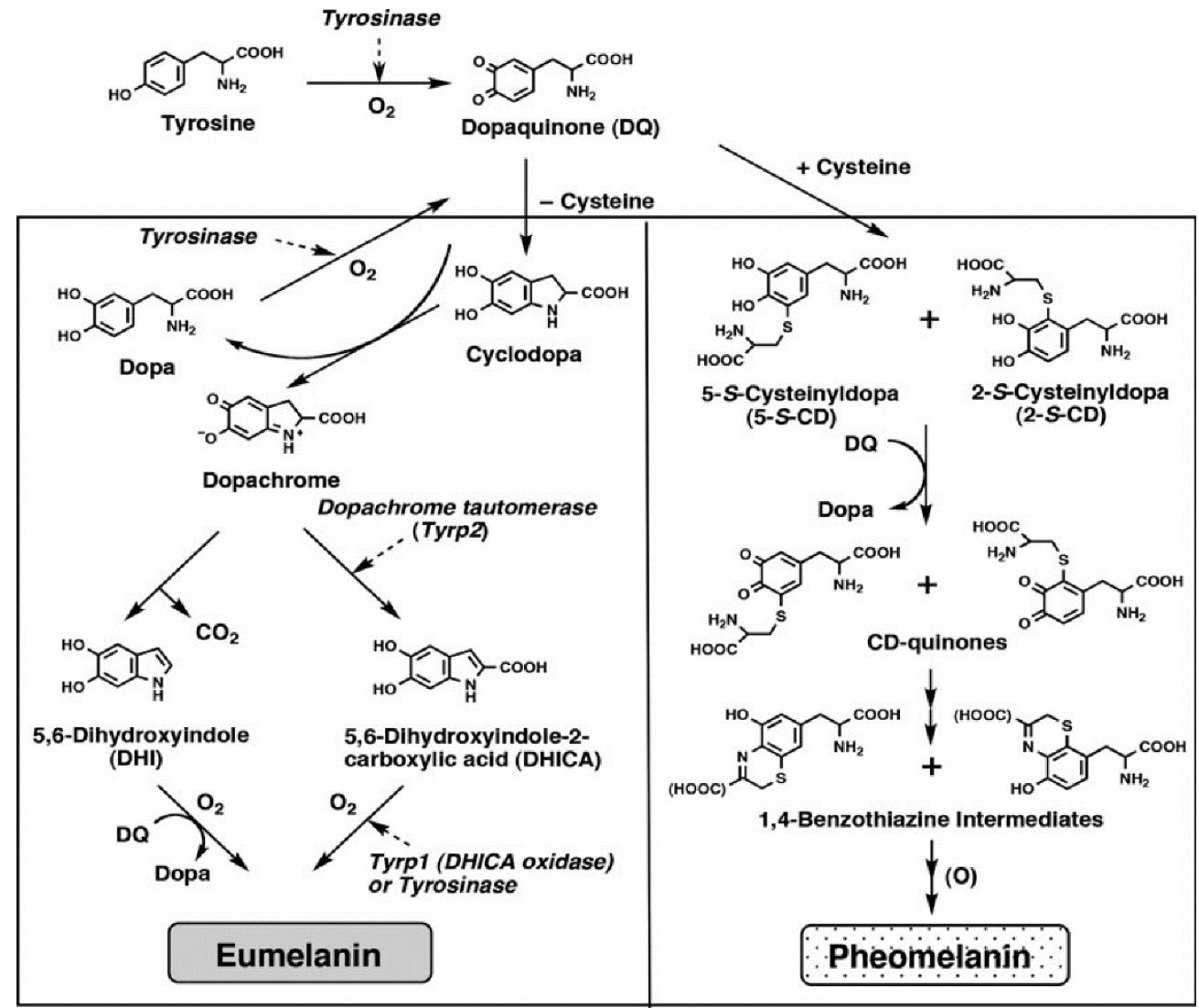

\section{Figure 2.}

Eumelanin and pheomelanin are polymerisation products of DOPA subunits in the absence or presence of cysteine. The process is catalysed be the enzyme Tyrosinase, and in some cases Tyrosinase Related Proteins. (from d'Ischia et al. [57])

The resulting macromolecules, termed eumelanin, show a brown to black colour and are very thermoand chemo-stable [52,58-60]. The addition of cysteine during polymerisation results in pheomelanin pigments, well known from human red hair [53,61-64]. This even more complex macromolecule can produce a colour range of yellows, oranges and reds and is well known from mammals and birds $[62,64]$. But it is chemically difficult to verify either of these melanins due to their specific characteristics and complex nature $[52,53,60]$. An established method for vertebrate samples is therefore to measure their characteristic oxidation products by HPLC-UV $[65,66]$. This method has 
been adapted from its initial use in human medical studies to some biological samples, including some mollusc species $[23,64,67,68]$. Following these protocols studies found some evidence for melanin in shells of gastropods (Clanculus spp.) and bivalves (Mizuhopecten yessoensis, Pteria penguin and Crassostrea gigas) and their pearl producing nacre $[23,67,69,70]$. When investigating colouration in mollusc shells one has to take into account the complex nature of this calcified sample matrix and the possible pigments involved (Fig. 3). Evidence based on HPLC-UV results as described above, without adjusted sample preparation steps, has to be regarded with caution. More sensitive methods based on mass spectrometric detection, as presented in the Pteria study [70], allows for more confident identification of shell pigments.

In addition to some difficulties in identifying eumlanin in previous studies [23,67,69], a surprisingly large number of prominently dark patterned mollusc shells have not been investigated with modern methods yet. In addition to investigations on melanin pigmentation in bivalves, cephalopods and gastropods special interest will be put on the terrestrial snail Cepaea nemoralis. This species shows a prominent dark brown to black banding pattern and shell background colours ranging from light yellow over pink and orange to dark brown. This variability in shell colour led to the assumption of melanin as one possible pigment class in previous studies [24,43,71], but melanins have never been chemically investigated in this species. 

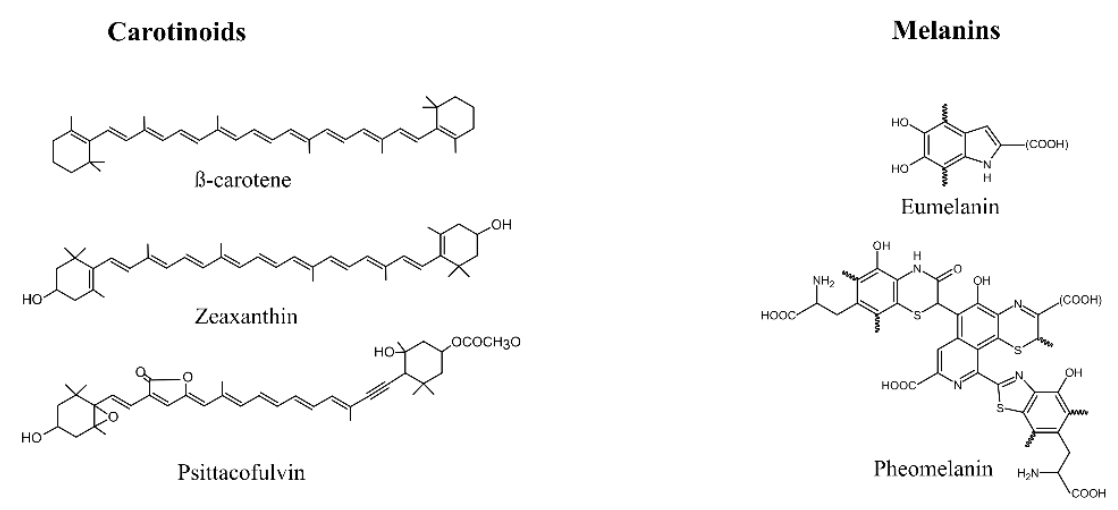

Tetrapyrrols
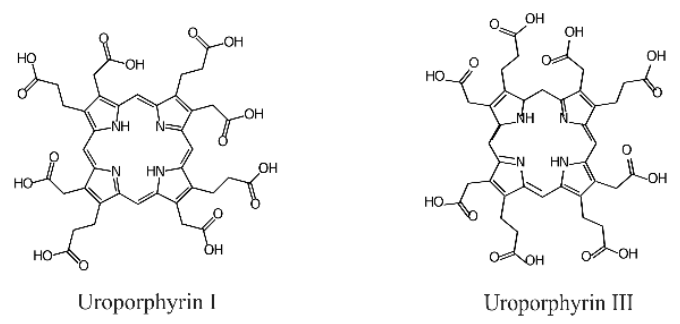

\section{Figure 3.}

Different pigment molecules have been indicated to be involved in shell colouration in molluscs: Carotinoids (adapted from de Oliveira et al. [48]), melanins (adapted from Chapter 3) and tetrapyrrols (adapted from Williams et al. [27])

\section{Patterns}

Mollusc shells not only exhibit a multitude of colours but they also show a wide range of patterns (Fig. 1). Many of these geometric markings on shells can be modelled computationally with near perfection $[21,22]$. For some time two major mechanisms were thought to explain these patterns produced by molluscs: the reaction-diffusion model [20] and the neural network model [72]. More recent models include more complicated feedback mechanisms allowing more sophisticated pattern approximations and even inference of ancestral states [73,74]. But new data from Haliotis suggests 
that pigmentation is actually not single cell dependent but uses a secretory duct system, indicating a much more complex pattern control system [37].

Haliotis is also the only species with a known link between spatial gene expression and pigment pattern. In juveniles of $H$. asinina the gene Somesuke shows spatial expression fitting the blue and red pattern in its shell $[2,25]$. Many other species showing patterning or polymorphisms have been investigated by quantitative methods for differential gene expression. In some bivalves Tyrosinase and Tyrosinase Related Protein genes were indicated as being involved in shell and nacre pigmentation [19,70,75-77]. Although these are promising results on the function of eumelanin as pigments in molluscs, many studies couldn't prove any spatial expression of these genes in shell building mantle regions. Additionally these efforts are hindered by a still incomplete understanding of the melanin synthesis pathway in molluscs.

One of the perhaps best studied cases of polymorphisms involving mollusc shell patterns is the terrestrial gastropod Cepaea nemoralis $[29,35,36]$. Its shell background colour and different banding patterns have been of interest to ecologists and evolutionary biologists alike [78-80]. Although many lines of investigation were undertaken in the past (e.g. effects on body temperature, crypsis, predation pressure) no convincing explanation for this phenomenon could be found [29,31,81-84]. While we still don't understand the evolutionary background of the polymorphism, this study system is a good starting point for investigating colourations and patterning mechanisms in mollusc shells $[30,33,82,85-87]$. Hopefully a better understanding of the genetic background will lead to revelations on the evolution of the Cepaea polymorphism.

Early crossing experiments showed a near perfect mendelian inheritance pattern for many shell colouration traits like background colour, banding pattern and shell lip colour $[30,78,82]$. Based on these observations a tightly linked supergene arrangement of genetic loci controlling the traits was 
assumed $[33,36,87,88]$. Efforts undertaken in recent years yielded a set of RAD-Seq markers flanking this supergene, allowing further investigations into recombination events of the relevant loci [33,35]. This new data set reveals that recombination events within the supergene might not be as common as previously assumed. Incomplete penetrance and epistasis are actually able to explain these phenotypes [35]. Together with new investigations on transcriptomic and proteomic data the fine mapping of the supergene of Cepaea nemoralis now seems to become possible. Still, data collected over the last years with new and advanced sequencing techniques could not reveal conclusive candidates for these patterning genes [32,89]. While Kerkvliet et al. [89] found metallothionein genes, thought to inhibit melanin synthesis, as most promising candidates, Mann and Jackson [32] could not detect any proteins associated directly with shell colouration. The genetic control for this complex polymorphism is therefore still unsolved and further investigations into differential gene expression in both bioinformatic and in situ experiments have to be undertaken it the future. The above mentioned recent gain in molecular data and methods in $C$. nemoralis affords the opportunity of combining molecular biology and shell chemistry to gain insights into the pigmentation and patterning mechanisms involved $[32,33,89]$.

In the following chapters I will describe insights gained from experiments on shell pigments and patterning mechanisms in shell bearing molluscs, with a special focus on $C$. nemoralis. Chapter 2 contains the establishment of reference genes for reverse transcription quantitative polymerase chain reaction in $C$. nemoralis. This method can be used to determine expression levels of certain genes. To selectively and sensitively measure oxidation products of both eumelanin and pheomelanin in complex biological sample matrices I developed and adapted a mass spectrometric method for use on a wide variety of samples (chapter 3). Both of these methods were applied in chapter 4 . These chemical analyses were conducted on a range of mollusc species (bivalves, cephalopods and 
gastropods) to determine the use of eumelanin and pheomelanin in mollusc shells (chapter 4). In chapter 5 I used both methods to test eumelanin and pheomelanin composition in different shell colour morphs and quantitative expression levels of known melanin pathway genes in C. nemoralis.

\section{References}

1. Kocot KM, Aguilera F, McDougall C, Jackson DJ, Degnan BM. 2016 Sea shell diversity and rapidly evolving secretomes: insights into the evolution of biomineralization. Front. Zool. 13. (doi:10.1186/s12983-016-0155-z)

2. Jackson DJ, Wörheide G, Degnan BM. 2007 Dynamic expression of ancient and novel molluscan shell genes during ecological transitions. BMC Evol. Biol. 7, 160. (doi:10.1186/1471-2148-7-160)

3. Taylor PD, Lewis DN. 2007 Fossil Invertebrates. Harvard University Press.

4. Rosenberg G. 2014 A New Critical Estimate of Named Species-Level Diversity of the Recent Mollusca*. Am. Malacol. Bull. 32, 308-322. (doi:10.4003/006.032.0204)

5. Erwin DH, Laflamme M, Tweedt SM, Sperling EA, Pisani D, Peterson KJ. 2011 The Cambrian Conundrum: Early Divergence and Later Ecological Success in the Early History of Animals. Science 334, 1091-1097. (doi:10.1126/science.1206375)

6. Marshall CR. 2006 Explaining the Cambrian "Explosion" of Animals. Annu. Rev. Earth Planet. Sci. 34, 355384. (doi:10.1146/annurev.earth.33.031504.103001)

7. Smith MP, Harper DAT. 2013 Causes of the Cambrian Explosion. Science 341, 1355-1356. (doi:10.1126/science.1239450)

8. Haszprunar G, Wanninger A. 2012 Molluscs. Curr. Biol. 22, R510-R514. (doi:10.1016/j.cub.2012.05.039)

9. Zuschin M, Harzhauser M, Mandic O. 2004 Taphonomy and Paleoecology of the lower Badenian (Middle Miocene) Molluscan Assemblages at Grund (Lower Austria). Geol. Carpathica 55, 117-128.

10. Gallmetzer I, Haselmair A, Tomašových A, Stachowitsch M, Zuschin M. 2017 Responses of molluscan communities to centuries of human impact in the northern Adriatic Sea. PLoS One 12, e0180820. (doi:10.1371/journal.pone.0180820)

11. Ogundiran A. 2002 Of Small Things Remembered: Beads, Cowries, and Cultural Translations of the Atlantic Experience in Yorubaland. Int. J. Afr. Hist. Stud. 35, 427-457. (doi:10.2307/3097620)

12. Gregory CA. 1996 Cowries and Conquest: Towards a Subalternate Quality Theory of Money. Comp. Stud. Soc. Hist. 38, 195-217. (doi:10.1017/S0010417500020235)

13. Yang B. 2011 The Rise and Fall of Cowrie Shells: The Asian Story. J. World Hist. 22, 1-25.

14. Doran E. 1958 The Caicos Conch Trade. Geogr. Rev. 48, 388-401. (doi:10.2307/212258)

15. Pietak LM. 1998 Body Symbolism and Cultural Aesthetics: The Use of Shell Beads and Ornaments by Delaware and Munsee Groups. North Am. Archaeol. 19, 135-161. (doi:10.2190/0BV6-Q0N1-37VU-PEQ7)

16. Williams ST. 2017 Molluscan shell colour: Molluscan shell colour. Biol. Rev. 92, 1039-1058. (doi:10.1111/brv.12268) 
17. Cai Z, Wu J, Chen L, Guo W, Li J, Wang J, Zhang Q. 2011 Purification and characterisation of aquamarine blue pigment from the shells of abalone (Haliotis discus hannai Ino). Food Chem. 128, 129-133. (doi:10.1016/j.foodchem.2011.03.006)

18. Canales-Gómez E, Correa G, Viana MT. 2010 cantaxanthin and $\beta$-carotene) in juvenile abalone Haliotis rufescens diets on the color of the shell or nacre. Vet. Mex. 41, 191-200.

19. Chen X, Liu X, Bai Z, Zhao L, Li J. 2017 HcTyr and HcTyp-1 of Hyriopsis cumingii, novel tyrosinase and tyrosinase-related protein genes involved in nacre color formation. Comp. Biochem. Physiol. B Biochem. Mol. Biol. 204, 1-8. (doi:10.1016/j.cbpb.2016.11.005)

20. Meinhardt H. 1984 Models for positional signalling, the threefold subdivision of segments and the pigmentation pattern of molluscs. Development 83, 289-311.

21. Meinhardt H. 2009 The Algorithmic Beauty of Sea Shells. Springer Science \& Business Media.

22. Meinhardt H, Klingler M. 1987 A model for pattern formation on the shells of molluscs. J. Theor. Biol. 126, 63-89. (doi:10.1016/S0022-5193(87)80101-7)

23. Williams ST et al. 2016 Identification of Shell Colour Pigments in Marine Snails Clanculus pharaonius and C. margaritarius (Trochoidea; Gastropoda). PLoS ONE 11, e0156664. (doi:10.1371/journal.pone.0156664)

24. Comfort A. 1951 The pigmentation of molluscan shells. Biol. Rev. 26, 285-301. (doi:10.1111/j.1469185X.1951.tb01358.x)

25. Jackson DJ, McDougall C, Green K, Simpson F, Wörheide G, Degnan BM. 2006 A rapidly evolving secretome builds and patterns a sea shell. BMC Biol. 4.

26. Herlitze I, Marie B, Marin F, Jackson DJ. 2018 Molecular modularity and asymmetry of the molluscan mantle revealed by a gene expression atlas. GigaScience 7, 1-15. (doi:10.1093/gigascience/giy056)

27. Williams ST, Lockyer AE, Dyal P, Nakano T, Churchill CKC, Speiser DI. 2017 Colorful seashells: Identification of haem pathway genes associated with the synthesis of porphyrin shell color in marine snails. Ecol. Evol. 7, 10379-10397. (doi:10.1002/ece3.3552)

28. Marin F, Luquet G, Marie B, Medakovic D. 2007 Molluscan Shell Proteins: Primary Structure, Origin, and Evolution. In Current Topics in Developmental Biology, pp. 209-276. Academic Press. (doi:10.1016/S00702153(07)80006-8)

29. Cain AJ, Sheppard PM. 1954 Natural Selection in Cepaea. Genetics 39, 89-116.

30. Cook LM. 1967 The genetics of Cepaea nemoralis. Heredity 22, 397-410. (doi:10.1038/hdy.1967.49)

31. Greenwood JJD. 1974 Visual and other selection in Cepaea: A further example. Heredity 33, 17-31. (doi:10.1038/hdy.1974.61)

32. Mann K, Jackson D. 2014 Characterization of the pigmented shell-forming proteome of the common grove snail Cepaea nemoralis. BMC Genomics 15, 249. (doi:10.1186/1471-2164-15-249)

33. Richards PM, Liu MM, Lowe N, Davey JW, Blaxter ML, Davison A. 2013 RAD-Seq derived markers flank the shell colour and banding loci of the Cepaea nemoralis supergene. Mol. Ecol. 22, 3077-3089. (doi:10.1111/mec.12262)

34. Davison A, Jackson HJ, Murphy EW, Reader T. 2019 Discrete or indiscrete? Redefining the colour polymorphism of the land snail Cepaea nemoralis. Heredity 123, 162-175. (doi:10.1038/s41437-019-0189-z)

35. Gonzalez DR, Aramendia AC, Davison A. 2019 Recombination within the Cepaea nemoralis supergene is confounded by incomplete penetrance and epistasis. Heredity 123, 153-161. (doi:10.1038/s41437-019-0190-6) 
36. Jones JS, Leith BH, Rawlings P. 1977 Polymorphism in Cepaea: A Problem with Too Many Solutions? Annu. Rev. Ecol. Syst. 8, 109-143. (doi:10.1146/annurev.es.08.110177.000545)

37. Budd A, McDougall C, Green K, Degnan BM. 2014 Control of shell pigmentation by secretory tubules in the abalone mantle. Front. Zool. 11, 62. (doi:10.1186/s12983-014-0062-0)

38. Affenzeller S, Cerveau N, Jackson DJ. 2018 Identification and validation of reference genes for qPCR in the terrestrial gastropod Cepaea nemoralis. PLoS One 13, e0201396.

39. Comfort A. 1949 Acid-soluble pigments of shells. 1. The distribution of porphyrin fluorescence in molluscan shells. Biochem. J. 44, 111-117.

40. Comfort A. 1949 Acid-soluble pigments of molluscan shells. 2. Pigments other than porphyrins. Biochem. J. 45, 199-204.

41. Comfort A. 1949 Acid-soluble pigments of molluscan shells. 3. The indigoid character of the blue pigment of Haliotis cracherodii Leach. Biochem. J. 45, 204-208.

42. Comfort A. 1950 Biochemistry of molluscan shell pigments. J. Molluscan Stud. 28, 79-85. (doi:10.1093/oxfordjournals.mollus.a064570)

43. Comfort A. 1951 Observations on the shell pigments of land pulmonates. J. Molluscan Stud. 29, 35-44. (doi:10.1093/oxfordjournals.mollus.a064598)

44. Verdes A, Cho W, Hossain M, Brennan PLR, Hanley D, Grim T, Hauber ME, Holford M. 2015 Nature's Palette: Characterization of Shared Pigments in Colorful Avian and Mollusk Shells. PLoS ONE 10, e0143545. (doi:10.1371/journal.pone.0143545)

45. Barnard W, de Waal D. 2006 Raman investigation of pigmentary molecules in the molluscan biogenic matrix. $J$. Raman Spectrosc. 37, 342-352. (doi:10.1002/jrs.1461)

46. Bergamonti L, Bersani D, Mantovan S, Lottici PP. 2013 Micro-Raman investigation of pigments and carbonate phases in corals and molluscan shells. Eur. J. Mineral. 25, 845-853. (doi:10.1127/0935-1221/2013/0025-2318)

47. Hedegaard C, Bardeau J-F, Chateigner D. 2006 Molluscan shell pigments: an in situ resonance raman study. $J$. Molluscan Stud. 72, 157-162. (doi:10.1093/mollus/eyi062)

48. de Oliveira LN, de Oliveira VE, D’ávila S, Edwards HGM, de Oliveira LFC. 2013 Raman spectroscopy as a tool for polyunsaturated compound characterization in gastropod and limnic terrestrial shell specimens. Spectrochim. Acta. A. Mol. Biomol. Spectrosc. 114, 541-546. (doi:10.1016/j.saa.2013.05.095)

49. Karampelas S, Fritsch E, Mevellec J-Y, Gauthier J-P, Sklavounos S, Soldatos T. 2007 Determination by Raman scattering of the nature of pigments in cultured freshwater pearls from the mollusk Hyriopsis cumingii. J. Raman Spectrosc. 38, 217-230. (doi:10.1002/jrs.1626)

50. Borodina AV, Maoka T, Soldatov AA. 2013 Composition and content of carotenoids in body of the Black sea gastropod Rapana venosa (Valenviennes, 1846). J. Evol. Biochem. Physiol. 49, 283-290. (doi:10.1134/S002209301303002X)

51. Prota G. 2012 Melanins and Melanogenesis. Academic Press.

52. Riley PA. 1997 Melanin. Int. J. Biochem. Cell Biol. 29, 1235-1239. (doi:10.1016/S1357-2725(97)00013-7)

53. Ito S. 2003 A Chemist's View of Melanogenesis. Pigment Cell Res 7, 230-236.

54. d'Ischia M, Napolitano A, Prota G. 1991 Peroxidase as an alternative to tyrosinase in the oxidative polymerization of 5,6-dihydroxyindoles to melanin(s). Biochim. Biophys. Acta BBA - Gen. Subj. 1073, 423-430. (doi:10.1016/0304-4165(91)90152-7) 
55. Lerner AB, Fitzpatrick TB. 1950 Biochemistry of melanin formation. Physiol. Rev. 30, 91-126. (doi:10.1152/physrev.1950.30.1.91)

56. Binns F, King JAG, Mishra SN, Percival A, Robson NC, Swan GA. 1970 Studies Related to the Chemistry of Melanins. Part XIII. Studies on the Structure of Dopamine-Melanin. J. Chem. Soc. C Org. 15, 2063-2070.

57. d'Ischia M et al. 2015 Melanins and melanogenesis: from pigment cells to human health and technological applications. Pigment Cell Melanoma Res. 28, 520-544. (doi:10.1111/pcmr.12393)

58. Swan GA, Waggott A. 1970 Studies related to the chemistry of melanins. Part X. Quantitative assessment of different types of units present in dopa-melanin. J. Chem. Soc. C Org. 0, 1409-1418.

(doi:10.1039/J39700001409)

59. Andersen NH et al. 1974 Structure, Chemistry, and Biosynthesis of the Melanins. In Fortschritte der Chemie Organischer Naturstoffe / Progress in the Chemistry of Organic Natural Products (eds W Herz, H Grisebach, GW Kirby), pp. 521-582. Vienna: Springer Vienna. (doi:10.1007/978-3-7091-7094-6_9)

60. Prota G. 1988 Progress in the chemistry of melanins and related metabolites. Med. Res. Rev. 8, 525-556. (doi:10.1002/med.2610080405)

61. Ito S, Jimbow K. 1983 Quantitative Analysis of Eumelanin and Pheomelanin in Hair and Melanomas. J. Invest. Dermatol. 80, 268-272. (doi:10.1111/1523-1747.ep12534616)

62. Ozeki H, Ito S, Wakamatsu K, Thody AJ. 1996 Spectrophotometric Characterization of Eumelanin and Pheomelanin in Hair. Pigment Cell Res. 9, 265-270. (doi:10.1111/j.1600-0749.1996.tb00116.x)

63. Sealy R, Hyde J, Felix C, Menon I, Prota G. 1982 Eumelanins and pheomelanins: characterization by electron spin resonance spectroscopy. Science 217, 545-547. (doi:10.1126/science.6283638)

64. Ito S, Wakamatsu K. 2003 Quantitative Analysis of Eumelanin and Pheomelanin in Humans, Mice, and Other Animals: a Comparative Review. Pigment Cell Res. 16, 523-531. (doi:10.1034/j.1600-0749.2003.00072.x)

65. Ito S, Nakanishi Y, Valenzuela RK, Brilliant MH, Kolbe L, Wakamatsu K. 2011 Usefulness of alkaline hydrogen peroxide oxidation to analyze eumelanin and pheomelanin in various tissue samples: application to chemical analysis of human hair melanins: Alkaline hydrogen peroxide oxidation of melanin. Pigment Cell Melanoma Res. 24, 605-613. (doi:10.1111/j.1755-148X.2011.00864.x)

66. Napolitano A, Pezzella A, Vincensi MR, Prota G. 1995 Oxidative degradation of melanins to pyrrole acids: A model study. Tetrahedron 51, 5913-5920. (doi:10.1016/0040-4020(95)00259-B)

67. Sun X, Wu B, Zhou L, Liu Z, Dong Y, Yang A. 2017 Isolation and characterization of melanin pigment from yesso scallop Patinopecten yessoensis. J. Ocean Univ. China 16, 279-284. (doi:10.1007/s11802-017-3162-6)

68. McGraw KJ et al. 2004 You can't judge a pigment by its color: carotenoid and melanin content of yellow and brown feathers in swallows, bluebirds, penguins, and domestic chickens. The Condor 106, 390. (doi:10.1650/7384)

69. Hao S, Hou X, Wei L, Li J, Li Z, Wang X. 2015 Extraction and Identification of the Pigment in the Adductor Muscle Scar of Pacific Oyster Crassostrea gigas. PLoS ONE 10, e0142439. (doi:10.1371/journal.pone.0142439)

70. Yu F, Pan Z, Qu B, Yu X, Xu K, Deng Y, Liang F. 2018 Identification of a tyrosinase gene and its functional analysis in melanin synthesis of Pteria penguin. Gene 656, 1-8. (doi:10.1016/j.gene.2018.02.060)

71. Vicario A, Mazon LI, Aguirre A, Estomba A, Lostao C. 1989 A tyrosinase-like enzyme in Cepaea nemoralis and its possible relation with shell banding polymorphism. J. Molluscan Stud. 55, 441-444.

(doi:10.1093/mollus/55.4.441) 
72. Ermentrout B, Campbell J, Oster G. 1986 A Model for Shell Patterns Based on Neural Activity. The Veliger 28, 369-388.

73. Boettiger A, Ermentrout B, Oster G. 2009 The neural origins of shell structure and pattern in aquatic mollusks. Proc. Natl. Acad. Sci. 106, 6837-6842. (doi:10.1073/pnas.0810311106)

74. Gong Z, Matzke NJ, Ermentrout B, Song D, Vendetti JE, Slatkin M, Oster G. 2012 Evolution of patterns on Conus shells. Proc. Natl. Acad. Sci. 109, E234-E241. (doi:10.1073/pnas.1119859109)

75. Zhang C, Xie L, Huang J, Chen L, Zhang R. 2006 A novel putative tyrosinase involved in periostracum formation from the pearl oyster (Pinctada fucata). Biochem. Biophys. Res. Commun. 342, 632-639. (doi:10.1016/j.bbrc.2006.01.182)

76. Nagai K, Yano M, Morimoto K, Miyamoto H. 2007 Tyrosinase localization in mollusc shells. Comp. Biochem. Physiol. B Biochem. Mol. Biol. 146, 207-214. (doi:10.1016/j.cbpb.2006.10.105)

77. Zhang G et al. 2012 The oyster genome reveals stress adaptation and complexity of shell formation. Nature 490, 49-54. (doi:10.1038/nature11413)

78. Fisher RA, Diver C. 1934 Crossing-over in the Land Snail Cepaea nemoralis, L. Nature 133, 834-835. (doi:10.1038/133834b0)

79. Cain AJ, Sheppard PM. 1950 Selection in the polymorphic land snail Cepaea nemoralis. Heredity 4, $275-294$. (doi:10.1038/hdy.1950.22)

80. Cain AJ, Sheppard PM. 1952 The effects of natural selection on body colour in the land snail Cepaea nemoralis. Heredity 6, 217-231. (doi:10.1038/hdy.1952.22)

81. Surmacki A, Ożarowska-Nowicka A, Rosin ZM. 2013 Color polymorphism in a land snail Cepaea nemoralis (Pulmonata: Helicidae) as viewed by potential avian predators. Naturwissenschaften 100, 533-540. (doi:10.1007/s00114-013-1049-y)

82. Cain AJ, King JMB, Sheppard PM. 1960 New Data on the Genetics of Polymorphism in the Snail Cepaea nemoralis L. Genetics 45, 393-411.

83. Lamotte M. 1959 Polymorphism of Natural Populations of Cepaea nemoralis. Cold Spring Harb. Symp. Quant. Biol. 24, 65-86. (doi:10.1101/SQB.1959.024.01.009)

84. Jones JS. 1973 Ecological Genetics and Natural Selection in Molluscs: Climatic selection has an important effect on some patterns of gene distribution in snail populations. Science 182, 546-552. (doi:10.1126/science.182.4112.546)

85. Cuthill IC et al. 2017 The biology of color. Science 357, eaan0221. (doi:10.1126/science.aan0221)

86. Cook LM. 1998 A two-stage model for Cepaea polymorphism. Philos. Trans. R. Soc. B Biol. Sci. 353, 15771593. (doi:10.1098/rstb.1998.0311)

87. Schwander T, Libbrecht R, Keller L. 2014 Supergenes and Complex Phenotypes. Curr. Biol. 24, R288-R294. (doi:10.1016/j.cub.2014.01.056)

88. Murray J, Clarke B. 1976 Supergenes in polymorphic land snails. Heredity 37, 253.

89. Kerkvliet J, de Boer T, Schilthuizen M, Kraaijeveld K. 2017 Candidate genes for shell colour polymorphism in Cepaea nemoralis. PeerJ 5, e3715. (doi:10.7717/peerj.3715) 


\section{CHAPTER 2: IDENTIFICATION AND VALIDATION OF REFERENCE GENES FOR qPCR IN} THE TERRESTRIAL GASTROPOD CEPAEA NEMORALIS.

The following manuscript was published as follows

Affenzeller S, Cerveau N, Jackson DJ. Identification and validation of reference genes for qPCR in the terrestrial gastropod Cepaea nemoralis. PloS one. 2018 Aug 29;13(8):e0201396.

and is reprinted here with permission form PLoS One.

Contributions by doctoral candidate: Formal analysis, Methodology, Writing - original draft, Writing - review \& editing 


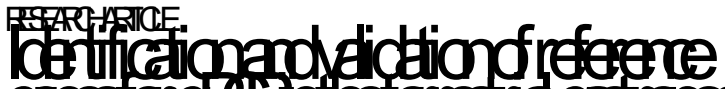

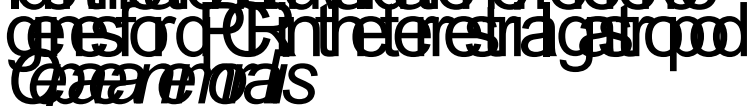

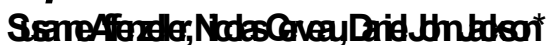

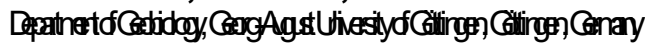

*gatss@iggetilingence

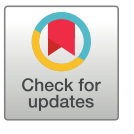

G OENACCSS

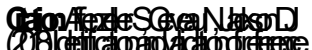

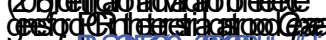

remots

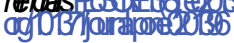

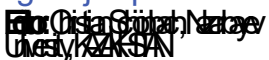

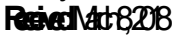

Aratedilly $B 218$

FuristedAmis2018

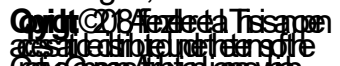

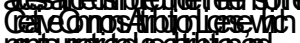

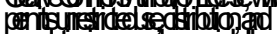

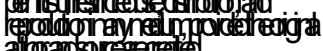

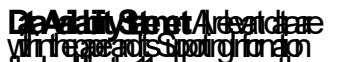

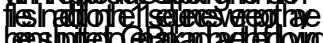

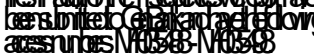

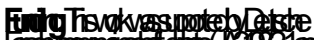

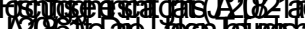

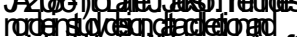

a s.

matssip

\section{Astrat}

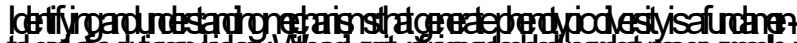

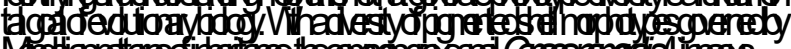

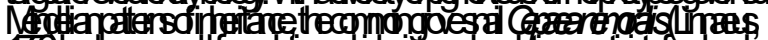

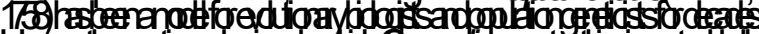

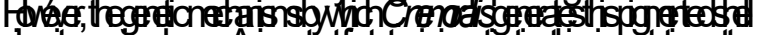

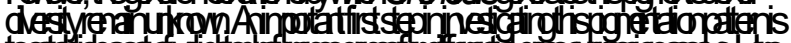

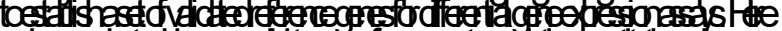

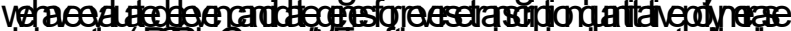

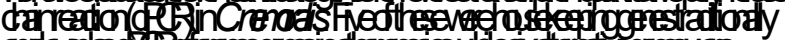

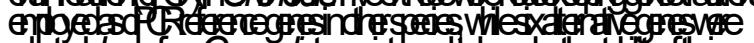

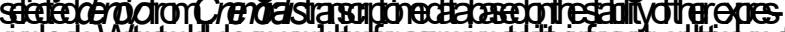

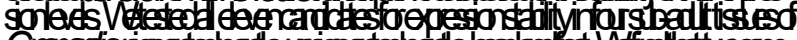

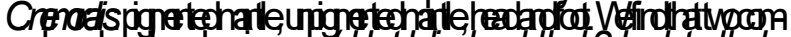

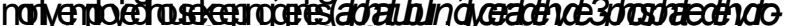

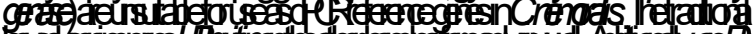

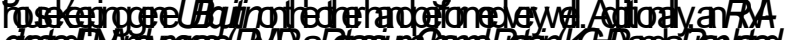

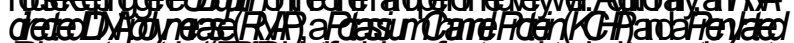

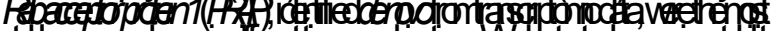

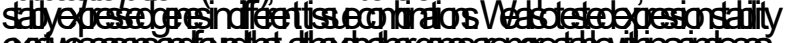

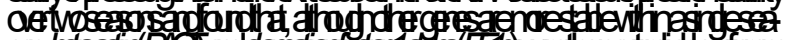

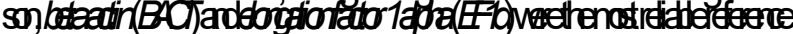
crosarsists

\section{Irtcoldion}

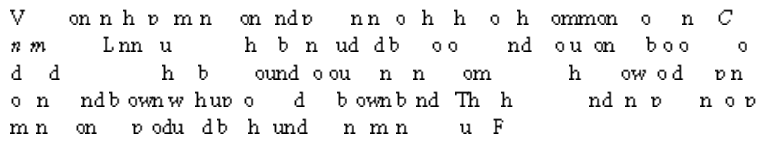

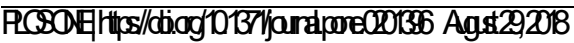




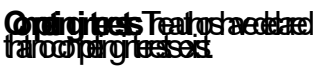
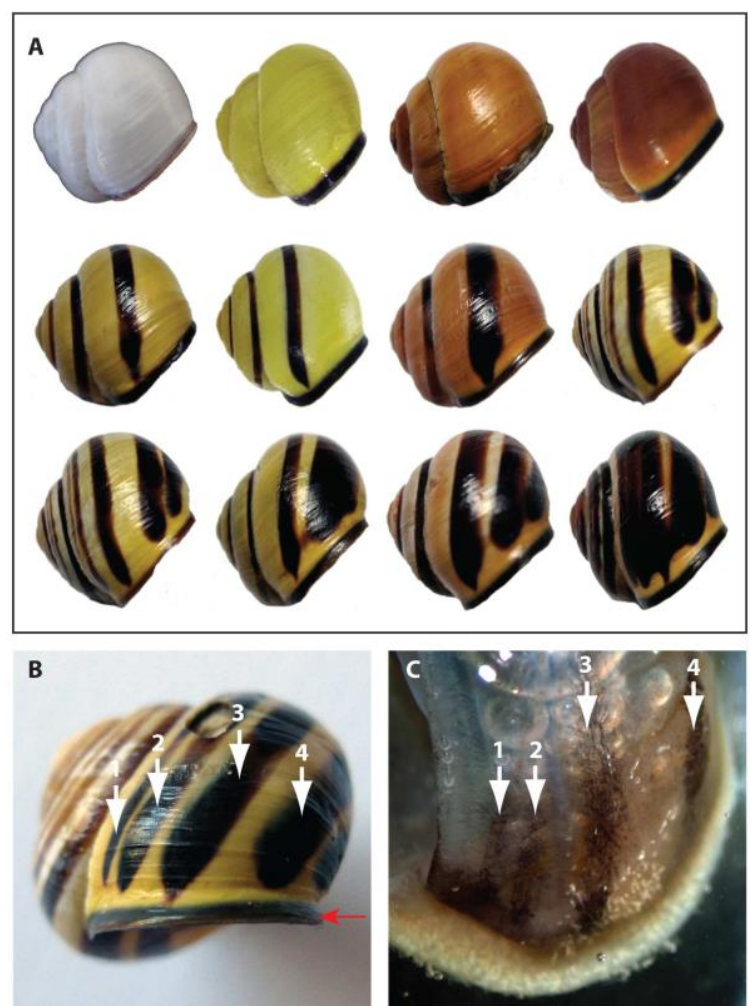

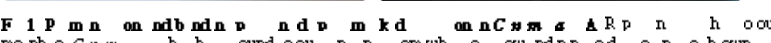

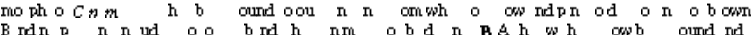

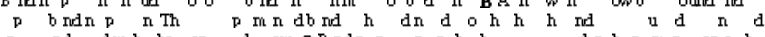

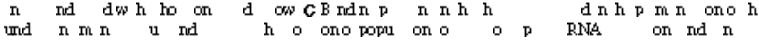

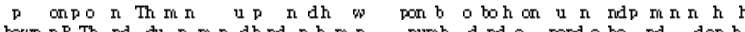

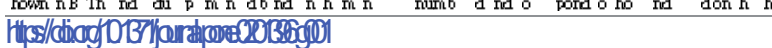

$$
\begin{aligned}
& \text { E ud OCnm ou don hd bu ono oou mooh nd mo d } \\
& \text { h ou on } b \text { u h }
\end{aligned}
$$




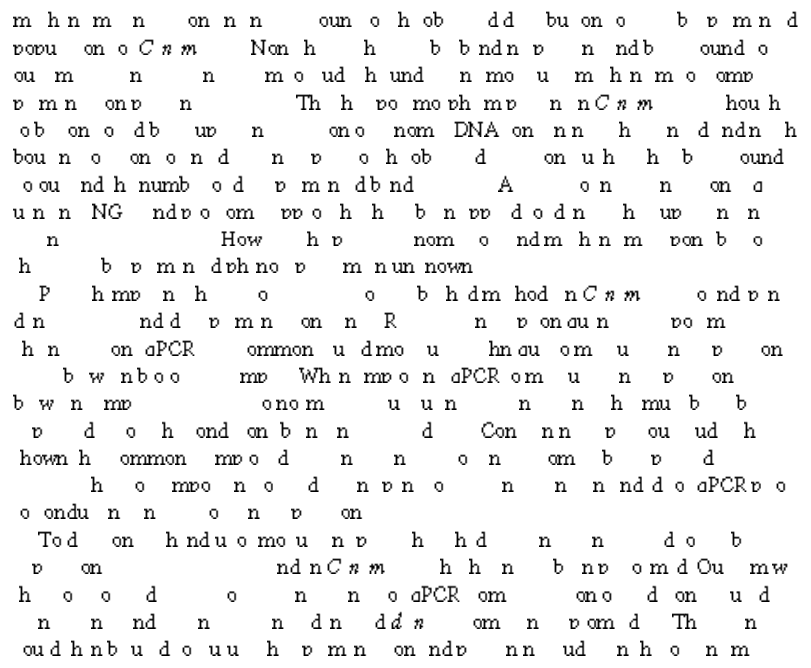

\section{Maidadhathes}

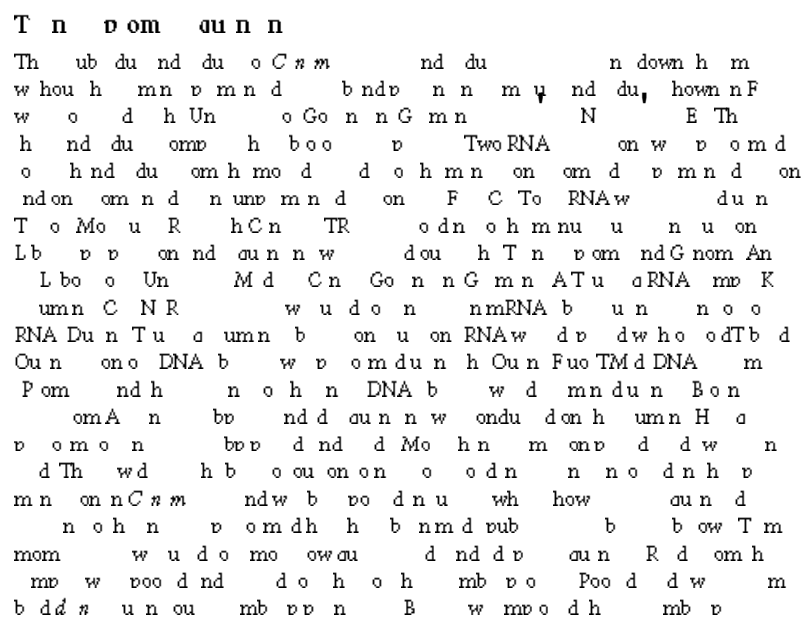




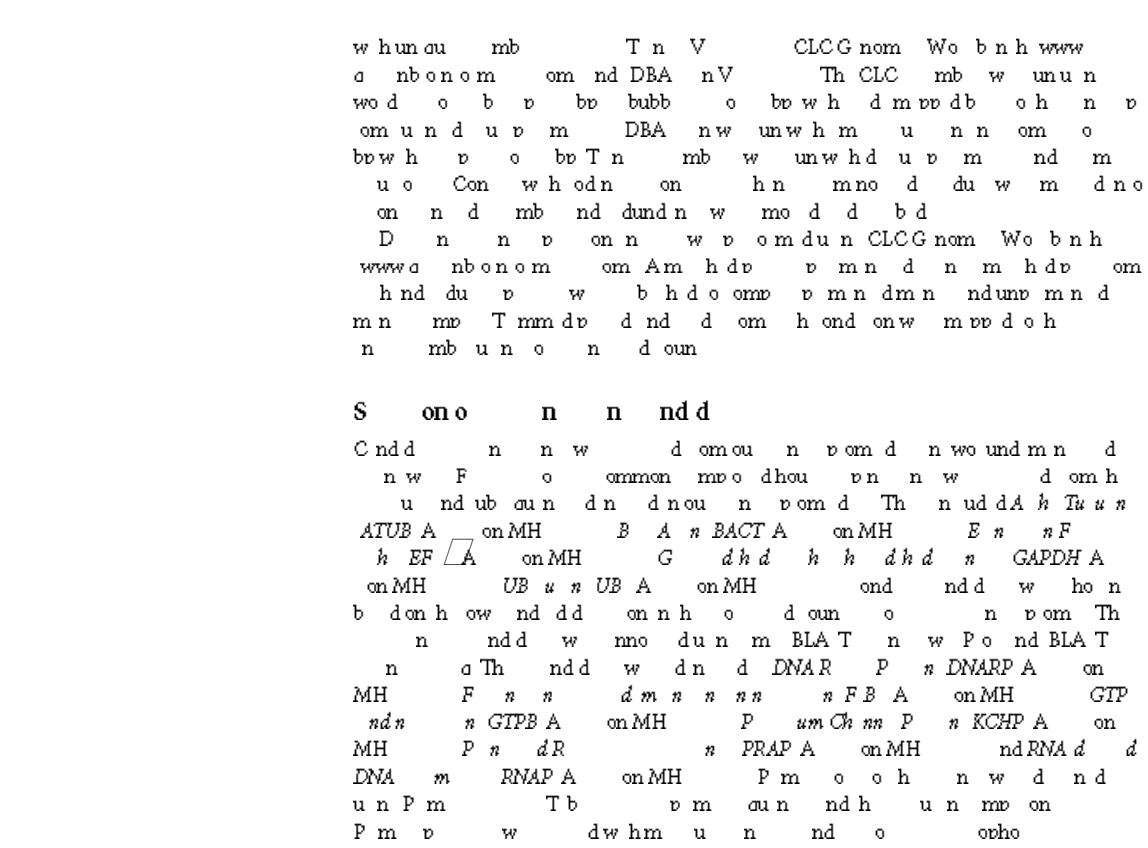

RNA on nd DNA $\mathrm{nh}$

To RNAw d om ub du nd du 0 C nm ndond $n$ o ho

\begin{tabular}{|c|c|c|c|c|}
\hline $6 n$ & Fow dp m $5^{\prime} 03^{\prime}$ & D m $5^{\prime} 03^{\prime}$ & Amp on & bp \\
\hline ATUR & AICGIANCACCTCACCET & ARAIG"WCECACETCLIG & & \\
\hline$B A C T$ & 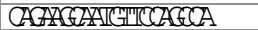 & TGFIECACACACAOALAA & & \\
\hline DNARP & 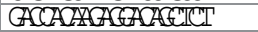 & GIIIICCICEATEAACAC & & \\
\hline$E \square$ & GIACCCEACAG" "CACEET" & 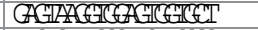 & & \\
\hline$F B$ & TCEAICAAICCECEACA & AICACIACCEACACEC & & \\
\hline GAPDH & 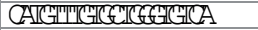 & TCACECCDCACAN"CCA & & \\
\hline$G T P E$ & 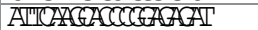 & TAMGCeCADACACACGI & & \\
\hline XCHP & 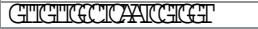 & ARAGCLCAMCCDC & & \\
\hline PRAP & ATC'MAALCCCCECET & GI"ICACACCCAICACG & & \\
\hline DNAP & CCETICACAICGA & CECTCICAICCTIACCC & & \\
\hline$U E$ & ACAAICECCCACAAICET & ADAICACECICICICCCG & & \\
\hline
\end{tabular}

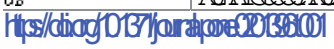




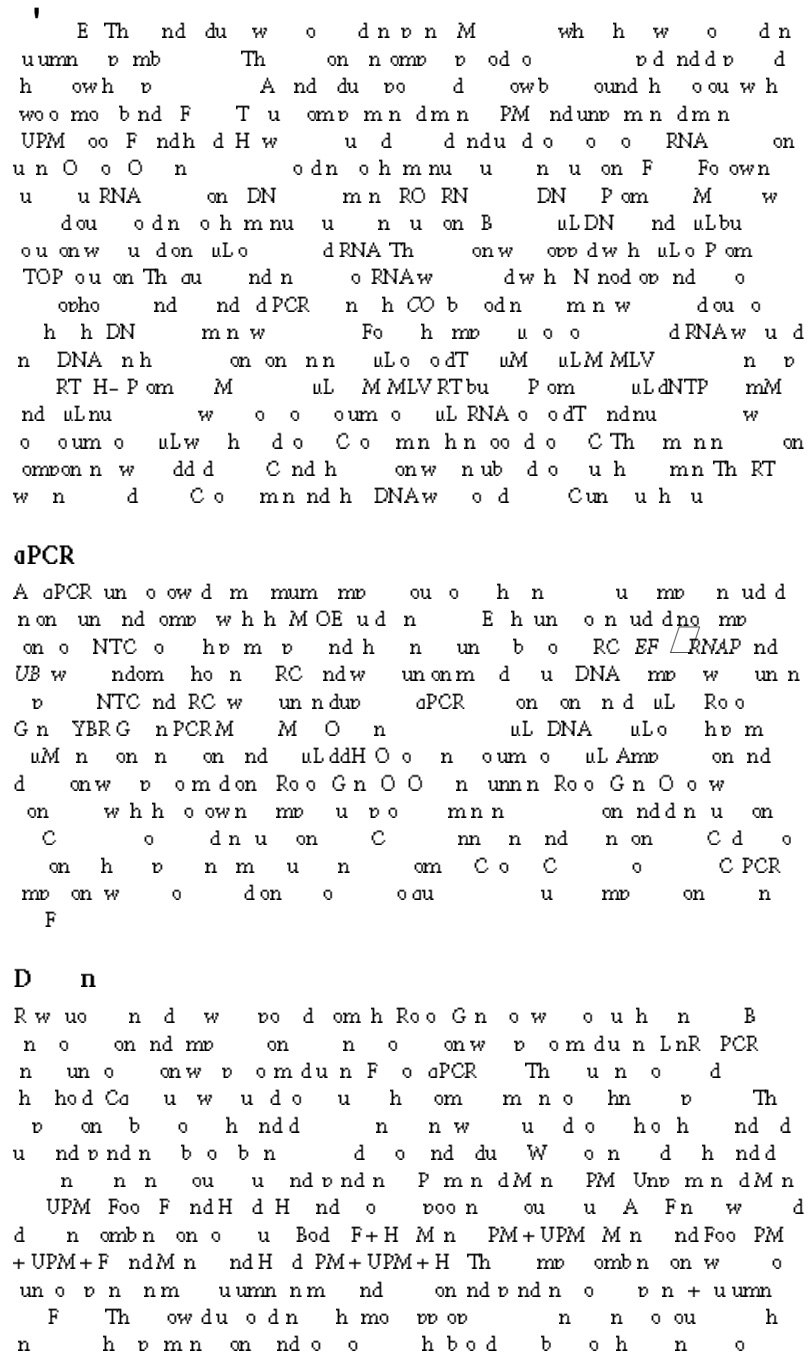




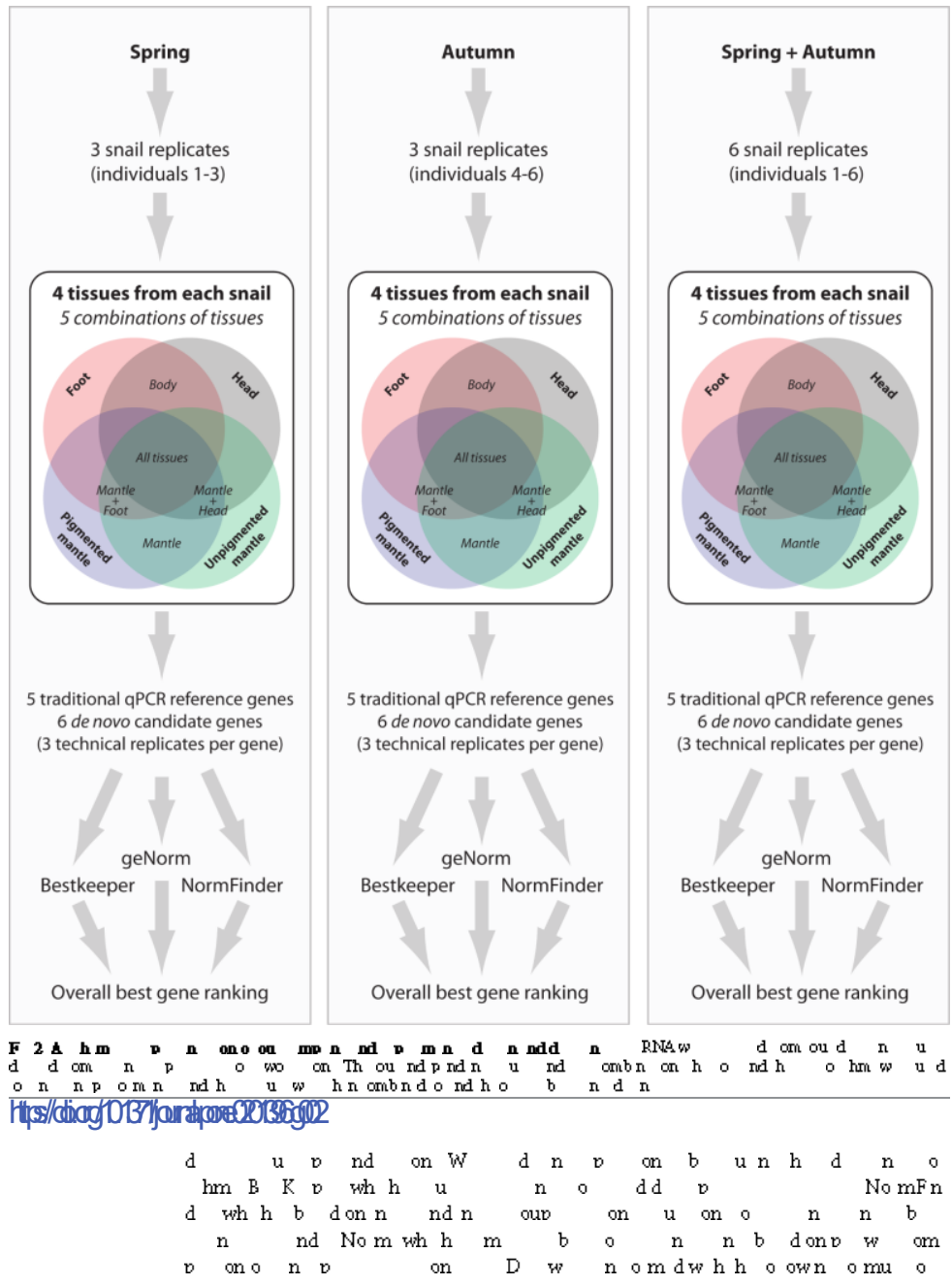




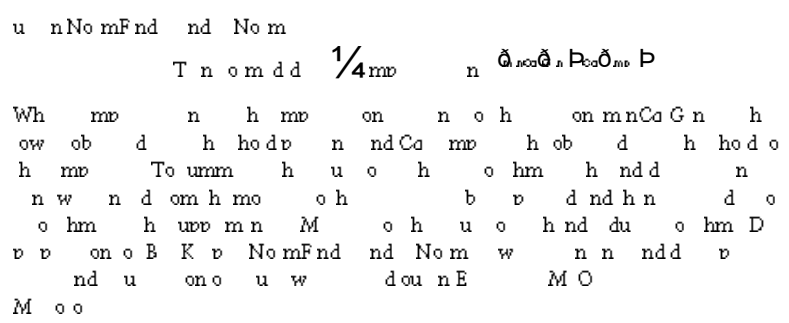

\section{Ralls}

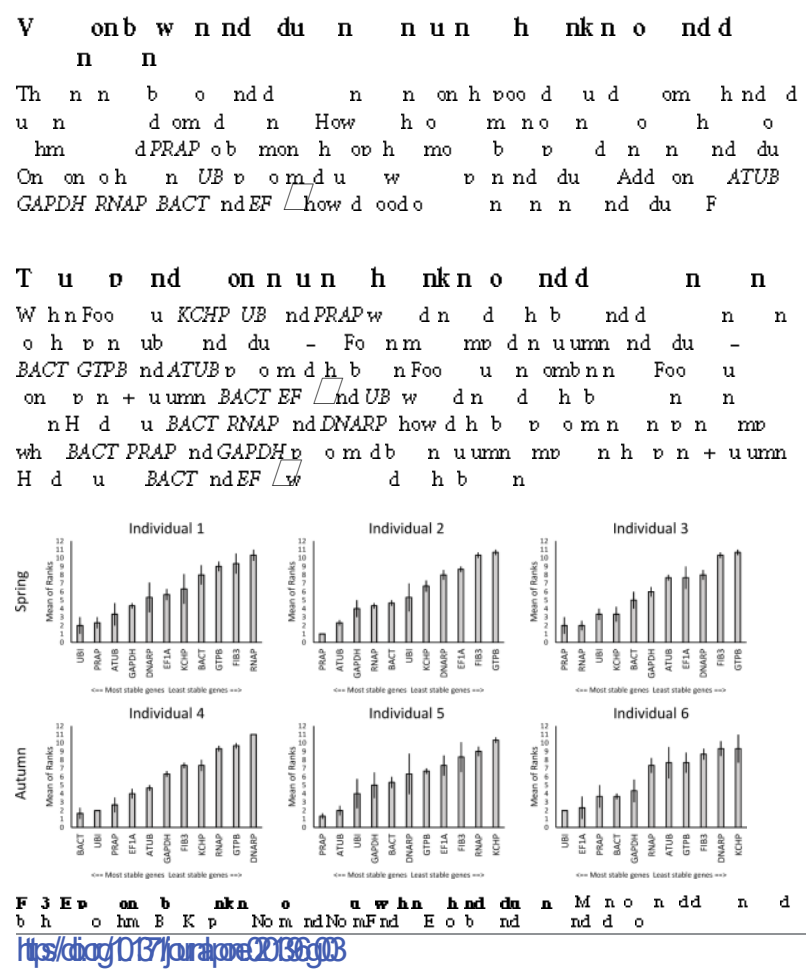




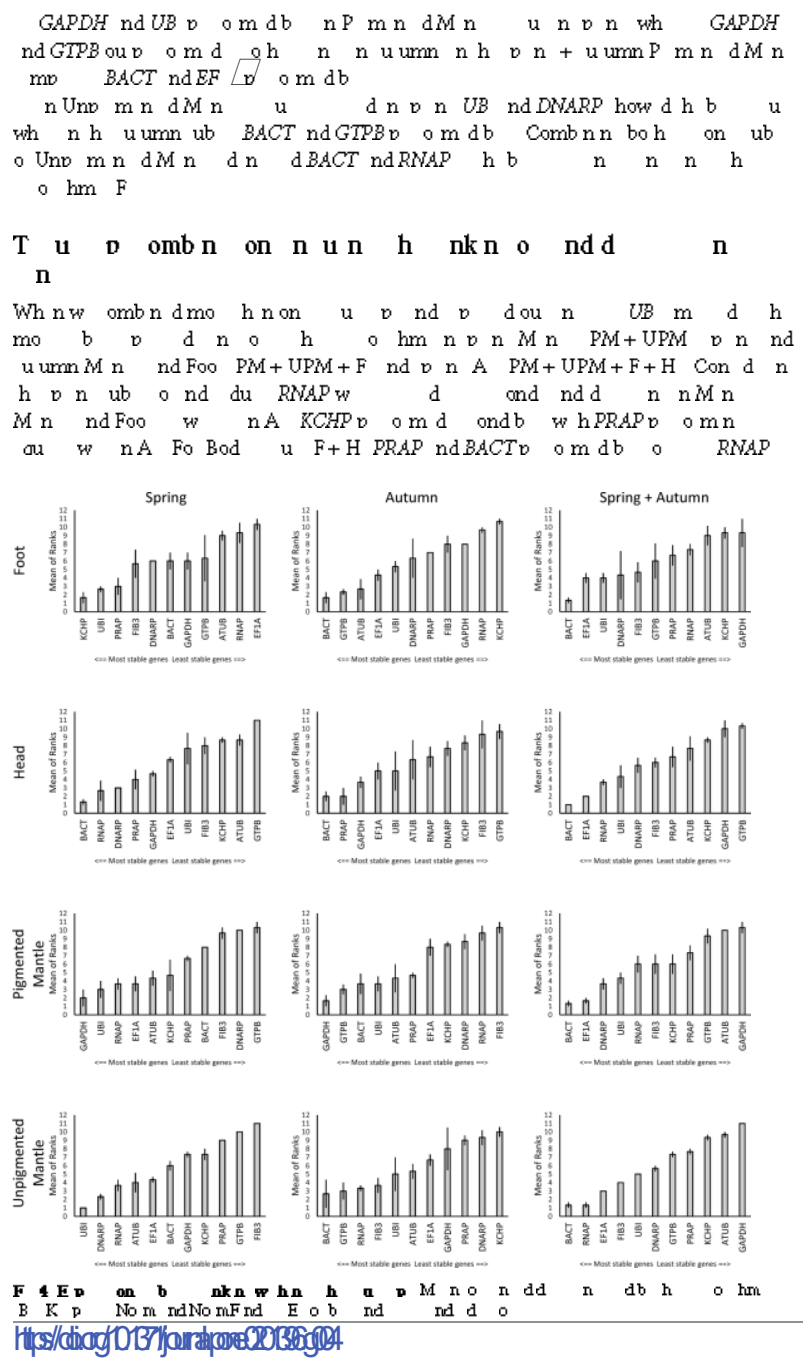



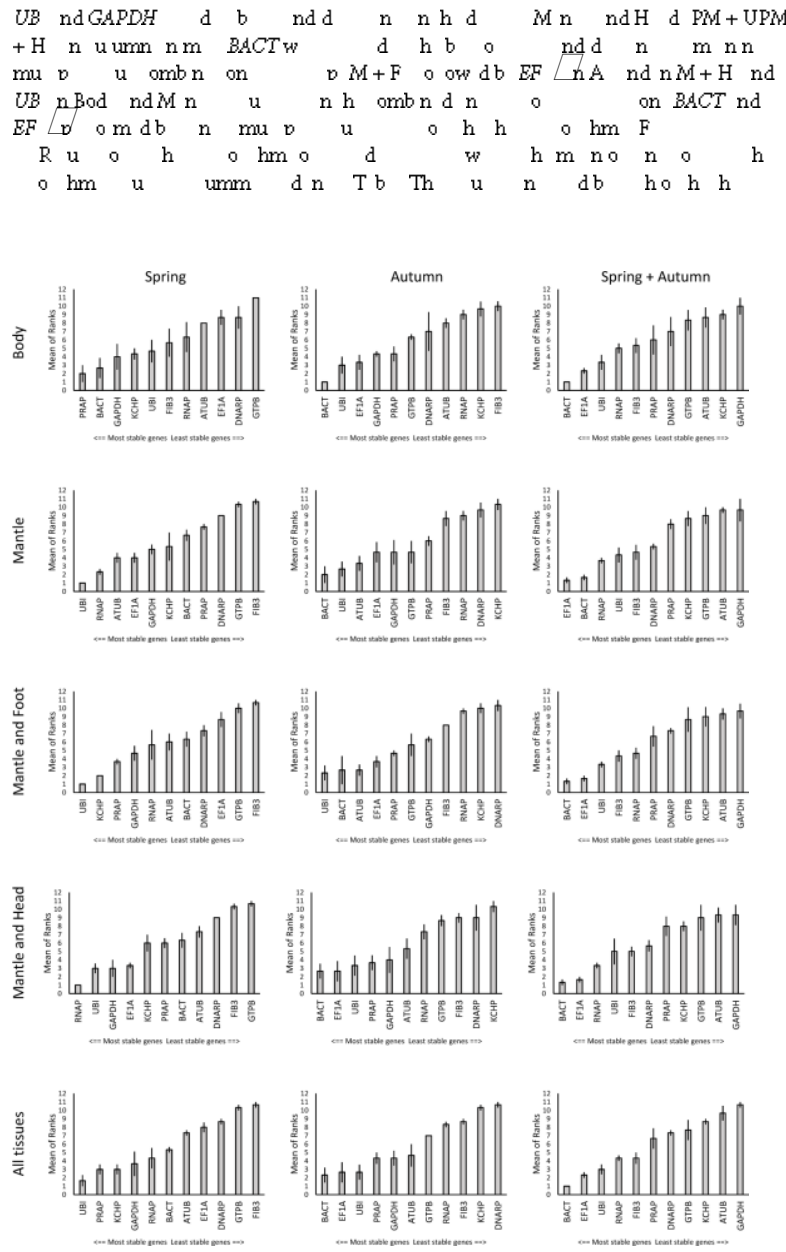

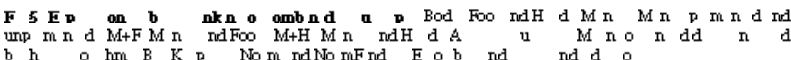

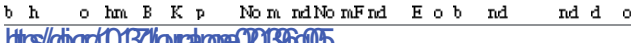

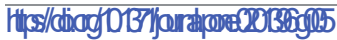




\section{Dasion}

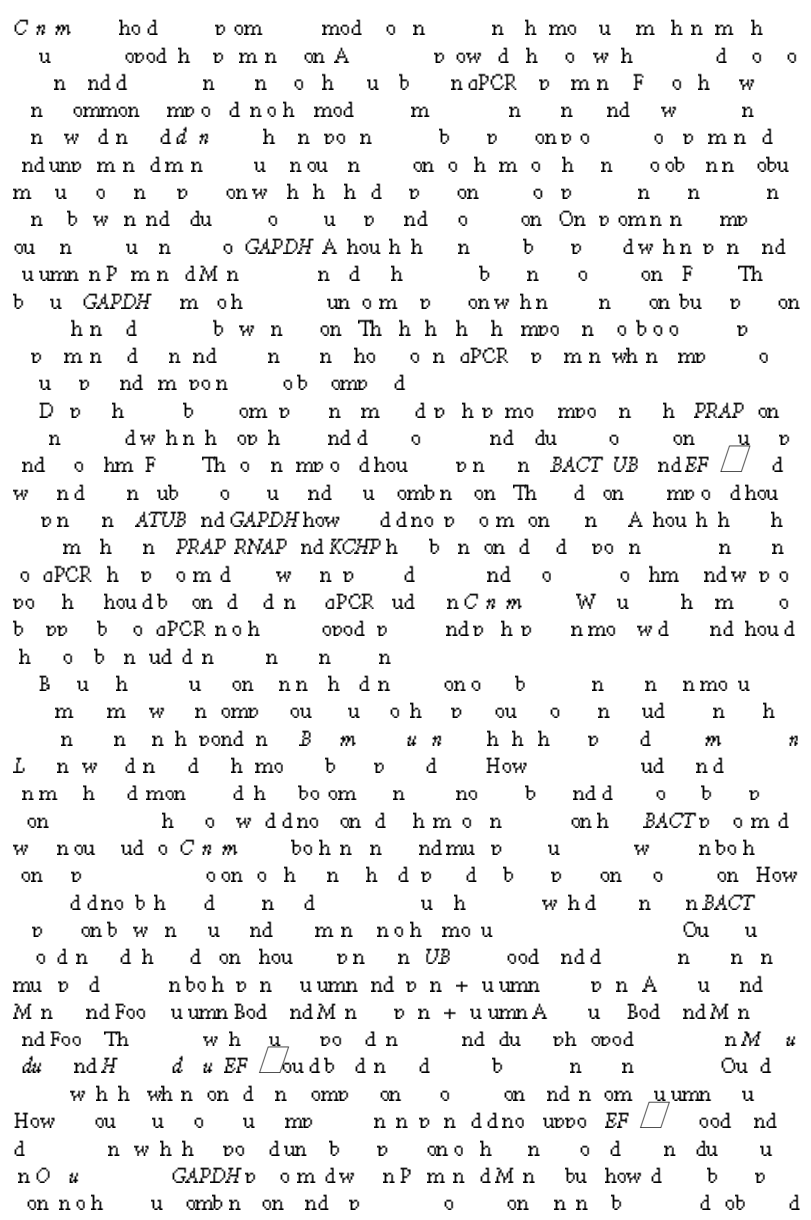




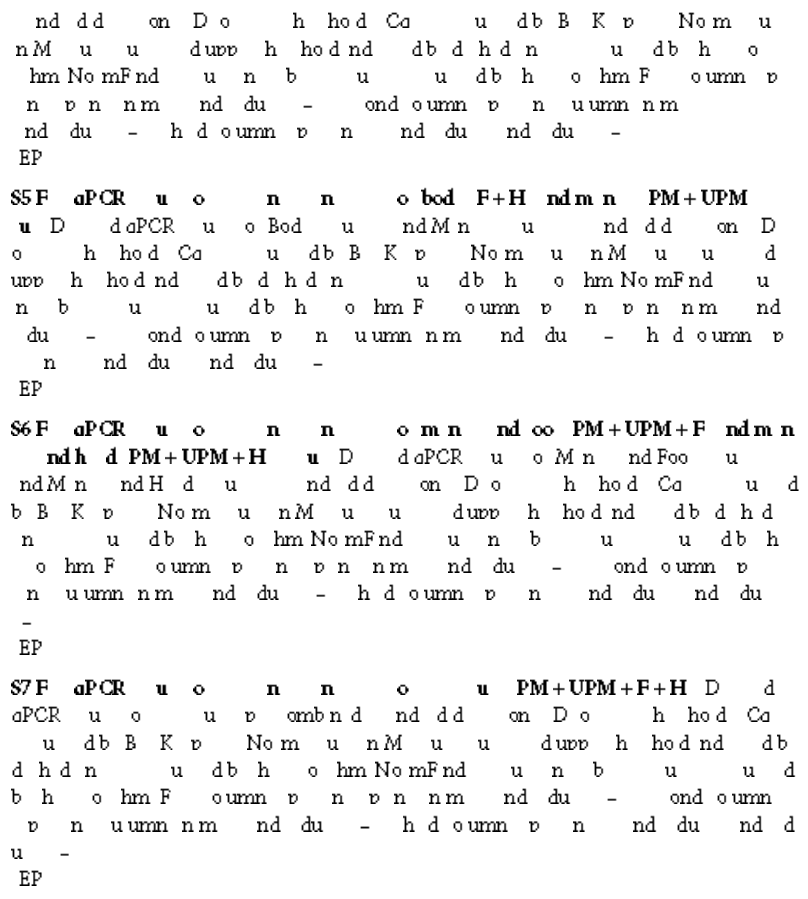

\section{Adrovatyats}

$G b \quad n \quad n$ ndh $m \quad h$ TAL bo $\circ$ Un $M d \quad n$ Go

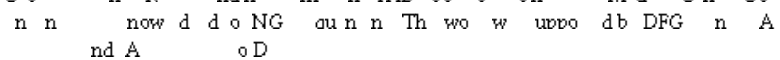

\section{Atrocotiafos}

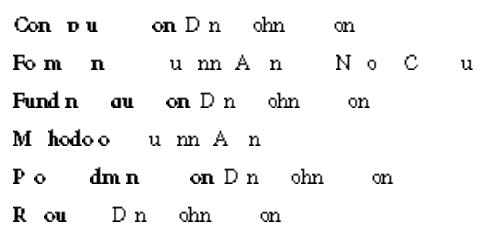




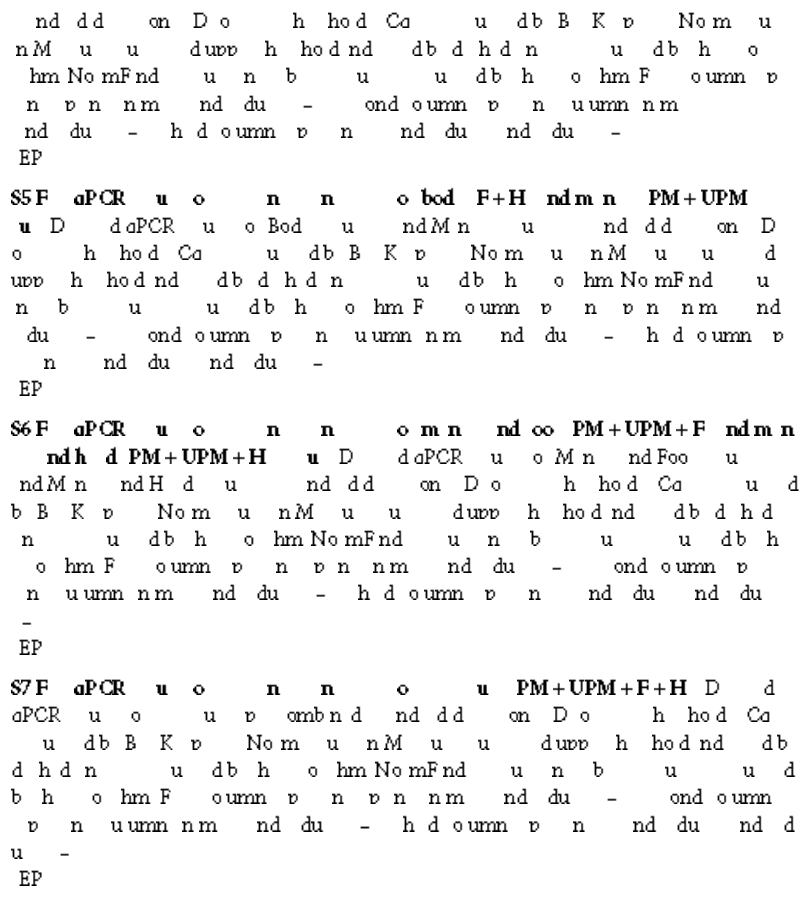

\section{Adrovatyats}

$G b \quad n \quad n$ ndh $m \quad h$ TAL bo $\circ$ Un $M d \quad n$ Go

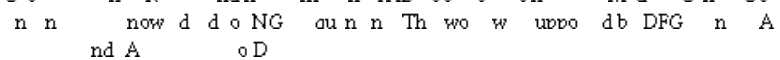

\section{Atrocotiafos}

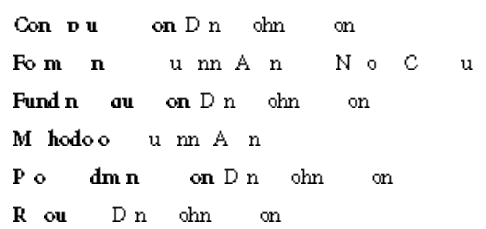




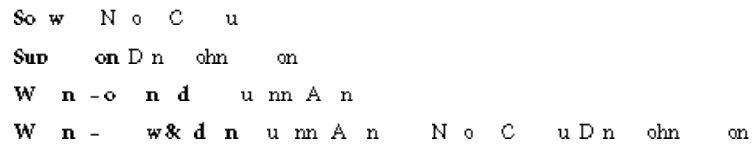

\section{Rfarves}

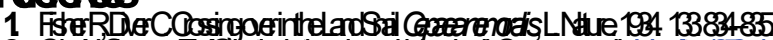

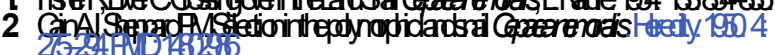

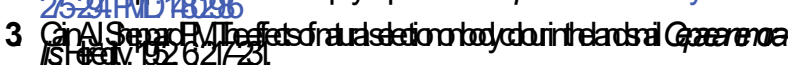

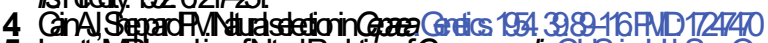

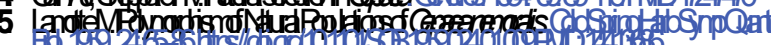

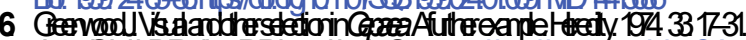

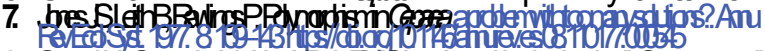

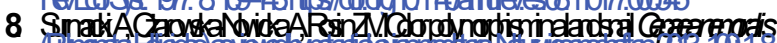

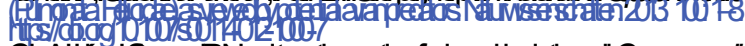

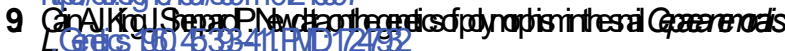

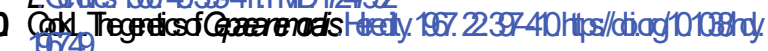

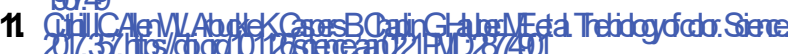

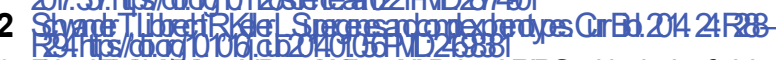

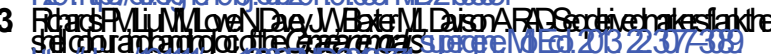

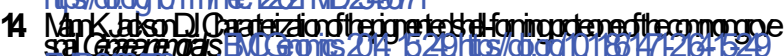

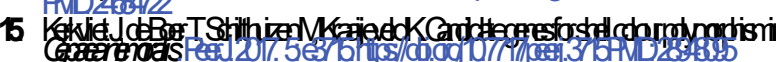

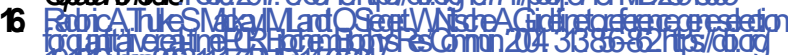

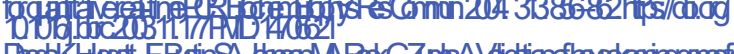

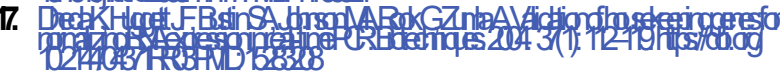

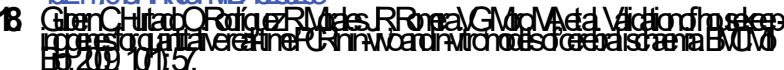

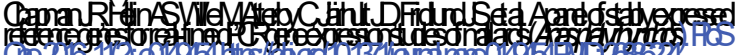

2

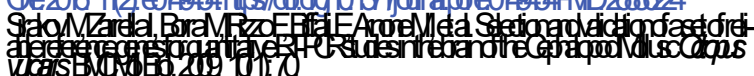

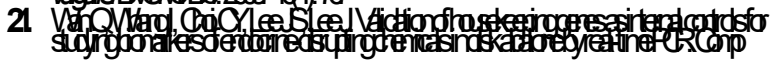




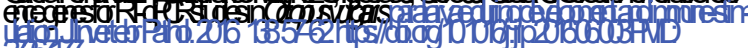

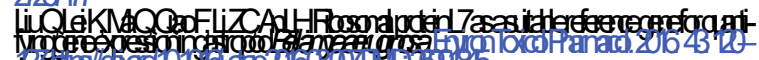

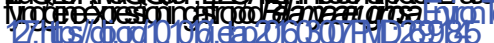

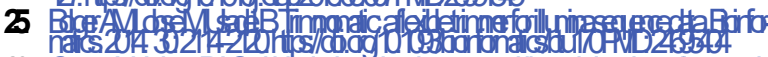

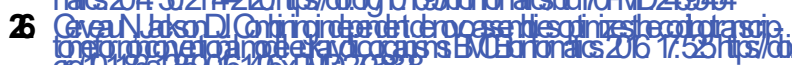

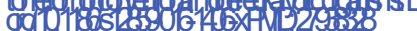

2.

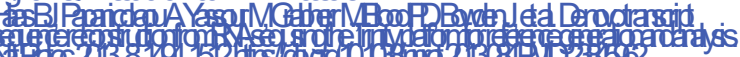

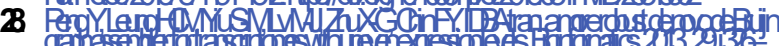

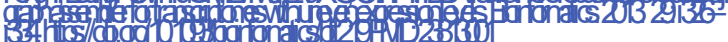

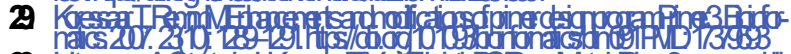

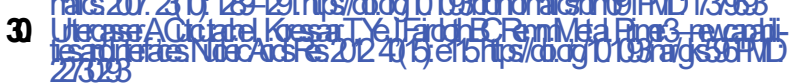

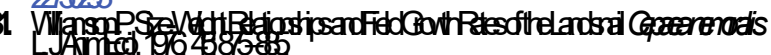

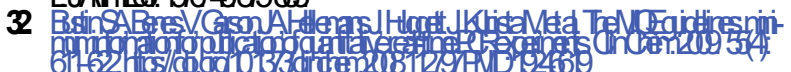

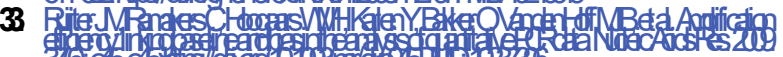

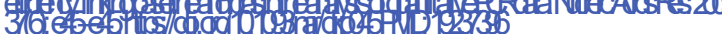

34 Rutar MildoAR Led

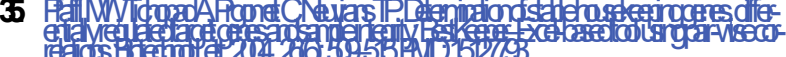

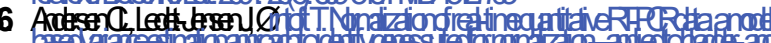

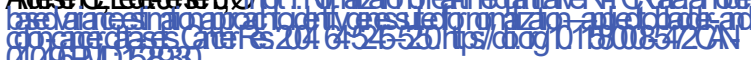

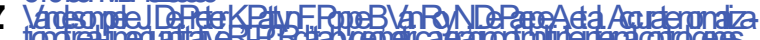

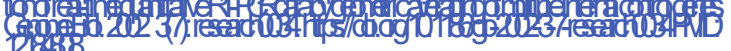

$\mathbf{B}$

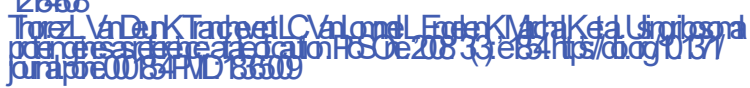


CHAPTER 3: QUANTITATION OF EUMELANIN AND PHEOMELANIN MARKERS IN DIVERSE BIOLOGICAL SAMPLES BY HPLC-UV-MS FOLLOWING SOLID-PHASE EXTRACTION

The following chapter was submitted to PloS One and is currently under revision.

Contributions by the doctoral candidate: Conceptualization, Formal analysis, Investigation, Methodology, Validation, Writing - original draft, Writing - review \& editing 


\section{Quantitation of eumelanin and pheomelanin markers in diverse biological samples by HPLC-UV-MS following solid-phase extraction}

Susanne Affenzeller ${ }^{1}$, Holm Frauendorf ${ }^{2}$, Tobias Licha $^{3}$, Daniel J. Jackson ${ }^{1, *}$ and Klaus Wolkenstein $^{1, *}$

${ }^{1}$ Department of Geobiology, Georg-August University, 37077 Göttingen, Germany

${ }^{2}$ Institute of Organic \& Biomolecular Chemistry, Georg-August University, 37077 Göttingen, Germany

${ }^{3}$ Department of Applied Geology, Georg-August University, 37077 Göttingen, Germany

\section{*Authors for correspondence:}

Daniel J. Jackson

email:djackso@uni-goettingen.de

ORCID: 0000-0001-9045-381X

Klaus Wolkenstein

email: klaus.wolkenstein@uni-goettingen.de

ORCID: 0000-0003-0944-6247 


\section{Abstract}

Eumelanin and pheomelanin are well known and common pigments found in nature. However, their complex polymer structure and high thermostability complicate their direct chemical identification. A widely used analytical method is indirect determination using HPLC with UV detection of both types of melanin by their most abundant oxidation products: pyrrole-2,3-dicarboxylic acid (PDCA), pyrrole-2,3,5-tricarboxylic acid (PTCA), thiazole-4,5-dicarboxylic acid (TDCA), and thiazole-2,4,5tricarboxylic acid (TTCA). An increasing interest in pigmentation in biological research led us to develop a highly sensitive and selective method to identify and quantify these melanin markers in diverse biological samples with complex matrices. By introducing solid phase extraction (SPE, reversed-phase) following alkaline oxidation we could significantly decrease background signals while maintaining recoveries greater than 70\%. Our HPLC-UV-MS method allows for confident peak identification via exact mass information in corresponding UV signals used for quantitation. In addition to synthetic melanin and Sepia officinalis ink as reference compounds eumelanin markers were detected in brown human hair and a brown bivalve shell (Mytilus edulis). Brown feathers from the common chicken (Gallus g. domesticus) yielded all four eumelanin and pheomelanin markers. The present method can be easily adapted for a wide range of future studies on biological samples with unknown melanin content.

Keywords: Eumelanin, Pheomelanin, Alkaline oxidation, High resolution mass spectrometry, Pigmentation 


\section{Introduction}

In the scientific literature the term 'melanin' has been used for any number of black, dark brown to orange and yellow pigments that are non-soluble and very thermostable ${ }^{1-7}$. A more accurate definition of melanin would be that they are built through enzymatic oxidative polymerisation of DOPA (L-3,4-dihydroxyphenylalanine) subunits ${ }^{4,8-12}$. The stability and sizes of the resulting macromolecules complicates their analysis by standard analytical methods ${ }^{10,12,13}$. A well-established method in human medical studies to identify the most common melanin types (eumelanin and pheomelanin) uses the oxidative degradation products of melanin (Fig 1): pyrrole-2,3-dicarboxylic acid (PDCA), pyrrole-2,3,5-tricarboxylic acid (PTCA), thiazole-4,5-dicarboxylic acid (TDCA) and thiazole-2,4,5-tricarboxylic acid (TTCA) ${ }^{6,14-17}$.<smiles>Cc1c(O)c(O)c(C)c2[nH]c(C(=O)O)cc12</smiles>

Eumelanin
PTCA
PDCA<smiles>Cc1c(O)c2c(c(C)c1CC(N)C(=O)O)SC(c1c(O)c3c(c4c(-c5nc6c(O)c(C)c(CC(N)C(=O)O)c(C)c6s5)nc(C(=O)O)cc14)S[C@@H](C)C(C(=O)O)=N3)C(=O)N2</smiles>

Fig. 1 Products of eumelanin and pheomelanin generated by alkaline oxidation 
Further experiments based on the initially established method of potassium permanganate as an oxidative agent ${ }^{14-16}$ yielded an improved oxidation protocol using alkaline oxidation by hydrogen peroxide ${ }^{6,18-20}$. High-performance liquid chromatography (HPLC) with UV detection and a mobile phase consisting of methanol-phosphate buffer $(\mathrm{pH} 2.1)$ has been used to separate and detect these specific melanin oxidation products ${ }^{6,20}$. This method was mainly developed to analyse human melanin in medical applications like hair and skin samples, where the presence of melanin is indisputable and interest lies mainly in quantitative analysis. But in recent years biologists have been increasingly interested in pigments and patterns and their presence in a variety of biological settings ${ }^{21-27}$. For these biological samples with unknown pigment content a more specific method is needed. Furthermore, in biological samples like hair, feathers and shells, analyses of melanin is greatly hindered by the presence of complex organic matrices resulting from the oxidation of proteins and other compounds by $\mathrm{H}_{2} \mathrm{O}_{2}$ (compare chromatograms in Ito et al. ${ }^{20}$, Williams et al. ${ }^{25}$ ). Another effect of these biological samples with naturally high background signals is that reliable peak identification can be very difficult. The introduction of a simple sample preparation step that minimizes background signals is therefore necessary. Yu et al. ${ }^{28}$ used a liquid-liquid extraction method for this purpose, but did not systematically test the effect of this step on established melanin oxidation markers. While Rioux et al. ${ }^{29}$ investigated the effects of solid phase extraction (SPE) using weak anion exchange columns on melanin oxidation products, but focused solely on melanoma cells as a biological sample and refrained from adapting the method for compatibility to mass spectrometric (MS) methods.

In order to overcome the limitation of low selectivity afforded by UV detection, recent methods have replaced the phosphate buffer in the eluent with formic acid to allow MS detection. For time of flight (TOF) -MS detection of eumelanin pigments, preparative separation of the analytes prior to MS analysis was required ${ }^{23}$, whereas more sensitive LC (liquid chromatography) MS/MS methods for the analysis of the eumelanin markers PDCA and PTCA in bivalve tissue ${ }^{28}$ and for PTCA in hair samples ${ }^{30}$ have been reported. However, to date, no method for the full 
chromatographic separation and sensitive MS detection of eumelanin and pheomelanin markers has been reported.

The aim of the present study is to establish a reliable analytical method for SPE sample cleanup and subsequent detection and quantitation even of trace amounts of the eumelanin markers PTCA and PDCA as well as the pheomelanin markers TTCA and TDCA from diverse biological samples.

\section{Materials and methods}

\subsection{Chemicals and reagents}

Water (HPLC gradient grade) was purchased from J.T. Baker (Deventer, The Netherlands). Pestinorm ${ }^{\circledR}$ Supra Trace ethyl acetate was purchased from VWR Chemicals (Leuven, Belgium). LiChrosolv® methanol (hypergrade for LC-MS), potassium carbonate (pro analysi grade) and calcium carbonate (pro analysi grade) were obtained from Merck KGaA (Darmstadt, Germany). Sodium sulphite (puriss p. a., ACS grade) and hydrogen peroxide solution $(\geq 30 \%$, trace analysis grade) were obtained from Sigma-Aldrich (St. Louis, USA). Rotipuran ${ }^{\circledR}$ formic acid ( $\geq 98 \%$, p.a., ACS grade), Rotipuran ${ }^{\circledR}$ hydrochloric acid (37\%, p.a., ACS, ISO grade) and Pufferan® TRIS hydrochloride ( $\geq 99 \%$, p.a. grade) were purchased from Carl Roth GmbH + Co. KG (Karlsruhe, Germany). Proteinase K was purchased from Qiagen GmbH (Hilden, Germany).

\subsection{Standards and samples}

Standards of the melanin oxidation products PDCA, PTCA, TDCA and TTCA (prepared according to previously published protocols ${ }^{31}$ ) were kindly provided by Prof. Shosuke Ito at stock solution concentrations of $100 \mu \mathrm{g} / \mathrm{mL}$. Synthetic melanin (prepared by oxidation of tyrosine with hydrogen peroxide) and melanin from Sepia officinalis were obtained from Sigma-Aldrich (St. Louis, USA). 
The human hair sample was donated by one of the authors (S.A.). Medium brown hair was cut approximately $10 \mathrm{~cm}$ from the scalp and then cut into $5 \mathrm{~mm}$ pieces. A brown chicken feather was obtained from a domestic chicken (Gallus gallus domesticus). Analyses were carried out on the distal tip of the brown feather. A shell of the bivalve Mytilus edulis was commercially obtained from a food market. Shell samples were taken from the distal growing edge which possessed brown longitudinal stripes.

\subsection{Sample preparation and melanin oxidation}

All biological samples were cleaned with deionized water in an ultrasonic bath for $10 \mathrm{~min}$ and allowed to dry. For synthetic melanin and Sepia ink melanin $0.2 \mathrm{mg}$, for feather and hair samples $5.5 \mathrm{mg}$ and for shell sample $1.5 \mathrm{~g}$ were used, respectively. Melanin oxidation was carried out as previously published ${ }^{20,25}$ with some modifications: Prepared shell pieces were dissolved in $\mathrm{HCl}$ (6 $\mathrm{M}$, approximately $7 \mathrm{~mL}$ ) and centrifuged at 13,000 rpm for $15 \mathrm{~min}$. The obtained supernatant was discarded and the residue was washed twice with $\mathrm{H}_{2} \mathrm{O}$.

Biological samples (hair, feather and shell) were treated with $10 \mu \mathrm{L}$ proteinase $\mathrm{K}(10 \mathrm{mg} / \mathrm{mL})$ in $500 \mu \mathrm{L}$ TRIS-HCl buffer $(1 \mathrm{M}, \mathrm{pH} 8.0)$ for $30 \mathrm{~min}$ at $37^{\circ} \mathrm{C}$ in a shaker. Treatment was stopped by the addition of $300 \mu \mathrm{L} \mathrm{HCl}(6 \mathrm{M})$. Samples were centrifuged at 13,000 rpm for $15 \mathrm{~min}$, the supernatant discarded and the pellet was washed in water.

All oxidation reactions (synthetic melanin, Sepia ink melanin, feather, hair and shell) were carried out for $20 \mathrm{~h}$ at $25{ }^{\circ} \mathrm{C}$ with vigorous shaking using $100 \mu \mathrm{L} \mathrm{H} \mathrm{H}_{2} \mathrm{O}, 375 \mu \mathrm{L} \mathrm{K}_{2} \mathrm{CO}_{3}(1 \mathrm{M})$ and 25 $\mu \mathrm{L} \mathrm{H}_{2} \mathrm{O}_{2}(30 \%)$ as reactants. After this time any remaining $\mathrm{H}_{2} \mathrm{O}_{2}$ was inactivated by the addition of $50 \mu \mathrm{L} \mathrm{Na}_{2} \mathrm{SO}_{3}(10 \%(\mathrm{w} / \mathrm{v})$ and $140 \mu \mathrm{L} \mathrm{HCl}(6 \mathrm{M})$. Samples were then centrifuged at 13,000 rpm for 30 min and the supernatant was transferred into a fresh tube. As a negative control $2.0 \mathrm{~g}$ of calcium 
carbonate was treated like the shell sample. For comparison, a mixture of PTCA, PDCA, TTCA and TDCA in $\mathrm{H}_{2} \mathrm{O}(2.5 \mu \mathrm{g} / \mathrm{mL}$ each $)$ was run under the same conditions as the oxidised samples.

\subsection{Sample treatment using SPE}

Oxidised samples were treated by SPE on Strata ${ }^{\mathrm{TM}}-\mathrm{X} 33 \mu \mathrm{m}$ Polymeric Reversed Phase cartridges $200 \mathrm{mg} / 6 \mathrm{~mL}$ (Phenomenex, Torrance, USA) under vacuum. Cartridges were conditioned with $5 \mathrm{~mL}$ methanol followed by $5 \mathrm{~mL} \mathrm{H}_{2} \mathrm{O}$. Samples were loaded onto the SPE cartridges diluted in $5 \mathrm{ml}$ formic acid $(0.3 \%(\mathrm{v} / \mathrm{v}))$ and washed once with $5 \mathrm{~mL}$ formic acid $(0.3 \%(\mathrm{v} / \mathrm{v}))$. The cartridges were then dried for $30 \mathrm{~min}$ and elution was carried out with $3 \mathrm{~mL}$ methanol followed by $3 \mathrm{~mL}$ ethyl acetate. Solvents were removed under a constant nitrogen stream at $40{ }^{\circ} \mathrm{C}$ and samples were re-dissolved in $200 \mu \mathrm{L} \mathrm{H} \mathrm{H}_{2} \mathrm{O}$.

\subsection{Chromatographic separation with UV and MS detection}

Measurements were carried out on a Thermo Fisher Scientific HPLC-MS system consisting of an Accela HPLC with a Finnigan Surveyor PDA Detector and coupled to an LTQ Orbitrap XL mass spectrometer equipped with an electrospray ionization (ESI) source. Chromatographic separation was carried out on a Gemini C18 column $(5 \mu \mathrm{m}$ particle size, $250 \times 2 \mathrm{~mm}$ i.d. (Phenomenex, Torrance, USA)). Aliquots (10 $\mu \mathrm{L})$ of the samples were injected into the HPLC system operating at a flow rate of $0.2 \mathrm{~mL} / \mathrm{min}$. The mobile phase consisted of $0.3 \%$ formic acid (eluent A) and methanol (eluent B) (80:20) was run at $45{ }^{\circ} \mathrm{C}$ for 20 min isocratically, followed by a wash step of A:B (5:95) for 10 min and an equilibration phase to reach starting conditions for $10 \mathrm{~min}$. UV data were recorded between 200 and $400 \mathrm{~nm}$. Quantitation was conducted in the range of 250-290 nm. Mass spectra were acquired in negative ion mode. The scan window was set to $\mathrm{m} / \mathrm{z}=120-220$. Optimized MS conditions 
included: gas flow rate of 50 (arbitrary units), a spray voltage of $5.0 \mathrm{kV}$ and a heated capillary temperature of $275^{\circ} \mathrm{C}$.

\subsection{Calibration and validation}

The linear range of the method was tested for each of the melanin oxidation products with a 9-point calibration curve at concentrations ranging from 0.01 to $10 \mu \mathrm{g} / \mathrm{mL}$ by multiple injections. Limit of detection (LOD) and limit of quantitation (LOQ) were determined with the signal-to-noise ratio method for each of the standards based on HPLC measurements with UV detection. LOD was set at 3:1 and LOQ at 10:1 signal-to-noise respectively.

Recoveries after sample preparation by SPE were tested with a mixture of all four melanin oxidation products in eluent A. Additionally, total method recovery was investigated in all three natural matrices (feather, hair, shell) by a 3-point standard addition ( 2 times, 5 times and 10 times) of all oxidation products. SPE recoveries without matrices were measured on an Agilent 1200 Series HPLC system with diode array detector using the same chromatographic conditions as described above.

Additional experiments on the oxidation protocol itself verified the linearity of PDCA and PTCA from a synthetic eumelanin standard in the range of $0.05-0.4 \mathrm{mg}$. A test with an elongated oxidation time $(40 \mathrm{~h})$ did not result in significantly higher amounts of oxidation products and even yielded slightly less eumelanin markers in the case of shell samples.

\section{Results and discussion}

\subsection{Method development}


Our method for alkaline oxidation of melanin from a wide range of biological samples combines and refines a variety of previously published protocols ${ }^{20,21,23,25}$. We demonstrate that by including a sample clean up step by SPE and adapting the chromatographic system to allow for dual detection with UV and MS, two markers each for eumelanin (PDCA and PTCA) and pheomelanin (TDCA and TTCA) can be analysed within one HPLC run. We could achieve baseline separation of all four melanin oxidation markers for chromatographic conditions compatible with mass spectrometry. By desalting and purifying samples via SPE we could significantly reduce the background of the diverse samples we investigated. In addition, the evaporation step brings the advantage of concentrating the analytes. A surprising observation during reversed-phase HPLC optimization was that the retention time of the analytes was almost unaffected by the concentration of organic solvent. Instead, retention times were strongly affected by the $\mathrm{pH}$ value of the eluent, an effect also observed in a recent study 29. 

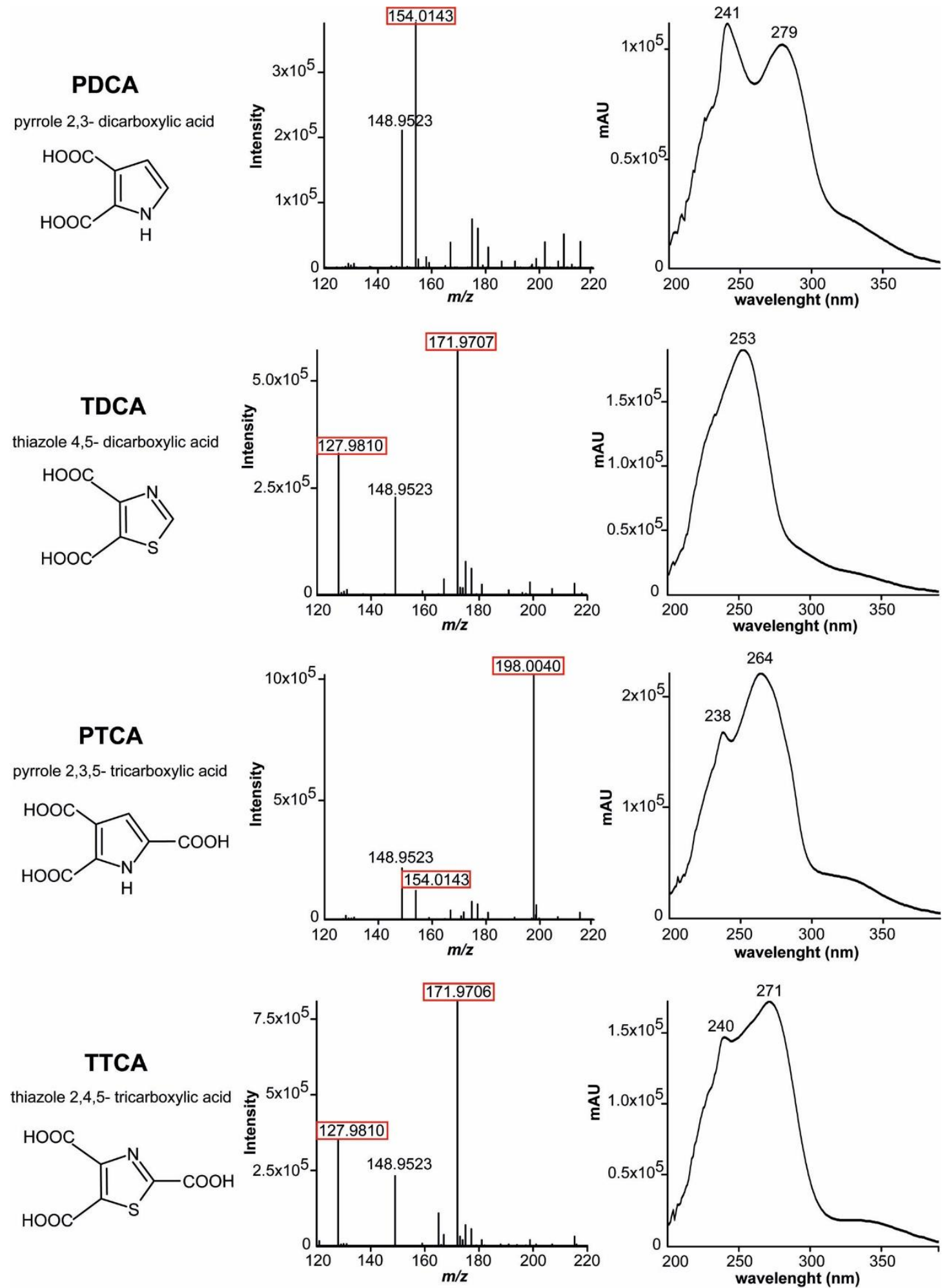

Fig. 2 Characterization of the melanin oxidation products PDCA, TDCA, PTCA and TTCA from brown chicken feather by mass spectra (negative ion mode) and UV spectra 
The high-resolution ESI mass spectra of PDCA, TDCA and PTCA show ion signals for the deprotonated molecules $[\mathrm{M}-\mathrm{H}]^{-}$. TDCA and PTCA show additional ions resulting from fragmentation of $\mathrm{CO}_{2}$ from one of the carboxyl groups. In contrast, for TTCA only fragment ions resulting from the loss of one and two carboxyl groups can be observed, yielding virtually the same mass spectrum as TDCA (see Table 1 and Fig. 2). Therefore the identification and quantitation of both TDCA and TTCA is only possible by the inclusion of a chromatographic separation. All four melanin oxidation products can be characterized by their specific UV absorption spectra (Fig. 2), when there are no interfering background peaks. Quantitation in MS requires appropriate internal standards which are not commercially available for the analysed melanin markers. In contrast, quantitation with UV detection can be done with melanin oxidation product standards via external calibration or standard addition. However peak identification must be carried out very carefully due to the naturally high backgrounds present in biological samples even after clean-up by SPE (compare Fig. 3). By coupling UV with high-resolution MS detection, straight-forward quantitation based on UV signals can be combined with reliable compound identification in complex biological samples. In addition, mass spectrometric measurements yield an approximately 1.5 times higher sensitivity than UV detection, an important factor when analysing biological samples with unknown melanin content.

Previous method validations for the analyses of melanin oxidation products have not been thoroughly performed ${ }^{6,17,20,32}$. We present here calibration and validation data for the quantitation of all four melanin oxidation product standards via UV detection (Table 2) following SPE. Linearity could be shown for both eumelanin oxidation markers (PDCA and PTCA) in the range from 0.05-10 $\mu \mathrm{g} / \mathrm{mL}$. For pheomelanin oxidation markers (TDCA and TTCA) linearity ranged from $0.1-10 \mu \mathrm{g} / \mathrm{mL}$.

Table 1 Accurate mass data of melanin oxidation products 


\begin{tabular}{ccccc}
\hline Compound & $\begin{array}{c}\text { Molecular } \\
\text { formula }\end{array}$ & $\begin{array}{c}\text { Calculated }[\mathrm{M}-\mathrm{H}]^{-} \\
\mathrm{m} / z\end{array}$ & $\begin{array}{c}\text { Observed }[\mathrm{M}-\mathrm{H}]^{-} \\
\mathrm{m} / z\end{array}$ & $\begin{array}{c}\text { Observed fragment } \\
\text { ions } \mathrm{m} / \mathrm{z}\end{array}$ \\
\hline PDCA & $\mathrm{C}_{6} \mathrm{H}_{5} \mathrm{NO}_{4}$ & 154.0140 & 154.0143 & - \\
PTCA & $\mathrm{C}_{7} \mathrm{H}_{5} \mathrm{NO}_{6}$ & 198.0039 & 198.0040, & 154.0143 \\
TDCA & $\mathrm{C}_{5} \mathrm{H}_{3} \mathrm{NO}_{4} \mathrm{~S}$ & 171.9705 & 171.9706, & 127.9810 \\
TTCA & $\mathrm{C}_{6} \mathrm{H}_{3} \mathrm{NO}_{6} \mathrm{~S}$ & 215.9603 & - & $171.9706,127.9810$ \\
\hline
\end{tabular}
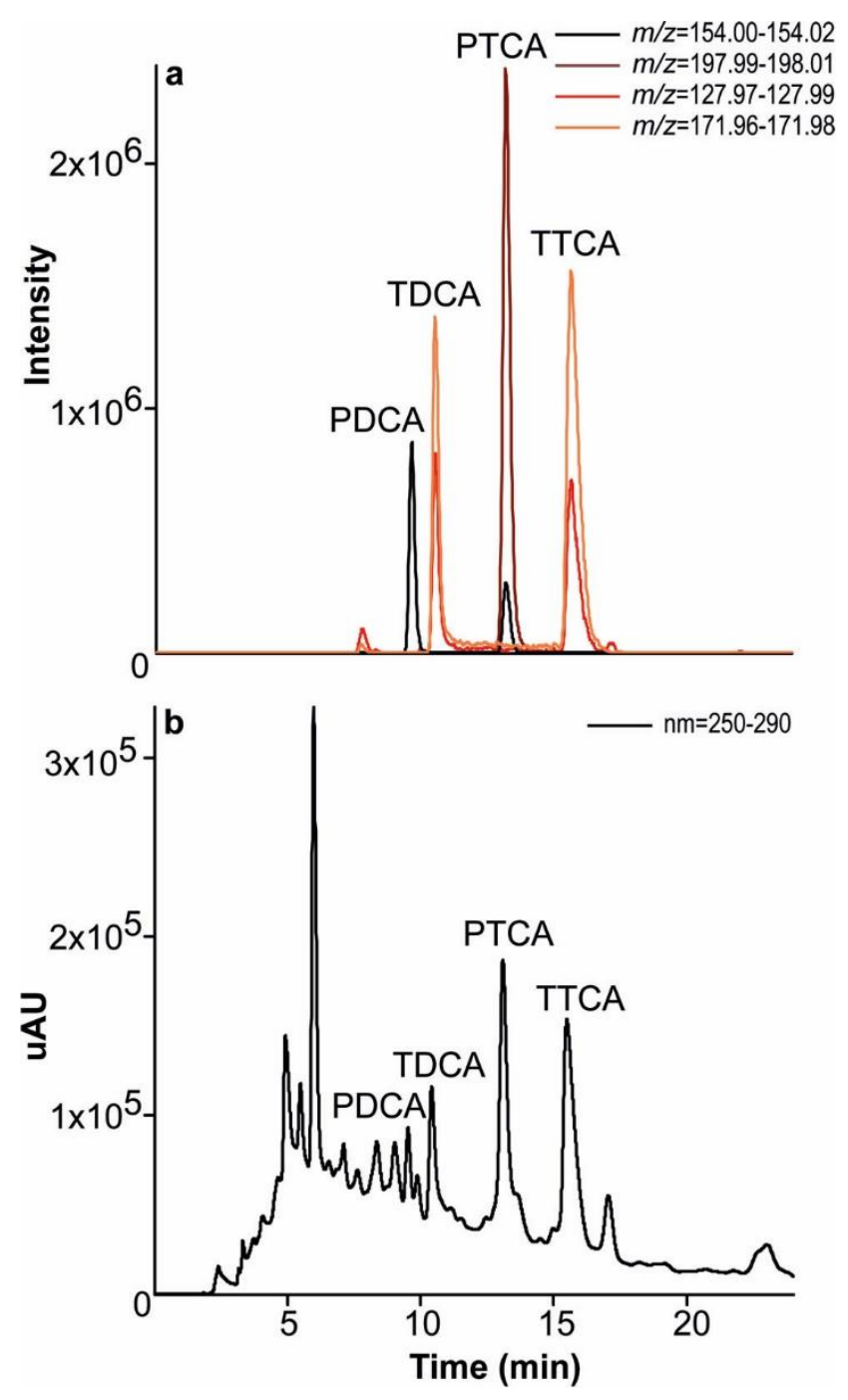

Fig. 3 Comparison of extracted ion chromatograms (a) and corresponding UV chromatogram (b) of oxidation products from a brown chicken feather following SPE, highlighting the need for peak confirmation in biological samples 
A recently published LC-MS/MS study on human hair determined LOD and LOQ for one of the four standard melanin oxidation markers (PTCA) ${ }^{30}$. Our method allows all four oxidation products to be detected in very small amounts, for PTCA below or at a comparable level to LODs previously published ${ }^{21,29,30}$. Both eumelanin markers can be quantified at concentrations as low as $0.1 \mu \mathrm{g} / \mathrm{mL}$. For pheomelanin markers the lowest quantifiable concentrations were $0.25 \mu \mathrm{g} / \mathrm{mL}$ for TDCA and $0.33 \mu \mathrm{g} / \mathrm{mL}$ for TTCA.

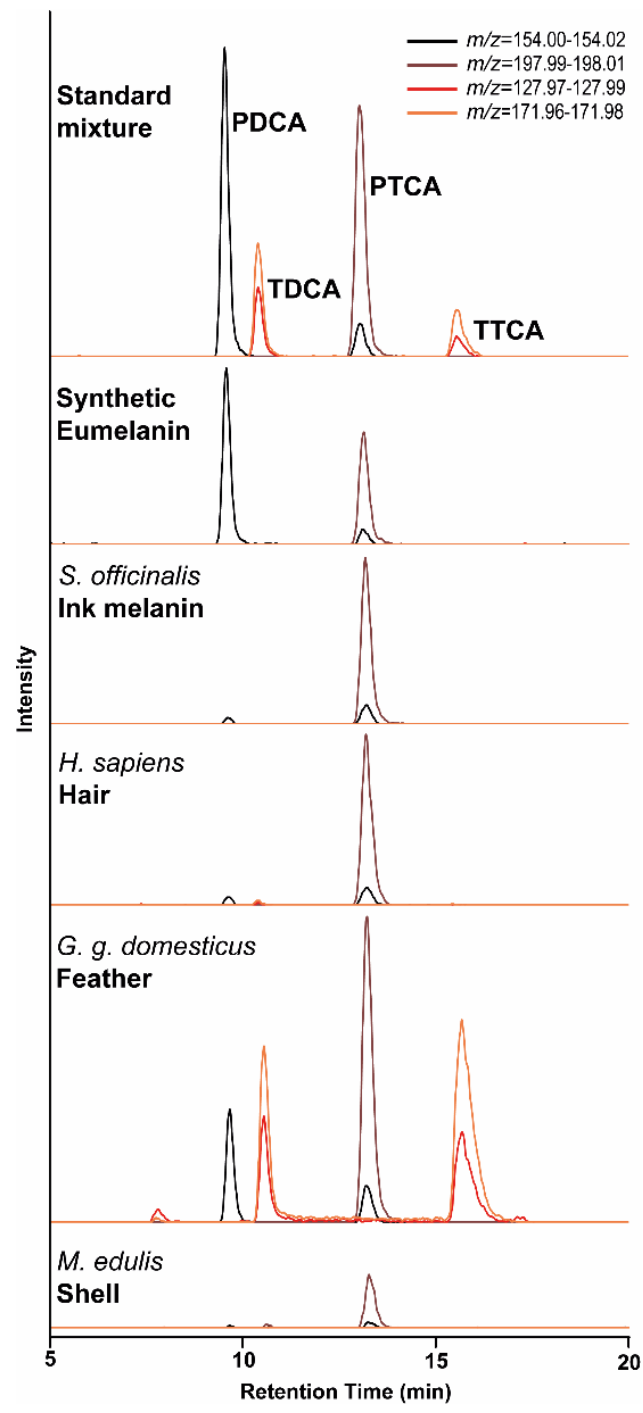

Fig. 4 Extracted ion chromatograms of melanin oxidation product standards and melanin reference compounds (standard mixture of oxidation products, synthetic eumelanin, Sepia ink melanin) as well as biological samples (human hair, chicken feather, bivalve shell) following alkaline oxidation

Table 2 Limit of detection (LOD), limit of quantitation (LOQ) and linearity ( $\mathrm{R}^{2}$ ) for HPLC with UV detection 


\begin{tabular}{ccccc}
\hline $\begin{array}{c}\text { Compoun } \\
\mathrm{d}\end{array}$ & $\begin{array}{c}\text { LOD } \\
(\mu \mathrm{g} / \mathrm{mL})\end{array}$ & $\begin{array}{c}\text { LOQ } \\
(\mu \mathrm{g} / \mathrm{mL})\end{array}$ & $\begin{array}{c}\text { Range of Linearity } \\
(\mu \mathrm{g} / \mathrm{mL})\end{array}$ \\
\hline PDCA & 0.03 & 0.08 & 0.995 & $0.05-10$ \\
PTCA & 0.04 & 0.10 & 0.994 & $0.05-10$ \\
TDCA & 0.08 & 0.25 & 0.994 & $0.1-10$ \\
TTCA & 0.10 & 0.33 & 0.990 & $0.1-10$ \\
\hline
\end{tabular}

Recovery of melanin oxidation products in eluent A after SPE ranged from $67 \%$ for TTCA to $95 \%$ for TDCA. A comparison of quantitation by external calibration and standard addition in all three tested biological matrices yielded good results with more than $70 \%$ for the eumelanin markers PDCA and PTCA. The pheomelanin markers TDCA and TTCA display a wide range of recoveries from different matrices. This might be explained by the interactions of different matrices on the SPE conditions as well as the purity of the peaks. These observations led us to conclude that accurate and precise quantitation of pheomelanin markers in biological matrices must be done very carefully with the appropriate controls and replicates, and any results interpreted critically.

Table 3 Effect of biological matrices on the recovery of melanin oxidation products following SPE Compound Recovery

$\begin{array}{llll}\text { No matrix } & \text { (a) } & \text { Hair }^{\mathrm{b}} & \text { Shell }^{\mathrm{b}}\end{array}$




\begin{tabular}{ccccc}
\hline PDCA & $82 \%$ & $93 \%$ & $71 \%$ & $81 \%$ \\
PTCA & $76 \%$ & $87 \%$ & $89 \%$ & $81 \%$ \\
TDCA & $95 \%$ & $179 \%$ & $64 \%$ & $194 \%$ \\
TTCA & $67 \%$ & $52 \%$ & $114 \%$ & $69 \%$ \\
\hline
\end{tabular}

${ }^{\mathrm{a}}$ Values determined on an Agilent 1200 Series HPLC system

$\mathrm{b}$ Three level standard additions following oxidation and prior to SPE

\subsection{Application of method to complex biological samples}

Both eumelanin markers PDCA and PTCA were found in synthetic melanin and Sepia officinalis ink melanin (Fig. 4). In synthetic melanin both eumelanin oxidation products can be found in near equal amounts, whereas in S. officinalis ink PTCA is the predominant marker, with only small amounts of PDCA (Table 4). This effect of differing ratios of oxidation product yields leads to the assumption of different compositions of the parent macromolecules ${ }^{14,20,31}$. Each biological sample investigated in this study produced a different PTCA/PDCA ratio (Table 4). Further research on the polymerisation process of natural melanins and investigations on their chemical structure would be needed to understand these differences and their effects on colour and functionality. As expected, pheomelanin oxidation products TDCA and TTCA could not be detected in either of the melanin reference compounds measured here.

Table 4 Amounts of melanin oxidation products in melanin standards and biological samples per $\mathrm{g}$ of oxidised starting material as quantified by HPLC with UV detection 


\begin{tabular}{|c|c|c|c|c|}
\hline & $\begin{array}{c}\text { PDCA } \\
(\mu \mathrm{g} / \mathrm{g} \text { sample })\end{array}$ & $\begin{array}{c}\text { PTCA } \\
(\mu \mathrm{g} / \mathrm{g} \\
\text { sample }) \\
\end{array}$ & $\begin{array}{c}\text { TDCA } \\
\text { ( } \mu \mathrm{g} / \mathrm{g} \text { sample })\end{array}$ & $\begin{array}{c}\text { TTCA } \\
(\mu \mathrm{g} / \mathrm{g} \text { sample })\end{array}$ \\
\hline Synthetic melanin & 1206.23 & 963.80 & $<$ LOD & $<$ LOD \\
\hline S. officinalis ink melanin & 99.40 & 1808.25 & $<\mathrm{LOD}$ & $<\mathrm{LOD}$ \\
\hline H. sapiens brown hair & 3.75 & 60.60 & $<\mathrm{LOQ}$ & $<$ LOD \\
\hline G. g. domesticus brown feather & 43.25 & 119.92 & 108.99 & 403.73 \\
\hline M. edulis brown shell & 0.03 & 0.11 & $<\mathrm{LOD}$ & $<\mathrm{LOD}$ \\
\hline
\end{tabular}

In all three of the investigated biological matrices (feather, hair, shell) we were able to detect eumelanin (Fig. 4 and Table 4). In the feather and hair samples we could also detect pheomelanin. It has been shown already that feathers of North American barn swallows (Hirundo rustica erythrogaster) contain both eumelanins and pheomelanins ${ }^{21}$. The same study investigated yellow chicken plumage from nestlings and found trace amounts of eumelanin. In applying our method to adult brown chicken feathers we detected an abundance of all four oxidation products, confirming the results of previous electron spin resonance investigations ${ }^{33}$.

A difficult biological matrix from which to extract organic macromolecules from are the calcified shells of molluscs. The pigment bearing layer of Mytilus edulis is very thin, providing only small amounts of pigment from relatively large amounts of shell material. Nonetheless, we were able to detect eumelanin in this bivalve, providing further evidence that our method is sensitive enough to detect these pigments in a range of biological matrices. Pigmentation and the use of melanin to pattern shells and nacreous materials by a variety of molluscs has seen an increase in research in recent years 28,34,35. Our method facilitates working with these complex samples and will hopefully lead to further investigations in melanic mollusc shell pigmentation.

An especially challenging sample type are fossilized tissues and matrices containing melanin. Although melanin seems to fossilize very well ${ }^{23,36,37}$ only few researchers have access to enough 
material to analyse these samples with chromatographic methods with UV detection. Mass spectrometric measurements were previously performed for fossilized Sepia ink ${ }^{23}$ which found evidence for eumelanin. The protocols presented here are a good starting point for further adjustments of sample preparation with SPE, and the development of even more sensitive MS methods for fossil samples suspected to contain melanin. Preliminary measurements using MS/MS detection have shown that the sensitivity of our method can be further improved by several orders of magnitude.

\section{Conclusion}

The method we present here allows researchers to detect eumelanin and pheomelanin in a variety of complex biological samples. The cleaning and concentrating effect afforded by SPE and the addition of mass spectrometry allows for the selective identification of even small amounts of known melanin oxidation products. High resolution mass spectrometry allows confident peak identification even in complex biological samples with interfering background and overlapping peaks in chromatograms provided by UV detection.

In contrast to the difficult analysis of their parent macromolecules, oxidation products for eumelanin and pheomelanin can be quantitated with the present method. However, due to the different compositions of natural melanins (e.g. PDCA/PTCA ratio differences in reference compounds and biological samples) and matrix effects of biological samples on SPE (see Table 3), we recommend the use of both oxidation markers for each type of melanin as indicators for the abundance of eumelanin and pheomelanin pigments in the original sample.

The highly sensitive method that we report here improves our ability to simultaneously detect eumelanin and pheomelanin in a variety of complex biological samples. 


\section{Conflict of interests}

There are no conflicts of interest to declare.

\section{Acknowledgements}

The authors are very grateful to Professors Shosuke Ito and Kazumasa Wakamatsu (Department of Chemistry, Fujita Health University School of Health Sciences) for providing standard solutions for melanin oxidation products. We thank Gabriele Müller for the donation of the brown chicken feather. This research was funded by DFG grant WO 1491/4-2 to KW, and JA 2108/2-1 and JA 2108/6-1 to DJJ.

\section{References}

1. Comfort A. The pigmentation of molluscan shells. Biol Rev. 1951;26(3):285-301.

2. Swan GA, Waggott A. Studies related to the chemistry of melanins. Part X. Quantitative assessment of different types of units present in dopa-melanin. J Chem Soc C: Org. 1970;(10):1409-18.

3. Swan G. Structure, chemistry, and biosynthesis of the melanins. Fortschr Chem Org Naturst. Springer, Vienna; 1974. pp. 521-582.

4. Riley PA. Melanin. Int J Biochem Cell Biol. 1997;29(11):1235-9.

5. Prota G. Progress in the chemistry of melanins and related metabolites. Med Res Rev . 1988;8(4):525-56.

6. Wakamatsu K, Ito S. Advanced chemical methods in melanin determination. Pigment Cell Res. 2002;15(3):174-83.

7. Ito S, Wakamatsu K. Quantitative analysis of eumelanin and pheomelanin in humans, mice, and other animals: a comparative review. Pigment Cell Res. 2003;16(5):523-31.

8. Lerner AB, Fitzpatrick TB. Biochemistry of melanin formation. Physiol Rev. 1950;30(1):91-126.

9. Binns F, King JA, Mishra SN, Percival A, Robson NC, Swan GA, Waggott A. Studies related to the chemistry of melanins. Part XIII. Studies on the structure of dopamine-melanin. J Chem Soc C: Org. 1970(15):2063-70.

10. Ito S. Reexamination of the structure of eumelanin. Biochim Biophys Acta Gen Subj. 1986;883(1):155-61.

11. d'Ischia M, Napolitano A, Prota G. Peroxidase as an alternative to tyrosinase in the oxidative polymerization of 5,6-dihydroxyindoles to melanin (s). Biochim Biophys Acta Gen Subj. 1991;1073(2):423-30.

12. Prota G. Melanins and Melanogenesis. New York: Academic Press; 1992. pp. 1-290. 
13. Prota G. The chemistry of melanins and melanogenesis. Fortschr Chem Org Naturst. Springer, Vienna; 1995. pp. 93-148.

14. Piattelli M, Nicolaus RA. The structure of melanins and melanogenesis-I: The structure of melanin in Sepia. Tetrahedron. 1961;15(1-4):66-75.

15. Nicolaus RA, Piattelli M, Fattorusso E. The structure of melanins and melanogenesis_-IV: On some natural melanins. Tetrahedron. 1964;20(5):1163-72.

16. Ito S, Fujita K. Microanalysis of eumelanin and pheomelanin in hair and melanomas by chemical degradation and liquid chromatography. Anal Biochem. 1985;144(2):527-36.

17. Napolitano A, Perzzella A, Vincensi MR, Prota G. Oxidative degradation of eumelanins to pyrrole acids: a model study. Tetrahedron 1995;51:5913-5920.

18. Ito S, Wakamatsu K. Chemical degradation of melanins: application to identification of dopamine melanin. Pigment Cell Res. 1998;11(2):120-6.

19. Wakamatsu K, Fujikawa K, Zucca FA, Zecca L, Ito S. The structure of neuromelanin as studied by chemical degradative methods. J Neurochem. 2003;86(4):1015-23.

20. Ito S, Nakanishi Y, Valenzuela RK, Brilliant MH, Kolbe L, Wakamatsu K. Usefulness of alkaline hydrogen peroxide oxidation to analyze eumelanin and pheomelanin in various tissue samples: application to chemical analysis of human hair melanins. Pigment Cell Melanoma Res. 2011;24(4): 605-613.

21. McGraw KJ, Wakamatsu K, Ito S, Nolan PM, Jouventin P, Dobson FS, Austic RE, Safran RJ, Siefferman LM, Hill GE, Parker RS. You can't judge a pigment by its color: carotenoid and melanin content of yellow and brown feathers in swallows, bluebirds, penguins, and domestic chickens. The Condor. 2004;106(2):390-5.

22. Chen SR, Jiang B, Zheng JX, Xu GY, Li JY, Yang N. Isolation and characterization of natural melanin derived from silky fowl (Gallus gallus domesticus Brisson). Food Chem. 2008;111(3):745-9.

23. Glass K, Ito S, Wilby PR, Sota T, Nakamura A, Bowers CR, Vinther J, Dutta S, Summons R, Briggs DEG, Wakamatsu K, Simon JD. Direct chemical evidence for eumelanin pigment from the Jurassic period. Proc Natl Acad Sci U S A. 2012;109(26):10218-10223.

24. Kronforst MR, Barsh GS, Kopp A, Mallet J, Monteiro A, Mullen SP, Protas M, Rosenblum EB, Schneider CJ, Hoekstra HE. Unraveling the thread of nature's tapestry: the genetics of diversity and convergence in animal pigmentation. Pigment Cell Melanoma Res. 2012;25(4):411-33.

25. Williams ST, Ito S, Wakamatsu K, Goral T, Edwards NP, Wogelius RA, Henkel T, de Oliveira LF, Maia LF, Strekopytov S, Jeffries T. Identification of shell colour pigments in marine snails Clanculus pharaonius and $C$. margaritarius (Trochoidea; Gastropoda). PloS One. 2016;11(7):e0156664.

26. Cuthill IC, Allen WL, Arbuckle K, Caspers B, Chaplin G, Hauber ME, Hill GE, Jablonski NG, Jiggins CD, Kelber A, Mappes J. The biology of color. Science. 2017;357(6350):eaan0221.

27. Williams ST. Molluscan shell colour. Biol Rev. 2017;92(2):1039-58.

28. Yu F, Pan Z, Qu B, Yu X, Xu K., Deng Y, Liang, F. Identification of a tyrosinase gene and its functional analysis in melanin synthesis of Pteria penguin. Gene. 2018;656:1-8.

29. Rioux B, Rouanet J, Akil H, Besse S, Debiton E, Bouchon B, Degoul F, Quintana M. Determination of eumelanin and pheomelanin in melanomas using solid-phase extraction and high performance liquid chromatography-diode array detection (HPLC-DAD) analysis. Journal of Chromatography B. 2019; 1113:6068

30. Petzel-Witt S, Meier SI, Schubert Zsilavecz M, Toennes SW. PTCA (1H pyrrole 2,3,5 tricarboxylic acid) as a marker for oxidative hair treatment. Drug Test Anal. 2018;10(4):768-73. 
31. d'Ischia M, Wakamatsu K, Napolitano A, Briganti S, Garcia-Borron J-C, Kovacs D, u.a. Melanins and melanogenesis: methods, standards, protocols. Pigment Cell \& Melanoma Research. September 2013;26(5):616-33.

32. Magarelli M, Passamonti P, Renieri C. Purification, characterization and analysis of sepia melanin from commercial sepia ink (Sepia officinalis)_Purificación, caracterización y análisis de la melanina de sepia a partir de la tinta de sepia (Sepia officinalis). CES Medicina Veterinaria y Zootecnia. 2010;5(2):18-28.

33. Sealy RC, Hyde JS, Felix CC, Menon IA, Prota G. Eumelanins and pheomelanins: characterization by electron spin resonance spectroscopy. Science. 1982;217(4559):545-7.

34. Hao S, Hou X, Wei L, Li J, Li Z, Wang X. Extraction and identification of the pigment in the adductor muscle scar of pacific oyster Crassostrea gigas. PloS One. 2015;10(11):e0142439.

35. Sun X, Wu B, Zhou L, Liu Z, Dong Y, Yang A. Isolation and characterization of melanin pigment from yesso scallop Patinopecten yessoensis. J Ocean Univ China. 2017;16(2):279-84.

36. Colleary C, Dolocan A, Gardner J, Singh S, Wuttke M, Rabenstein R, Habersetzer J, Schaal S, Feseha M, Clemens M, Jacobs BF. Chemical, experimental, and morphological evidence for diagenetically altered melanin in exceptionally preserved fossils. Proc Natl Acad Sci U S A. 2015;112(41):12592-7.

37. Lindgren J, Sjövall P, Thiel V, Zheng W, Ito S, Wakamatsu K, Hauff R, Kear BP, Engdahl A, Alwmark C, Eriksson ME, Jarenmark M, Sachs S, Ahlberg PE, Marone F, Kuriyama T, Gustafsson O, Malmberg P, Thomen A, Rodríguez-Meizoso I, Uvdal P, Ojika M, Schweitzer MH. Soft-tissue evidence for homeothermy and crypsis in a Jurassic ichthyosaur. Nature. 2018;564(7736):359-365. 
CHAPTER 4: EUMELANIN AND PHEOMELANIN PIGMENTATION IN MOLLUSC SHELLS MAY BE LESS COMMON THAN EXPECTED: INSIGHTS FROM MASS SPECTROMETRY

The following chapter is prepared for publication in Proceedings of the Royal Society B and is currently being revised by my co-authors.

Contributions by the doctoral candidate: Conceptualization, Formal analysis, Investigation, Methodology, Validation, Writing - original draft, Writing - review \& editing 


\section{Eumelanin and pheomelanin pigmentation in mollusc shells may be less common than expected: insights from mass spectrometry}

Susanne Affenzeller ${ }^{1}$, Klaus Wolkenstein ${ }^{1, *}$, Holm Frauendorf ${ }^{2}$ and Daniel J. Jackson ${ }^{1, *}$

${ }^{1}$ Department of Geobiology, Georg-August University of Göttingen, Goldschmidtstrasse 3, 37077 Göttingen, Germany

${ }^{2}$ Institute of Organic \& Biomolecular Chemistry, Georg-August University, 37077 Göttingen, Germany

*Author for correspondence:

Klaus Wolkenstein

email: klaus.wolkenstein@uni-goettingen.de

Daniel J. Jackson

email: djackso@uni-goettingen.de 


\begin{abstract}
Both simple and complex geometric patterns adorn the shells of many disparate molluscan species, and are expressed in many colours from the visible spectrum. Although early chemical studies implicated melanin as a commonly employed pigment, surprisingly little evidence generated with more recent and sensitive techniques exists to support these observations. Here we present the first mass spectrometric investigations for the presence of eumelanin and pheomelanin in 13 different species from three conchiferan classes: Bivalvia, Cephalopoda and Gastropoda. In the bivalve Mytilus edulis we demonstrate that eumelanin mainly occurs in the outermost and highly pigmented layer of the shell, the periostractum. Eumelanin was also identified in the shells of the cephalopod Nautilus pompilius and the marine gastropods Clanculus pharaonius and Steromphala adriatica. In the terrestrial gastropod Cepaea nemoralis the presence of pheomelanin in a mollusc shell is verified using mass spectrometry for the first time. Surprisingly, in a large number of brown/black coloured shells we did not find any evidence for either type of melanin, suggesting that these species employ as yet unidentified pigments to pattern their shells.
\end{abstract}

Keywords: Eumelanin, Pheomelanin, molluscs, shell pigmentation, liquid chromatography mass spectroscopy 


\section{Introduction}

Shell bearing molluscs (Conchifera Gegenbauer, 1878) constitute one of the most abundant and diverse groups of extant and extinct life [1-4]. The colouration and patterning of the molluscan shell and associated biominerals (i.e. pearls) have fascinated human cultures since prehistoric times [510]. The pigmentation of these structures hold not only aesthetic beauty, but can also dictate their commercial value [11-13]. It is therefore surprising that these pigments (which range from blue, red and yellow to monochromatic brown/black and white) are not well characterised [14]. Early chemical studies based on chromatographic properties and UV-visible spectra of pigments carried out by Comfort [7,15-19] identified the presence of different classes of organic pigments, including tetrapyrroles and melanins. More recent studies have shown that tetrapyrroles (porphyrins and biliverdins) and carotenoids are present in colourful mollusc shells [14,20-25]), with melanins being associated with dark purple, brown and black shell patterns most often [7,19,20,20,26,27]. For example black-brown eumelanin has been linked to the dark colouration of pearls [11,28-31]. Despite the common association of melanin with dark colours in mollusc shells, very few studies have used extensive analytical methods to support its presence. Evidence of eumelanin was reported recently in the shells of Clanculus (Gastropoda) which bear black dots (via high performance liquid chromatography with UV detection (HPLC-UV)), and in the bivalves Mizuhopecten yessoensis (HPLC--UV), Pteria penguin (HPLC with mass spectrometric detection (HPLC-MS) and Crassostrea gigas (infrared absorbtion spectra)[20,29,30,32]. However, analysing mollusc shells for melanins is challenging due to the presence of complex organic matrices, leading to a high background of signals (see chromatograms in the above publications). Moreover, melanins are complex macromolecules that are generally very difficult to analyse $[33,34]$. Finally, to complicate matters further, the term 'melanin' has been used in the literature as an umbrella term in reference to black/brown and reddish to yellow pigments that are non-soluble and very stable. Here we define melanin as the product of enzymatic oxidative polymerisation of DOPA (L-3,4- 
dihydroxyphenylalanine) subunits. While different methods to characterize melanins in biological samples have been reported, for example Raman spectroscopy [22,28,35], electron resonance spectroscopy [36,37] and pyrolysis-gas chromatography-mass spectroscopy [37,38], these all have their short-comings. Currently, only one identification method is well established and accepted in melanin research $[39,40]$, namely analysis of characteristic oxidation products following alkaline oxidation of the melanin polymers [40,41]. After alkaline oxidation the products PDCA (pyrrole-2,3dicarboxylic acid) and PTCA (pyrrole-2,3,5-tricarboxylic acid) for eumelanin and TDCA (thiazole4,5-dicarboxylic acid) and TTCA (thiazole-2,4,5-tricarboxylic acid) for pheomelanin can be analysed with HPLC-UV [37,40,42]. However, distinguishing these specific melanin markers from background signals resulting from the oxidation of proteins and other compounds without mass information is challenging. We have recently demonstrated that a sample preparation and clean-up step after alkaline oxidation, followed by HPLC-MS permits the unequivocal detection of even trace amount of melanins in mollusc shells (Affenzeller et al. in revision). 


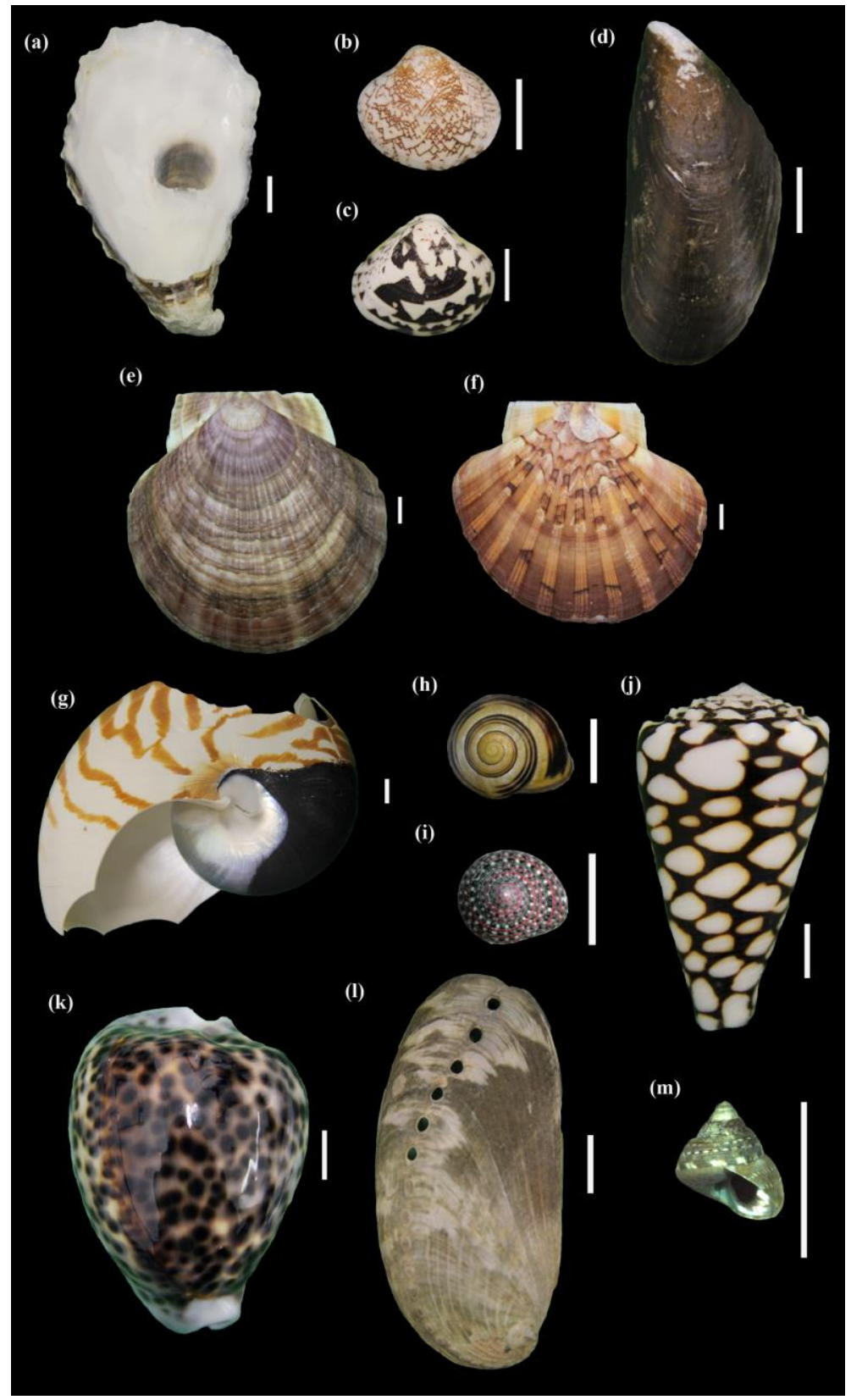

Figure 1.

Pigmented shell samples investigated for eumelanin and pheomelanin colouration: (a) Crassostrea gigas (b) Lioconcha ornata (c) Lioconcha tigrina (d) Mizohupecten yessoensis (e) Mytilus edulis (f) Pecten maximus (g) Nautilus pompilius (h) Cepaea nemoralis (i) Clanculus pharaonius (j) Conus marmoreus (k) Cypraea tigrine (l) Haliotis asinina (m) Steromphala adriatica (Scale bars are $1 \mathrm{~cm})$ 
Here we look for the presence of eumelanin and pheomelanin pigmentation in 13 different species of shell bearing molluscs (Table 1) using alkaline oxidation followed by HPLC-MS. All of these species display prominent patterns on their shells with colours ranging from yellow, light brown, orange and red to dark brown and black (Fig. 1). A number of these species are of significant commercial or cultural value (Mytilus edulis, Pecten maximus, Cypraea tigrina, Haliotis asinina), while others (Crassostrea gigas, Mizohupecten yessoensis, Cepaea nemoralis, Clanculus pharaonius, were chosen due to previous reports of melanic pigmentation [7,20,27,29,32].

\section{Material and methods}

\section{(a) Samples and standards}

Shells from 13 different mollusc species were obtained either commercially or by donation from the Natural History Museum Vienna or private collectors for analysis (Figure 1 for images of used samples and Table 1 for previous literature and sample sources). For species previously reported to contain eumelanin in their shells (C. gigas, $M$, yessoensis, $C$. pharaonius $(19,27,30))$ three replicates were analysed. For $C$. nemoralis a morph with yellow background and multiple brown bands was analysed. For M. edulis the periostracum was removed by scrubbing the shell with sand for one shell valve, while the other valve remained intact. As $S$. adriatica are very small seven shells were combined into one sample. Samples contained approximately $1.5 \mathrm{~g}$ of shell material each. For $L$. ornata $0.6 \mathrm{~g}$ and for $C$. pharaonius approximatly $1 \mathrm{~g}$ of shell material per sample was available due to shell sizes.

For comparison, standards of the melanin oxidation products PDCA, PTCA, TDCA and TTCA kindly provided by Prof. Ito were used. 


\section{(b) Sample preparation, melanin oxidation and HPLC-MS analysis}

Samples were processed as previously described (Affenzeller et al. in revision). In brief, shells were cleaned in deionized water, dried and weighed, and then dissolved in $6 \mathrm{M} \mathrm{HCl}$. Residues were washed with water and were treated with proteinase $\mathrm{K}$ in $1 \mathrm{M}$ Tris- $\mathrm{HCl}$ buffer at $37{ }^{\circ} \mathrm{C}$ for $2 \mathrm{~h}$. Pigmented residues were treated with alkaline oxidation via $\mathrm{H}_{2} \mathrm{O}_{2}$ [40]: Oxidation reactions for each sample were carried out for $20 \mathrm{~h}$ at $25{ }^{\circ} \mathrm{C}$ under vigorous shaking using $100 \mu \mathrm{L} \mathrm{H} \mathrm{H}_{2} \mathrm{O}, 375 \mu \mathrm{L} 1 \mathrm{M} \mathrm{K}_{2} \mathrm{CO}_{3}$ and 25 $\mu \mathrm{L} 30 \% \mathrm{H}_{2} \mathrm{O}_{2}$ as reactants. Remaining $\mathrm{H}_{2} \mathrm{O}_{2}$ was decomposed by the addition of $50 \mu \mathrm{L} 10 \% \mathrm{Na}_{2} \mathrm{SO}_{3}$ and the mixture was acidified with $140 \mu \mathrm{L} 6 \mathrm{M} \mathrm{HCl}$. The solutions were centrifuged and supernatants were transferred to fresh tubes.

Samples were treated by solid-phase extraction (Phenomenex Strata-X Polymeric Reversed Phase columns, $33 \mu \mathrm{m})$. Columns were conditioned with methanol $(\mathrm{MeOH})$ followed by $\mathrm{H}_{2} \mathrm{O}$. Shell extracts were loaded onto the columns and washed with $0.3 \%$ formic acid. Columns were dried and elution was carried out with $\mathrm{MeOH}$ followed ethyl acetate. Solvents were removed under constant nitrogen stream at $40{ }^{\circ} \mathrm{C}$ and samples were dissolved in $200 \mu \mathrm{L} \mathrm{H}_{2} \mathrm{O}$.

Measurements were carried out on a Thermo Fisher Scientific HPLC-MS system consisting of an Accela HPLC with a Finnigan Surveyor PDA Detector coupled to an LTQ Orbitrap XL mass spectrometer equipped with an electrospray ionisation (ESI) source. Separation was performed on a Phenomenex Gemini C18 column $(250 \times 2 \mathrm{~mm}, 5 \mu \mathrm{m})$. The mobile phase was $0.3 \%$ formic acid in $\mathrm{H}_{2} \mathrm{O}: \mathrm{MeOH}$ (80:20). Analyses were performed at $45^{\circ} \mathrm{C}$ at a flow rate of $0.2 \mathrm{ml} / \mathrm{min}$. Mass spectra were acquired in negative ion mode over an $\mathrm{m} / \mathrm{z}$ range of 120-220.

Identification of melanin oxidation products were based on exact mass data. Quantitation was carried out by HPLC-UV using external calibration with melanin oxidation product standards. 


\section{Results and discussion}

\section{(a) Evidence of melanins in mollusc shells}

This study currently represents the largest screen for melanins in molluscan shells using mass spectrometry. Using our newly developed method (Affenzeller et al. in revision) we unequivocally demonstrate the presence of eumelanin in five mollusc species belonging to three major clades of Conchifera. In addition, we found the first conclusive evidence of pheomelanin in a terrestrial gastropod known for its colour and banding polymorphism (C. nemoralis). However we also demonstrate that previous reports of eumelanin in two species (C. gigas and M. yessoensis) were possibly technical artefacts (see below), and that for a total of eight of the 13 species we investigated, which have brown/black pigmented patterns on their shells, we could find no evidence of melanin in their shells.

In the oxidised sample of $M$. edulis we detected the characteristic eumelanin oxidation products PDCA and PTCA as revealed by ion chromatograms of their deprotonated and decarboxylated molecules (PDCA: $m / z$ 154.01 $[\mathrm{M}-\mathrm{H}]^{-}$, PTCA: $m / z$ 198.00 $[\mathrm{M}-\mathrm{H}]^{-}$and $m / z 154.01[\mathrm{M}-\mathrm{COOH}]^{-}$) (Figure 2). M. edulis is a commercially relevant food source and is readily available, however surprisingly little literature is available on its pigmentation. The measurements we present here and in Affenzeller et al. (in revision) corroborate the findings of Waite and Andersen [43] who found that DOPA decreases along the shell growth axis, which is likely due to DOPA being polymerized to eumelanin $[43,44]$. To further investigate Waite and Andersens' [43] observations on the colour differences between the outermost brown periostracal layer and the underlying blue or purple banded calcified shell, we removed the periostracum from one shell valve and compared the amounts of eumelanin markers to the matched intact valve. This analysis provides the first evidence of the 
periostracum being the main source of eumelanic pigmentation in $M$. edulis with the intact valve yielding approximately four times more PTCA than the valve without periostracum (Figure 3 and Table S1).

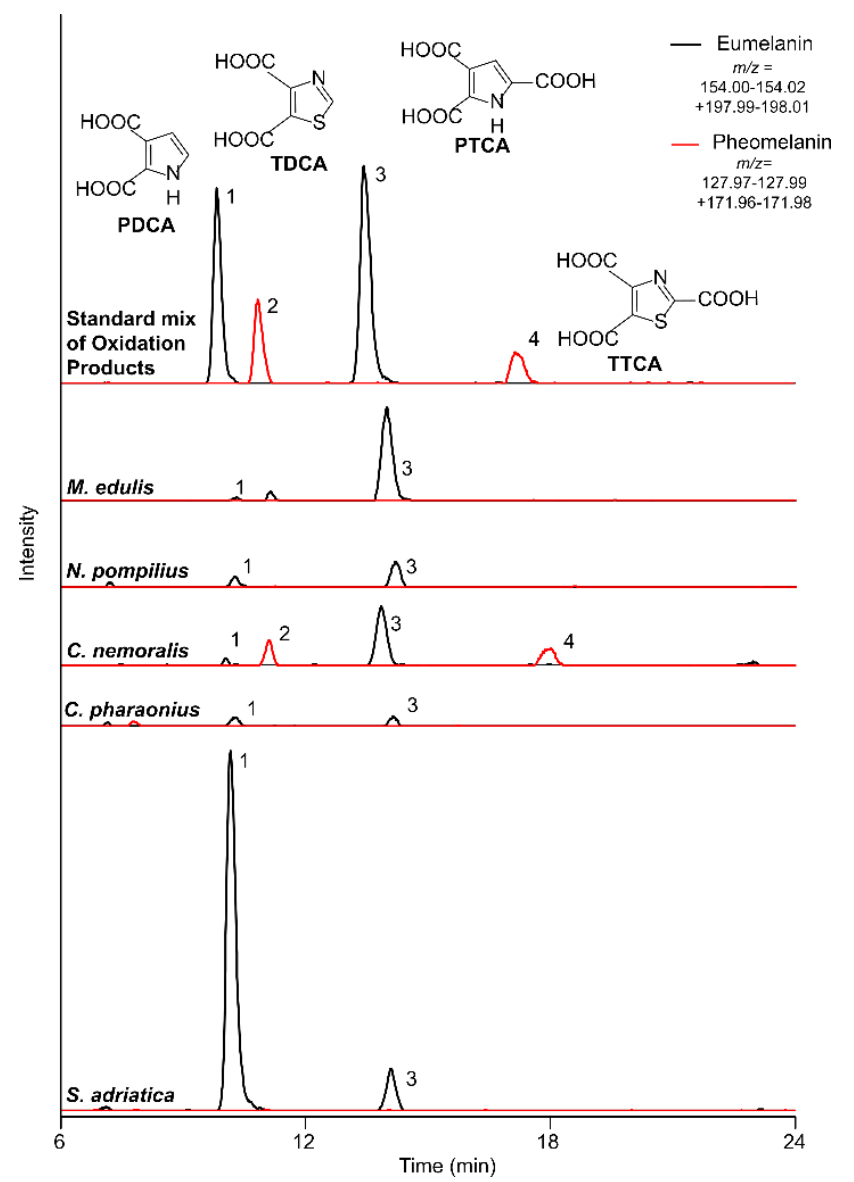

Figure 2.

Extracted ion chromatograms (negative-ion mode) for eumelanin (black) and pheomelanin (red) specific oxidation products. Evidence for melanin in shell pigmentation was found in one bivalve (M. edulis), one cephalopod ( $N$. pompilius) and three gastropods (C. nemoralis, $C$. pharaonius, S. adriatica). All other species investigated showed no detectable signal for melanin oxidation products (chromatograms not pictured here).

The eumelanin markers PDCA and PTCA were also detected in oxidised $N$. pompilius shell fragments with brown flame colouration (Figure 1g, figure 2 and Table S1). It is well-known that cephalopods use eumelanin in their ink $[37,42]$. We can show here that the ability to produce melanin is not only used as a defensive mechanism, but also contributes to external shell colouration in $N$. pompilius. This finding might be of interest to palaeontologists working on shell bearing Cephalopoda, as colour patterns can be observed in fossilized specimens [45]. Our method might allow for the chemical analyses of melanin in these fossilized shells. 


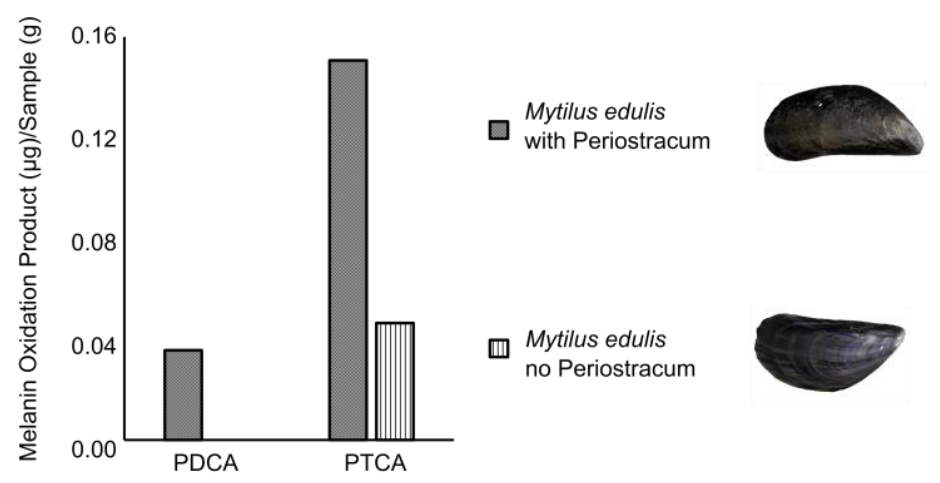

\section{Figure 3.}

To test the predominance of eumelanin in different shell layers of M. edulis the outermost brown periostracum was removed from one shell valve while the other valve was measured with intact periostracum. Eumelanin oxidation products PDCA and PTCA were quantitated by HPLC with UV detection with external calibration and measurements were normalized to initial sample weight. 


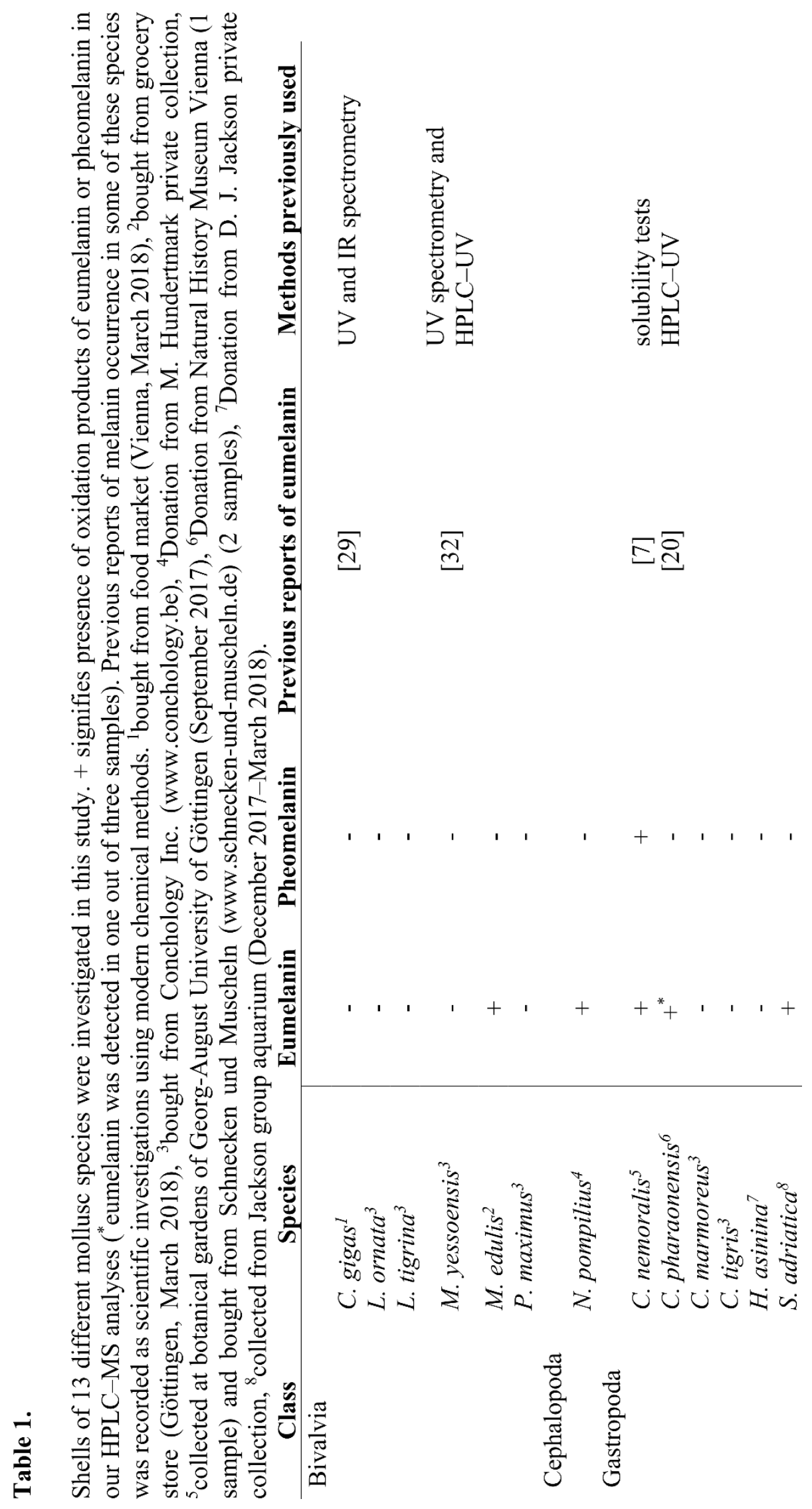


Within the gastropods we found melanin markers in the oxidised samples of three species: $C$. nemoralis, C. pharaonius and S. adriatica (table 1, Table S1). For the terrestrial gastropod $C$. nemoralis we found mass spectrometric evidence for all four melanin oxidation products (Figure 2 and Table S1), the characteristic pheomelanin markers TDCA and TTCA revealed by the ion chromatograms of the deprotonated molecule and ions resulting from the loss of one and two carboxyl groups (TDCA: $m / z 171.97[\mathrm{M}-\mathrm{H}]^{-}$and $m / z 127.98[\mathrm{M}-\mathrm{COOH}]^{-}$, TTCA: $m / z 171.97[\mathrm{M}-\mathrm{COOH}]^{-}$ and $\left.\mathrm{m} / \mathrm{z} 127.98\left[\mathrm{M}-\mathrm{C}_{2} \mathrm{HO}_{4}\right]^{-}\right)$. This is the first mass spectrometric evidence of simultaneous eumelanin and pheomelanin use in a molluscan shell. Further investigation on the spatial distribution of these melanic pigments within the shell are needed to clarify their contribution to band and background colouration.

We could identify both eumelanin markers in one out of three replicates of the colourful marine gastropod C. pharaonius (strawberry topshell) (Figure 1i and Figure 2). Using HPLC with UV detection but without additional mass information, the eumelanin marker PTCA was recently identified in another study of $C$. pharaonius [20]. In our study of this species we detected a peak with nearly the same retention time as PTCA. The use of exact mass data allowed us to verify that for two shells this is in fact not the eumelanin marker, but another substance with a very similar chromatographic behaviour. This sporadic finding of eumelanin with no obvious linkage to the shell phenotype (see Figure S1) complicates the interpretation of this data.

In the marine gastropod $S$. adriatica (Figure $1 \mathrm{~m}$ ) we found an abundance of eumelanin markers (Figure 2 and Table S1). This species is known to live in shallow waters in the Mediterranean sea grazing on microfilm algae [46]. Melanin incorporation into the shell might therefore play a role in 
sun protection or habitat blending, but further research is needed functionally characterise this melanic pigment in S. adriatica.

\section{(b) The surprising absence of melanins in diverse pigmented mollusc shells}

Surprisingly, no traces of melanin oxidation products were detected for many prominently patterned and brown coloured mollusc shells (Figure 1, Table 1). This is especially surprising as brown and black colour patterns on bivalve and gastropod shells have generally been believed to be of melanic origin since the early studies of Comfort $[7,14,16,18]$. Moreover, for some of the species the absence of melanins is in contrast to previous studies. In a recent study, analysis of melanin oxidation products by HPLC with UV detection suggested that the brown valve of the bicoloured bivalve M. yessoensis contain eumelanin and pheomelanin (as Patinopecten yessoensis in Sun et al. [32]). However in that study peak identification relied solely on retention times and no identification with mass data was used to verify those results. This practice can easily lead to the misidentification of melanin oxidation products (see Affenzeller et. al. in review). Pigmentation present in the dark adductor scar of $C$. gigas was assumed to be (eu)melanin. However, this result is based solely on measurements obtained by UV spectrophotometry and IR spectrometry [29]. During sample preparation we observed acid solubility and fluorescence of pigments from the shell of $C$. gigas, possibly indicating porphyrin-like pigments known to be produced by the bivalves Pinctada spp. and Pteria penguin $[47,48]$.

The method we have used to detect melanin oxidation products was developed and adapted for challenging biological sample matrices such as molluscan shells and is highly sensitive (limit of detection ranging from $0.03 \mu \mathrm{g} / \mathrm{mL}$ to $0.10 \mu \mathrm{g} / \mathrm{mL}$ ). Further efforts to detect melanins in the intensely brown coloured Conus shell (grinding of shell before dissolution, longer oxidation time among others) were unsuccessful. We are therefore confident that in the indicated specimens melanin is 
genuinely absent (or exists in trace amounts inadequate to appreciably pigment the shell). This leads us to question what the prominent brown to black pigments are in shells where no melanin is detected. For some cases (e.g. L. tigrina) we observed the pigmented pattern on the shell preserves its geometric configuration even after the calcium carbonate is dissolved in high molarity acid. This suggests a complex and very stable pigment, possibly a macromolecule tightly bound to shell proteins. Unfortunately we were not able to identify other oxidation products in our samples that would indicate the chemical composition of this pigment. Further investigations are necessary to unravel its nature.

\section{Conclusions}

We have found mass spectrometric evidence for melanins in three conchiferan classes: Cephalopoda, Gastropoda and Bivalvia. This is the first time melanin has been detected in cephalopod shells $(N$. pompilius). In the marine bivalve M. edulis eumelanin is predominantly located in the periostracum layer relative to the calcified shell. For the first time both eumelanin and pheomelanin were detected in a mollusc shell (the terrestrial gastropod C. nemoralis), however further study is needed to spatially localise the distribution of these pigments in this shell. Eumelanin markers could only be detected in one out of three marine $C$. pharaonius individuals. In another marine gastropod ( $S$. adriatica) eumelanin was abundant. We could not detect melanin in a surprisingly large number of prominently patterned gastropod and bivalve shells. Further investigations are needed to identify the underlying pigmentation mechanism responsible for these complex geometric colourations.

\section{Acknowledgements}


We gratefully acknowledge Professors Shosuke Ito and Kazumasa Wakamatsu (Department of Chemistry, Fujita Health University School of Health Sciences) for donating standard solutions for melanin oxidation products. We would like to thank Axel Hackmann for help with sample preparation and Max Hundertmark for the kind donation of his Nautilus shell. For the donation of the Clanculus shell we thank Anita Eschner and the NHM Vienna. Furthermore thanks are due to Tobias Licha for valuable input during the method development and for providing equipment and assistance. We thank Volker Thiel and Leyla Seyfullah for productive suggestions and discussions. This research was funded by DFG grant WO 1491/4-2 to KW, and JA 2108/2-1 and JA 2108/6-1 to DJJ.

The authors declare no competing interests.

\section{Author contributions}

SA conceived the study design, prepared samples and contributed to data acquisition, analysed data and prepared figures and drafted the manuscript. KW conceived the study design, provided equipment and funding, supervised experiments and contributed to data acquisition and revised the manuscript. HF carried out mass spectrometric measurements and revised the manuscript. DJJ conceived the study design, provided equipment and funding, supervised experiments and revised the manuscript. All authors gave final approval for publication.

\section{References}

1. Caze B, Merle D, Saint Martin J-P, Pacaud J-M. 2011 Contribution of residual colour patterns to the species characterization of Caenozoic molluscs (Gastropoda, Bivalvia). Comptes Rendus Palevol 10, 171-179. (doi:10.1016/j.crpv.2010.10.005)

2. Caze B, Merle D, Schneider S. 2015 UV Light Reveals the Diversity of Jurassic Shell Colour Patterns: Examples from the Cordebugle Lagerstätte (Calvados, France). PLoS ONE 10, e0126745. (doi:10.1371/journal.pone.0126745)

3. Jackson DJ, Wörheide G, Degnan BM. 2007 Dynamic expression of ancient and novel molluscan shell genes during ecological transitions. BMC Evol. Biol. 7, 160. (doi:10.1186/1471-2148-7-160)

4. Kocot KM, Aguilera F, McDougall C, Jackson DJ, Degnan BM. 2016 Sea shell diversity and rapidly evolving secretomes: insights into the evolution of biomineralization. Front. Zool. 13. (doi:10.1186/s12983-016-0155-z) 
5. Sakalauskaite J et al. 2019 'Palaeoshellomics' reveals the use of freshwater mother-of-pearl in prehistory. eLife 8, e45644. (doi:10.7554/eLife.45644)

6. Adamkewicz L, Castagna M. 1988 Genetics of Shell Color and Pattern in the Bay Scallop Argopecten irradians. J. Hered. 79, 14-17. (doi:10.1093/oxfordjournals.jhered.a110436)

7. Comfort A. 1951 The pigmentation of molluscan shells. Biol. Rev. 26, 285-301. (doi:10.1111/j.1469185X.1951.tb01358.x)

8. Ogundiran A. 2002 Of Small Things Remembered: Beads, Cowries, and Cultural Translations of the Atlantic Experience in Yorubaland. Int. J. Afr. Hist. Stud. 35, 427-457. (doi:10.2307/3097620)

9. Doran E. 1958 The Caicos Conch Trade. Geogr. Rev. 48, 388-401. (doi:10.2307/212258)

10. Pietak LM. 1998 Body Symbolism and Cultural Aesthetics: The Use of Shell Beads and Ornaments by Delaware and Munsee Groups. North Am. Archaeol. 19, 135-161. (doi:10.2190/0BV6-Q0N1-37VU-PEQ7)

11. Bai Z, Zheng H, Lin J, Wang G, Li J. 2013 Comparative Analysis of the Transcriptome in Tissues Secreting Purple and White Nacre in the Pearl Mussel Hyriopsis cumingii. PLoS ONE 8, e53617. (doi:10.1371/journal.pone.0053617)

12. Cai Z, Wu J, Chen L, Guo W, Li J, Wang J, Zhang Q. 2011 Purification and characterisation of aquamarine blue pigment from the shells of abalone (Haliotis discus hannai Ino). Food Chem. 128, 129-133. (doi:10.1016/j.foodchem.2011.03.006)

13. Canales-Gómez E, Correa G, Viana MT. 2010 cantaxanthin and $\beta$-carotene) in juvenile abalone Haliotis rufescens diets on the color of the shell or nacre. Vet. Mex. 41, 191-200.

14. Williams ST. 2017 Molluscan shell colour. Biol. Rev. 92, 1039-1058. (doi:10.1111/brv.12268)

15. Comfort A. 1949 Acid-soluble pigments of shells. 1. The distribution of porphyrin fluorescence in molluscan shells. Biochem. J. 44, 111-117.

16. Comfort A. 1949 Acid-soluble pigments of molluscan shells. 2. Pigments other than porphyrins. Biochem. J. 45, 199-204.

17. Comfort A. 1949 Acid-soluble pigments of molluscan shells. 3. The indigoid character of the blue pigment of Haliotis cracherodii Leach. Biochem. J. 45, 204-208.

18. Comfort A. 1950 Biochemistry of molluscan shell pigments. J. Molluscan Stud. 28, 79-85. (doi:10.1093/oxfordjournals.mollus.a064570)

19. Comfort A. 1951 Observations on the shell pigments of land pulmonates. J. Molluscan Stud. 29, 35-44. (doi:10.1093/oxfordjournals.mollus.a064598)

20. Williams ST et al. 2016 Identification of Shell Colour Pigments in Marine Snails Clanculus pharaonius and $C$. margaritarius (Trochoidea; Gastropoda). PLoS ONE 11, e0156664. (doi:10.1371/journal.pone.0156664)

21. Barnard W, de Waal D. 2006 Raman investigation of pigmentary molecules in the molluscan biogenic matrix. $J$. Raman Spectrosc. 37, 342-352. (doi:10.1002/jrs.1461)

22. Bergamonti L, Bersani D, Mantovan S, Lottici PP. 2013 Micro-Raman investigation of pigments and carbonate phases in corals and molluscan shells. Eur. J. Mineral. 25, 845-853. (doi:10.1127/0935-1221/2013/0025-2318)

23. Hedegaard C, Bardeau J-F, Chateigner D. 2006 Molluscan shell pigments: an in situ resonance raman study. $J$. Molluscan Stud. 72, 157-162. (doi:10.1093/mollus/eyi062) 
24. de Oliveira LN, de Oliveira VE, D’ávila S, Edwards HGM, de Oliveira LFC. 2013 Raman spectroscopy as a tool for polyunsaturated compound characterization in gastropod and limnic terrestrial shell specimens. Spectrochim. Acta. A. Mol. Biomol. Spectrosc. 114, 541-546. (doi:10.1016/j.saa.2013.05.095)

25. Verdes A, Cho W, Hossain M, Brennan PLR, Hanley D, Grim T, Hauber ME, Holford M. 2015 Nature's Palette: Characterization of Shared Pigments in Colorful Avian and Mollusk Shells. PLoS ONE 10, e0143545. (doi:10.1371/journal.pone.0143545)

26. Nagai K, Yano M, Morimoto K, Miyamoto H. 2007 Tyrosinase localization in mollusc shells. Comp. Biochem. Physiol. B Biochem. Mol. Biol. 146, 207-214. (doi:10.1016/j.cbpb.2006.10.105)

27. Mao J, Zhang W, Wang X, Song J, Yin D, Tian Y, Hao Z, Han B, Chang Y. 2019 Histological and Expression Differences Among Different Mantle Regions of the Yesso Scallop (Patinopecten yessoensis) Provide Insights into the Molecular Mechanisms of Biomineralization and Pigmentation. Mar. Biotechnol. (doi:10.1007/s10126019-09913-x)

28. Karampelas S, Fritsch E, Mevellec J-Y, Gauthier J-P, Sklavounos S, Soldatos T. 2007 Determination by Raman scattering of the nature of pigments in cultured freshwater pearls from the mollusk Hyriopsis cumingii.J. Raman Spectrosc. 38, 217-230. (doi:10.1002/jrs.1626)

29. Hao S, Hou X, Wei L, Li J, Li Z, Wang X. 2015 Extraction and Identification of the Pigment in the Adductor Muscle Scar of Pacific Oyster Crassostrea gigas. PLoS ONE 10, e0142439. (doi:10.1371/journal.pone.0142439)

30. Yu F, Pan Z, Qu B, Yu X, Xu K, Deng Y, Liang F. 2018 Identification of a tyrosinase gene and its functional analysis in melanin synthesis of Pteria penguin. Gene 656, 1-8. (doi:10.1016/j.gene.2018.02.060)

31. Chen X, Liu X, Bai Z, Zhao L, Li J. 2017 HcTyr and HcTyp-1 of Hyriopsis cumingii, novel tyrosinase and tyrosinase-related protein genes involved in nacre color formation. Comp. Biochem. Physiol. B Biochem. Mol. Biol. 204, 1-8. (doi:10.1016/j.cbpb.2016.11.005)

32. Sun X, Wu B, Zhou L, Liu Z, Dong Y, Yang A. 2017 Isolation and characterization of melanin pigment from yesso scallop Patinopecten yessoensis. J. Ocean Univ. China 16, 279-284. (doi:10.1007/s11802-017-3162-6)

33. Ito S. 1986 Reexamination of the structure of eumelanin. Biochim. Biophys. Acta 883, 155-161.

34. Prota G. 1995 The Chemistry of Melanins and Melanogenesis. In Fortschritte der Chemie organischer Naturstoffe / Progress in the Chemistry of Organic Natural Products (eds W Herz, GW Kirby, RE Moore, W Steglich, Ch Tamm), pp. 93-148. Vienna: Springer Vienna. (doi:10.1007/978-3-7091-9337-2_2)

35. Huang Z, Lui H, Chen XK, Alajlan A, McLean DI, Zeng H. 2004 Raman spectroscopy of in vivo cutaneous melanin. J. Biomed. Opt. 9, 1198. (doi:10.1117/1.1805553)

36. Sealy R, Hyde J, Felix C, Menon I, Prota G. 1982 Eumelanins and pheomelanins: characterization by electron spin resonance spectroscopy. Science 217, 545-547. (doi:10.1126/science.6283638)

37. Glass K et al. 2012 Direct chemical evidence for eumelanin pigment from the Jurassic period. Proc. Natl. Acad. Sci. 109, 10218-10223. (doi:10.1073/pnas.1118448109)

38. Stępień K, Dzierżęga-Lęcznar A, Kurkiewicz S, Tam I. 2009 Melanin from epidermal human melanocytes: Study by pyrolytic GC/MS. J. Am. Soc. Mass Spectrom. 20, 464-468. (doi:10.1016/j.jasms.2008.11.003)

39. Napolitano A, Pezzella A, Vincensi MR, Prota G. 1995 Oxidative degradation of melanins to pyrrole acids: A model study. Tetrahedron 51, 5913-5920. (doi:10.1016/0040-4020(95)00259-B)

40. Ito S, Nakanishi Y, Valenzuela RK, Brilliant MH, Kolbe L, Wakamatsu K. 2011 Usefulness of alkaline hydrogen peroxide oxidation to analyze eumelanin and pheomelanin in various tissue samples: application to chemical analysis of human hair melanins: Alkaline hydrogen peroxide oxidation of melanin. Pigment Cell Melanoma Res. 24, 605-613. (doi:10.1111/j.1755-148X.2011.00864.x) 
41. Wakamatsu K, Fujikawa K, Zucca FA, Zecca L, Ito S. 2003 The structure of neuromelanin as studied by chemical degradative methods: Chemical structure of neuromelanin. J. Neurochem. 86, 1015-1023. (doi:10.1046/j.1471-4159.2003.01917.x)

42. Magarelli M, Passamonti P, Renieri C. 2010 Purification, characterization and analysis of sepia melanin from commercial sepia ink (Sepia officinalis). Rev. CES Med. Vet. Zootec. 5, 18-28.

43. Waite JH, Andersen SO. 1980 3,4-dihydroxyphenylalanine (dopa) and sclerotization of periostracum in Mytilus edulis L. Biol. Bull. 158, 164-173. (doi:10.2307/1540767)

44. Ito S, Wakamatsu K. 1989 Melanin Chemistry and Melanin Precursors in Melanoma. J. Invest. Dermatol. 92, S261-S265. (doi:10.1038/jid.1989.78)

45. Mapes RH, Sneck DA. 1987 The oldest ammonoid 'colour' patterns: description, comparison with Nautilus, and implications. Paleontology 30, 299-309.

46. Affenzeller S, Haar N, Steiner G. 2017 Revision of the genus complex Gibbula: an integrative approach to delineating the Eastern Mediterranean genera Gibbula Risso, 1826, Steromphala Gray, 1847, and Phorcus Risso, 1826 using DNA-barcoding and geometric morphometrics (Vetigastropoda, Trochoidea). Org. Divers. Evol. 17, 789-812. (doi:10.1007/s13127-017-0343-5)

47. Iwahashi Y, Akamatsu S. 1994 Porphyrin Pigment in Black-Lip Pearls and Its Application to Pearl Identification. Fish. Sci. 60, 69-71. (doi:10.2331/fishsci.60.69)

48. Miyoshi T, Matsuda Y, Komatsu H. 1987 Fluorescence from Pearls and Shells of Black Lip Oyster, Pinctada margaritifera, and Its Contribution to the Distinction of Mother Oysters Used in Pearl Culture. Jpn. J. Appl. Phys. 26, 1069-1072. (doi:10.1143/JJAP.26.1069) 
CHAPTER 5: EUMELANIN IS NOT THE BANDED PIGMENT IN CEPAEA NEMORALIS

The following chapter is prepared for publication as Correspondence in Current Biology and is currently being revised by my co-authors.

Contributions by the doctoral candidate: Conceptualization, Formal analysis, Investigation, Methodology, Validation, Writing - review \& editing 


\section{Eumelanin is not the banded pigment in Cepaea nemoralis}

Susanne Affenzeller ${ }^{1}$, Klaus Wolkenstein ${ }^{1}$ and Daniel J. Jackson ${ }^{1, *}$

${ }^{1}$ Department of Geobiology, Georg-August University of Göttingen, Goldschmidtstrasse 3, 37077 Göttingen, Germany

*Author for correspondence:

Daniel J. Jackson

email: djackso@uni-goettingen.de

Keywords: Eumelanin, Pheomelanin, mollusc, shell pigmentation, mass spectroscopy, qPCR 


\section{Main text}

With highly variable and colourful patterns of shell pigmentation (Fig. 1A) the terrestrial snail Cepaea nemoralis has long been a textbook example of phenotypic variability and a model system for evolution, ecology and population genetics (Cain and Sheppard, 1954). Early studies established that the shell background colour, the number of dark pigmented bands on the shell and several other shell-pigment characteristics are inherited in a Mendelian fashion (Cain et al., 1960). It has also been long assumed that melanin (specifically eumelanin) is the pigment that underlies the dark pigmented bands (Comfort, 1951; Helmcke, 1935). We tested this assumption using a combination of sensitive chemical and molecular techniques and find no evidence that eumelanin is differentially distributed within the shells of $C$. nemoralis. This implies that an unknown pigment adorns the shells of $C$. nemoralis, and has implications for the continuing search for the supergene that generates the various pigmentation morphotypes.

Recently we developed a highly sensitive LC-MS based method for the detection of eu- and pheomelanin from a variety of biological matrices including molluscan shells (Affenzeller et al., in revision). Our initial experiments on whole shells of the common yellow banded morph of $C$. nemoralis detected all four common melanin oxidation products: PDCA (pyrrole-2,3-dicarboxylic acid) and PTCA (pyrrole-2,3,5-tricarboxylic acid) for eumelanin, and TDCA (thiazole-4,5dicarboxylic acid) and TTCA (thiazole-2,4,5-tricarboxylic acid) for pheomelanin, albeit for eumelanin at levels significantly lower than the darkly pigmented shells of Mytillus edulis (Affenzeller et al., in prep). To further investigate the spatial distribution of eu- and pheomelanin in C. nemoralis shells we have conducted quantitative measurements of colour-sorted shell fragments (pink banded, pink background, yellow banded and yellow background; Figure 1A). All four shell colour fractions contained the markers PDCA and PTCA, indicating a broad distribution of eumelanin, however we could not detect significant differences in the amounts of these eumelanin 
markers between banded and background shell fragments for either yellow or pink shells (Figure 1B). We also detected the pheomelanin markers TDCA and TTCA in both yellow banded and yellow background shell fragments in high abundance, but with no significant difference between the two (Figure 1B). In pink morphs we detected far less TDCA in both fractions while TTCA was below the limit of quantitation but could still be detected (Supplementary Table 1).

To further investigate the role of melanin in the banding pattern of $C$. nemoralis shells we studied the expression of four known melanin synthesis pathway genes using recently established RT-qPCR reference genes (Affenzeller et al., 2018). We selected the genes Yellow, Tyrosinase Related Protein, Tyrosinase and Laccase, all of which are known to be involved in melanin synthesis in a variety of species including molluscs. Tyrosinases and Tyrosinase Related Proteins have been the focus of recent research due to their proposed involvement in nacre colour formation in bivalves, thus influencing the value of pearls. Despite considerable variation Yellow was significantly differentially expressed in pigmented vs. non-pigmented regions of the mantle ( $\mathrm{p}<0.05$ but not $<0.01$; Fig. 1C). However Yellow was significantly more abundant (approximately three fold) in foot tissue relative to mantle tissue overall, suggesting that this gene either has pleiotropic roles in these tissues or is not involved in melanogenesis in C. nemoralis. Supporting this latter scenario the Yellow homolog we identified here has relatively low sequence similarity (35\% identity) with insect isoforms known to be involved in pigmentation. Tyrosinase Related Protein was significantly upregulated in mantle vs. foot tissues suggesting it plays either a role in biomineralization as is known for molluscs, or pigmentation. However comparisons between pigmented and non-pigmented mantle tissue revealed no significant differences in Tyrosinase Related Protein expression (Fig. 1C). Finally Tyrosinase and 
Laccase 2 were equally expressed between foot and mantle tissues and also between pigmented and non-pigmented mantle tissue (Figure 1C).

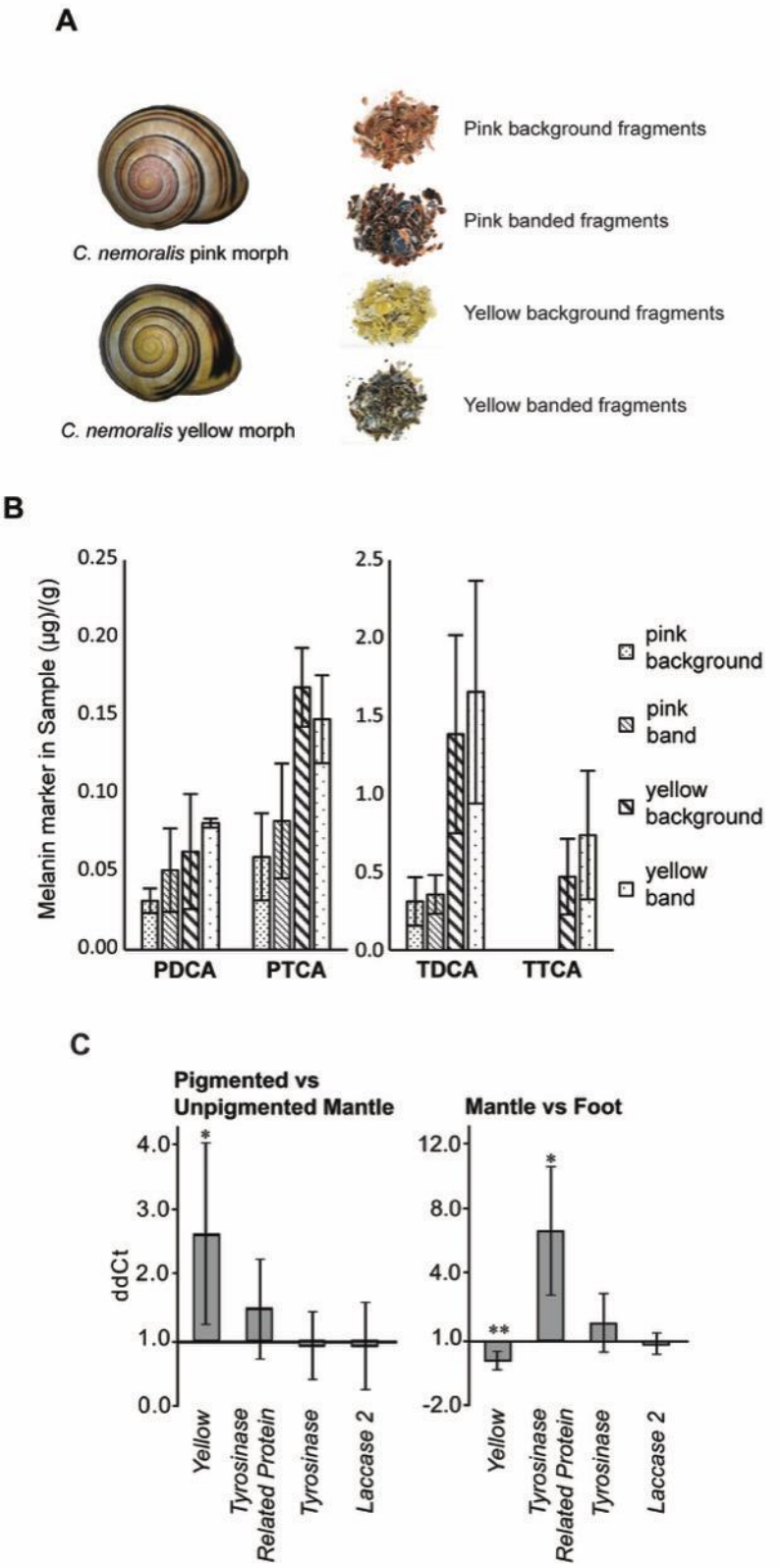

Figure 1. Eumelanin and pheomelanin are not differentially localised in the shells of C. nemoralis. A Pink banded and Yellow banded morphs of $C$. nemoralis and shell fragments used for LC-MS analysis sorted by colour. B Eumelanin and pheomelanin oxidation products were quantitated in UV chromatograms with external calibration. Eumelanin (PDCA and PTCA) and pheomelanin (TDCA and TTCA) oxidation markers were quantified for each shell colour fraction and normalised to initial sample weight. $\mathrm{n}=3$ for each shell colour fraction. C Normalized relative expression values $(\mathrm{ddCt})$ of four melanin pathway genes from yellow background pigmented vs. non-pigmented mantle tissue (first panel) and whole mantle vs. foot tissue ( $\mathrm{n}=6$ for each sample, ${ }^{*} \mathrm{p} \leq 0.05 * * \mathrm{p} \leq 0.01$ for Mann-Whitney).

The independent LC-MS and RT-qPCR data we present here demonstrates that eumelanin is not the banding pigment used by $C$. nemoralis. As far as we can tell the defining work that biochemically suggests melanin to be the responsible pigment in C. nemoralis was published more than 80 years ago (Helmcke, 1935). Interestingly Comfort later states in regard to the banded pigment in C. nemoralis that "Attempts to attack the chemistry of the pigments with melanin inhibitors such as phenyl thiourea have not so far succeeded...." and that "Very little can be said of these colour patterns in terms of chemistry. The black pigment 
('melanocochlin') is alkali-soluble (Helmcke, 1935)." (Comfort, 1951). Nonetheless subsequent works refer to pigmented cells in the mantle as melanocytes (Emberton, 1963) and have worked from the assumption that melanin is the banded pigment (Vicario et al., 1989). We previously demonstrated that the banded pigment is apparently not covalently linked to a protein (Mann and Jackson, 2014), however the banded and background pigments are yet to be identified. Taken together, our results indicate that a novel molecular mechanism which deposits a dark brown pigment in a banded fashion is operating in the mantle tissue of $C$. nemoralis. A knowledge of what this dark pigment is (together with the background pigments and their respective synthesis pathways) would likely assist efforts to identify the supergene that is thought to regulate the famous Cepaea colour polymorphism. Such a complete understanding of this process at the genetic and chemical scales would in turn provide deep insight into the long studied population genetics and evolutionary biology of this system.

\section{Acknowledgements}

We are grateful to Professors Shosuke Ito and Kazumasa Wakamatsu (Department of Chemistry, Fujita Health University School of Health Sciences) for donating standard solutions for melanin oxidation products. Furthermore thanks are due to Tobias Licha for valuable input on understanding the chemistry and for providing equipment and assistance. We thank Leyla Seyfullah and Volker Thiel for productive suggestions and discussions. This research was funded by DFG grant WO 1491/4-2 to KW, and JA 2108/2-1 and JA 2108/6-1 to DJJ.

\section{References}

Affenzeller, S., Frauendorf, H., Licha, T., Jackson, D.J., and Wolkenstein, K. (in revision). Quantitation of eumelanin and pheomelanin markers in diverse biological samples by HPLC-UV-MS following solid-phase extraction. PLoS One. 
Affenzeller, S., Wolkenstein, K., Frauendorf, H., and Jackson, D.J. (in prep). Eumelanin and pheomelanin pigmentation in mollusc shells may be less common than expected: insights from mass spectrometry.

Affenzeller, S., Cerveau, N., and Jackson, D.J. (2018). Identification and validation of reference genes for qPCR in the terrestrial gastropod Cepaea nemoralis. PLoS One 13, e0201396.

Cain, A.J., and Sheppard, P.M. (1954). Natural Selection in Cepaea. Genetics 39, 89-116.

Cain, A.J., King, J., and Sheppard, P. (1960). New data on the genetics of polymorphism in the snail Cepaea nemoralis L. Genetics 45, 393.

Comfort, A. (1951). Observations on the shell pigments of land pulmonates. J. Molluscan Stud. 29, 35-44.

Emberton, L.R.B. (1963). Relationships Between Pigmentation of Shell and of Mantle in the Snails Cepaea Nemoralis (1.) and Cepaea Hortensis (mull.). Proc. Zool. Soc. Lond. 140, 273-293.

Helmcke, J.-G. (1935). Untersuchungen über die Schalen- und Körperfärbung der Landschnecken. Fischer.

Mann, K., and Jackson, D. (2014). Characterization of the pigmented shell-forming proteome of the common grove snail Cepaea nemoralis. BMC Genomics 15, 249.

Vicario, A., Mazon, L.I., Aguirre, A., Estomba, A., and Lostao, C. (1989). A tyrosinase-like enzyme in Cepaea nemoralis and its possible relation with shell banding polymorphism. J. Molluscan Stud. 55, 441-444. 


\section{CHAPTER 6: GENERAL DISCUSSION}

Mollusc shell pigmentation and the underlying genetic mechanisms responsible for these patterns are a fascinating topic. But for many investigations basic protocols for dealing with molluscs are missing. One very useful tool to quantitatively measure gene expression levels is reverse transcription quantitative polymerase chain reaction (qPCR). To be able to accurately use this technique I tested potential reference genes for a terrestrial gastropod Cepaea nemoralis (chapter 2, [1]). In addition to finding suitable reference genes, this study highlighted how difficult and complicated gene expression studies can be. I found that expression levels of so-called housekeeping genes vary greatly, not only depending on tissue, but also on season. As even constantly used genes in the organism show such high variability, one has to be very careful with interpreting any results gained from qPCR on seasonally employed genes. Especially genes involved in shell building and pigmentation in a temperate climate snail like $C$. nemoralis will very likely undergo seasonal fluctuations, as shell material and the pigments responsible for the well known $C$. nemoralis polymorphism are mainly laid down in spring and summer[2-4].

Eumelanin has long since been thought to be the banding pigment in $C$. nemoralis [5-9]. I aimed to test this assumption. To this end a specialized protocol to sensitively detect melanin oxidation markers in complex biological samples was developed (chapter 3). Mollusc shell samples have to be prepared carefully for any chemical analyses on high performance liquid chromatography (HPLC) to guarantee quality and reproducibility of these experiments. One way to obtain desalted and cleaned mollusc shell samples suitable for HPLC is solid phase extraction. Additionally this method allowed me to concentrate the samples through evaporation, an important advantage for species with small shells or little pigmentation. By adjusting existing protocols $[10,11]$ to allow for mass spectrometric (MS) measurements, identification of trace amounts of melanin oxidation products via exact masses became possible. This was necessary as on top of small pigment amounts in some shells, even cleaned 
mollusc samples still contain a complex matrix. With these adaptations the presented method allows for confident identification and quantitation of eumelanin and pheomelanin oxidation products in diverse biological samples including feathers, hair and mollusc shells.

The new chemical method was applied to 13 different mollusc species with prominent shell pigmentation (chapter 4). Some of them have been previously indicated as containing eumelanin [10,12-14], while others were chosen due to their brown or black colouration. In C. nemoralis I was able to detect the first mass spectrometric evidence od pheomelanin use in mollusc shell pigmentation. We found evidence for eumelanin in three prominent mollusc classes (Mytilus edulis, Bivalvia; Nautilus pompilius, Cephalopoda; Cepaea nemoralis, Clanculus pharaonius, Steromphala adriatica, all Gastropoda). Still, a surprisingly large number of species showed no trace of eumelanin in their dark patterned shells. This contradicts some of the previous findings for Mizuhopecten yessoensis and Crassostrea gigas, $[12,13]$. In $C$. pharaonius the data is inconclusive as eumelanin could only be detected in one out of three shells.

To further investigate the use of eumelanin and pheomelanin in C. nemoralis I used a combination of the developed methods to gain more insight (chapter 5). I analysed colour sorted shell fragments for yellow and pink background coloured snails and their corresponding bands to test the contribution of pheomelanin and eumelanin to background and band pigmentation. Although both pigments are present in $C$. nemoralis shells, I wasn't able to find any conclusive evidence for eumelanin as the banding pigment. Pheomelanin might contribute to the background colour, but comparisons of yellow and pink background indicate that this pigment is not solely responsible for these colours. I further tested expression levels of known melanin pathway genes in shell producing mantle tissue. As expected from studies on other mollusc species (namely Mizuhopecten yessoensis, Pteria penguin, Hyriopsis cumingii and Crassostrea gigas $[12,13,15-17])$ these genes are active in the mantle, but they don't show differential expression between band building and background building tissue. This 
adds to the conclusion that while $C$. nemoralis does lay down melanin pigments into its shell, eumelanin and pheomelanin are not the primary pigments used for the well known polymorphism.

One of the most surprising conclusions to be drawn from the here presented studies is that although shell bearing molluscs have the ability to produce eumelanin, and probably also pheomelanin, many species don't use that pigment for patterning their shell. This is contradicting many early works indicating eumelanin as a broadly used pigment in molluscs $[7,18,19]$. For those species shown here to have eumelanin in their shells, only $C$. nemoralis was available in enough sample quantities to investigate the spatial distribution of pigment within the shell. This experiment showed that eumelanin is not the pigment building the band, as previously assumed $[5,6,9]$. It would of cause be interesting to see wither eumelanin is involved in the patterns of N. pompilius, C. pharaonius and $S$. adriatica. In Clanculus first efforts were undertaken to this end by Williams et al. [10], who tested for eumelanin after removing the uppermost pigment bearing shell layer. They found no traces of eumelanin were left, proving that the pigment is part of the visible shell colouration. In light of our inconclusive results in addition to previous work described above, further experiments on eumelanin shell pigmentation in this species would be very interesting, but might be difficult to archive. On top of technical difficulties in separating black coloured shell fragments, the availability of enough shells might pose a problem. Clanculus pharaonius is one of the most beautiful mollusc shells, and though not severely protected at the moment, should be collected with care.

If these patterns are not built by melanin, the question remains: What pigment is it? At the current moment, this is a difficult question to answer. Two other major pigment classes have been shown in mollusc shells up to now: Carotinoids and tetrapyrrols [10,14,20-23]. Tetrapyrrols, as porphyrins, can appear in a multitude of colours, but they all share a strong fluorescence under UV light $[7,10]$. All species testing negative for eumelanin in chapter 4, except Crassostrea gigas, show no such 
fluorescence (data not shown here). I would therefore assume that porphyrins can be disregarded as likely candidate pigments in these species. Carotinoids on the other hand are a possible source for light brown patterns observed. Employing Raman spectroscopy might shed some light on the likelihood of carotinoid pigments being responsible for the patterns in these shells.

Still, the mystery of the dark brown to black pigment (e.g. in Conus marmoreus, but also in $C$. nemoralis) remains unsolved. For $C$. nemoralis Mann and Jackson [24] observed that there is no obvious linkage of pigment to a shell protein as seen in juveniles of Haliotis asinina $[25,26]$. The pigment itself is thermo- and chemo stable and according to Comfort [6] also resists enzymatic attempts to attack it. From a chemistry point of view gaining the pigment in clean state might be the next step in understanding its nature and allow further tests. A possible hinderance is the amount of pigment need, and therefore the amount of shell material required to extract the pigment. Furthermore extraction of the pure pigment is difficult to undertake with no clear idea about the chemical nature of the molecule. A solution to circumvent these challenges might be to understand the genetic background for banding in $C$. nemoralis. If we were able to understand the genes involved in the polymorphism, especially the locus for band pigmentation, we might discover what kind of pigment we are looking for. Recent efforts on understanding recombination, epistasis and incomplete penetrance in the $C$. nemoralis supergene, together with more transcriptomic data being available, are a solid groundwork for future studies [27,28]. Especially long read sequencing technology might prove useful in finally unravelling the $C$. nemoralis supergene [27].

Research on patterning mechanisms in the 1980s allowed computational reconstructions of most shell patterns found in nature by reaction-diffusion and neural network models [29-31]. But although this knowledge is readily available, further investigations were hindered by lacking methods for molluscs in both molecular biology and analytical chemistry. Now, new protocols and sequencing techniques 
are available and we can start understanding these mechanisms. Further investigations based on transcriptomic and genomic data, together with in situ expression experiments and investigations on pigment chemistry, will hopefully help further our knowledge on these beautiful works of art built by nature.

\section{References}

1. Affenzeller S, Cerveau N, Jackson DJ. 2018 Identification and validation of reference genes for qPCR in the terrestrial gastropod Cepaea nemoralis. PLoS One 13, e0201396.

2. Cain AJ, Sheppard PM. 1950 Selection in the polymorphic land snail Cepaea nemoralis. Heredity 4, $275-294$. (doi:10.1038/hdy.1950.22)

3. Cain AJ, Sheppard PM. 1954 Natural Selection in Cepaea. Genetics 39, 89-116.

4. Jones JS, Leith BH, Rawlings P. 1977 Polymorphism in Cepaea: A Problem with Too Many Solutions? Annu. Rev. Ecol. Syst. 8, 109-143. (doi:10.1146/annurev.es.08.110177.000545)

5. Vicario A, Mazon LI, Aguirre A, Estomba A, Lostao C. 1989 A tyrosinase-like enzyme in Cepaea nemoralis and its possible relation with shell banding polymorphism. J. Molluscan Stud. 55, 441-444. (doi:10.1093/mollus/55.4.441)

6. Comfort A. 1951 Observations on the shell pigments of land pulmonates. J. Molluscan Stud. 29, 35-44. (doi:10.1093/oxfordjournals.mollus.a064598)

7. Williams ST. 2017 Molluscan shell colour. Biol. Rev. 92, 1039-1058. (doi:10.1111/brv.12268)

8. Helmcke J-G. 1935 Untersuchungen über die Schalen- und Körperfärbung der Landschnecken. Fischer, Jena.

9. Emberton LRB. 1963 Relationships Between Pigmentation of Shell and of Mantle in the Snails Cepaea Nemoralis (1.) and Cepaea Hortensis (mull.). Proc. Zool. Soc. Lond. 140, 273-293. (doi:10.1111/j.14697998.1963.tb01864.x)

10. Williams ST et al. 2016 Identification of Shell Colour Pigments in Marine Snails Clanculus pharaonius and $C$. margaritarius (Trochoidea; Gastropoda). PLOS ONE 11, e0156664. (doi:10.1371/journal.pone.0156664)

11. Ito S, Nakanishi Y, Valenzuela RK, Brilliant MH, Kolbe L, Wakamatsu K. 2011 Usefulness of alkaline hydrogen peroxide oxidation to analyze eumelanin and pheomelanin in various tissue samples: application to chemical analysis of human hair melanins: Alkaline hydrogen peroxide oxidation of melanin. Pigment Cell Melanoma Res. 24, 605-613. (doi:10.1111/j.1755-148X.2011.00864.x)

12. Hao S, Hou X, Wei L, Li J, Li Z, Wang X. 2015 Extraction and Identification of the Pigment in the Adductor Muscle Scar of Pacific Oyster Crassostrea gigas. PLoS ONE 10, e0142439. (doi:10.1371/journal.pone.0142439)

13. Sun X, Wu B, Zhou L, Liu Z, Dong Y, Yang A. 2017 Isolation and characterization of melanin pigment from yesso scallop Patinopecten yessoensis. J. Ocean Univ. China 16, 279-284. (doi:10.1007/s11802-017-3162-6)

14. Hedegaard C, Bardeau J-F, Chateigner D. 2006 Molluscan shell pigments: an in situ resonance raman study. J. Molluscan Stud. 72, 157-162. (doi:10.1093/mollus/eyi062) 
15. Bai Z, Zheng H, Lin J, Wang G, Li J. 2013 Comparative Analysis of the Transcriptome in Tissues Secreting Purple and White Nacre in the Pearl Mussel Hyriopsis cumingii. PLoS ONE 8, e53617. (doi:10.1371/journal.pone.0053617)

16. Chen X, Liu X, Bai Z, Zhao L, Li J. 2017 HcTyr and HcTyp-1 of Hyriopsis cumingii, novel tyrosinase and tyrosinase-related protein genes involved in nacre color formation. Comp. Biochem. Physiol. B Biochem. Mol. Biol. 204, 1-8. (doi:10.1016/j.cbpb.2016.11.005)

17. Yu F, Pan Z, Qu B, Yu X, Xu K, Deng Y, Liang F. 2018 Identification of a tyrosinase gene and its functional analysis in melanin synthesis of Pteria penguin. Gene 656, 1-8. (doi:10.1016/j.gene.2018.02.060)

18. Comfort A. 1950 Biochemistry of molluscan shell pigments. J. Molluscan Stud. 28, 79-85. (doi:10.1093/oxfordjournals.mollus.a064570)

19. Comfort A. 1951 The pigmentation of molluscan shells. Biol. Rev. 26, 285-301. (doi:10.1111/j.1469185X.1951.tb01358.x)

20. Williams ST, Lockyer AE, Dyal P, Nakano T, Churchill CKC, Speiser DI. 2017 Colorful seashells: Identification of haem pathway genes associated with the synthesis of porphyrin shell color in marine snails. Ecol. Evol. 7, 10379-10397. (doi:10.1002/ece3.3552)

21. Barnard W, de Waal D. 2006 Raman investigation of pigmentary molecules in the molluscan biogenic matrix. $J$. Raman Spectrosc. 37, 342-352. (doi:10.1002/jrs.1461)

22. Bergamonti L, Bersani D, Mantovan S, Lottici PP. 2013 Micro-Raman investigation of pigments and carbonate phases in corals and molluscan shells. Eur. J. Mineral. 25, 845-853. (doi:10.1127/0935-1221/2013/0025-2318)

23. de Oliveira LN, de Oliveira VE, D’ávila S, Edwards HGM, de Oliveira LFC. 2013 Raman spectroscopy as a tool for polyunsaturated compound characterization in gastropod and limnic terrestrial shell specimens. Spectrochim. Acta. A. Mol. Biomol. Spectrosc. 114, 541-546. (doi:10.1016/j.saa.2013.05.095)

24. Mann K, Jackson D. 2014 Characterization of the pigmented shell-forming proteome of the common grove snail Cepaea nemoralis. BMC Genomics 15, 249. (doi:10.1186/1471-2164-15-249)

25. Jackson DJ, McDougall C, Green K, Simpson F, Wörheide G, Degnan BM. 2006 A rapidly evolving secretome builds and patterns a sea shell. BMC Biol. 4.

26. Jackson DJ, Wörheide G, Degnan BM. 2007 Dynamic expression of ancient and novel molluscan shell genes during ecological transitions. BMC Evol. Biol. 7, 160. (doi:10.1186/1471-2148-7-160)

27. Gonzalez DR, Aramendia AC, Davison A. 2019 Recombination within the Cepaea nemoralis supergene is confounded by incomplete penetrance and epistasis. Heredity 123, 153-161. (doi:10.1038/s41437-019-0190-6)

28. Kerkvliet J, de Boer T, Schilthuizen M, Kraaijeveld K. 2017 Candidate genes for shell colour polymorphism in Cepaea nemoralis. PeerJ 5, e3715. (doi:10.7717/peerj.3715)

29. Meinhardt H. 1984 Models for positional signalling, the threefold subdivision of segments and the pigmentation pattern of molluscs. Development 83, 289-311.

30. Meinhardt H, Klingler M. 1987 A model for pattern formation on the shells of molluscs. J. Theor. Biol. 126, 63-89. (doi:10.1016/S0022-5193(87)80101-7)

31. Ermentrout B, Campbell J, Oster G. 1986 A Model for Shell Patterns Based on Neural Activity. The Veliger 28, 369-388. 


\section{APPENDIX A: SUPPLEMENTARY MATERIAL FOR CHAPTER 2}

\section{Table S1}

\begin{tabular}{|c|c|c|c|}
\hline 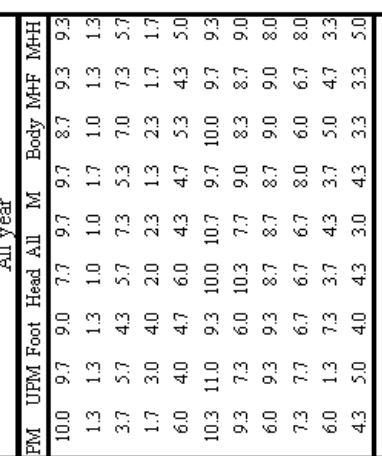 & 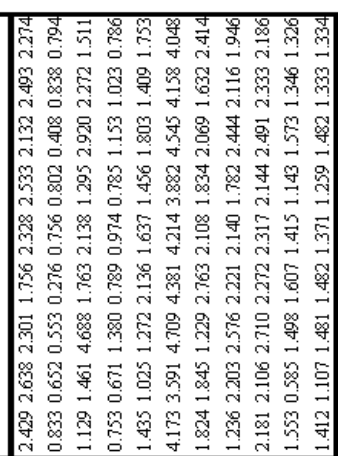 & 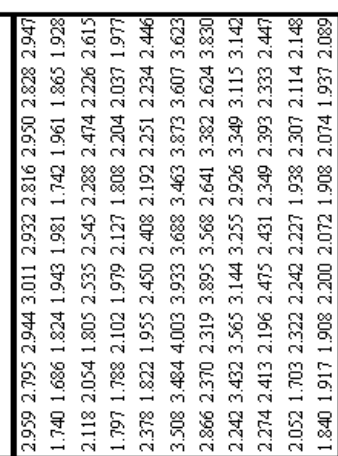 & 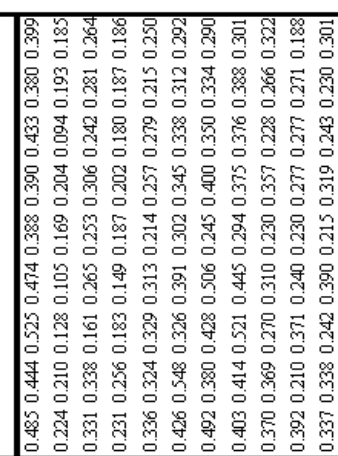 \\
\hline 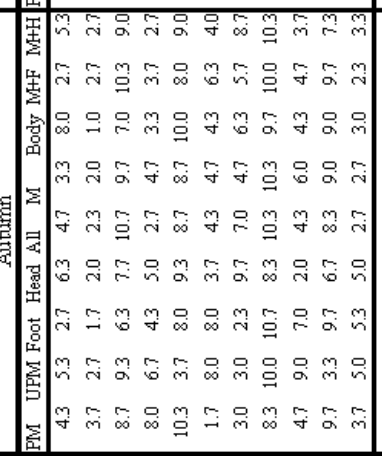 & 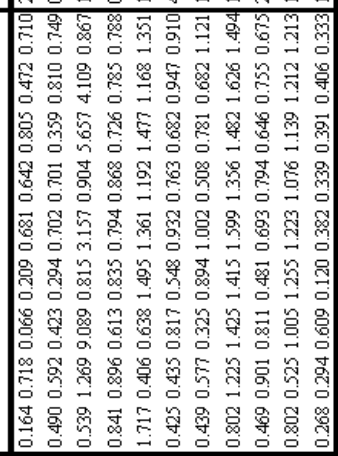 & 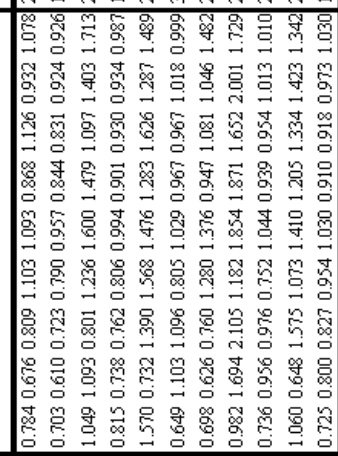 & 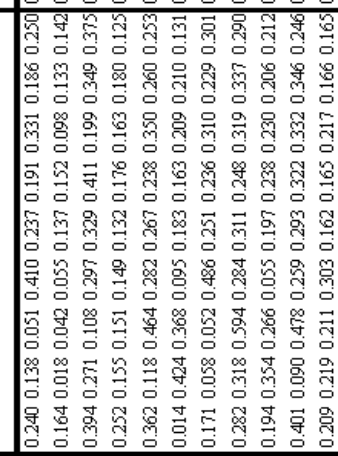 \\
\hline 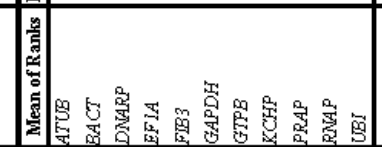 & & & \\
\hline 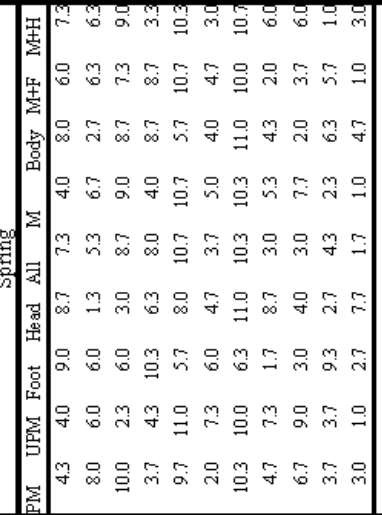 & 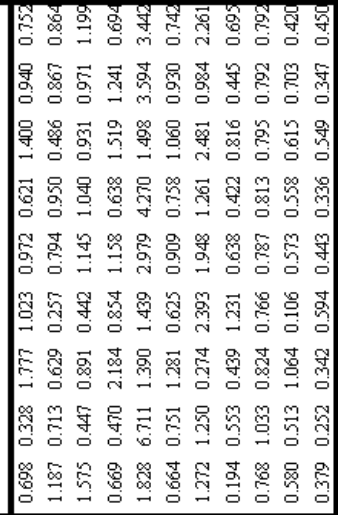 & 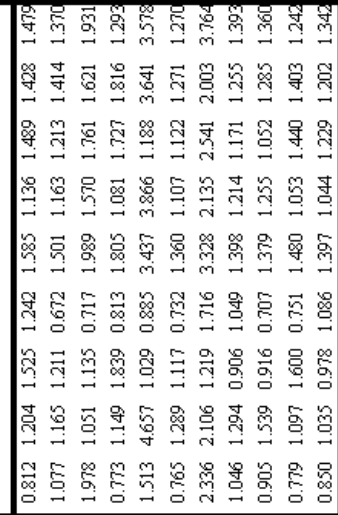 & 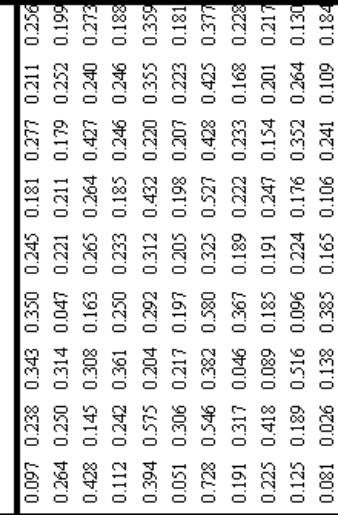 \\
\hline 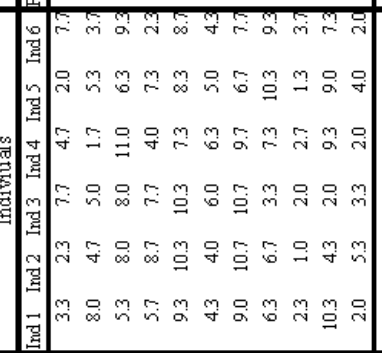 & 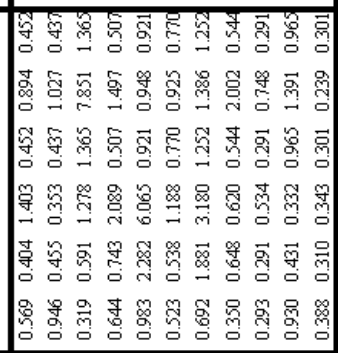 & 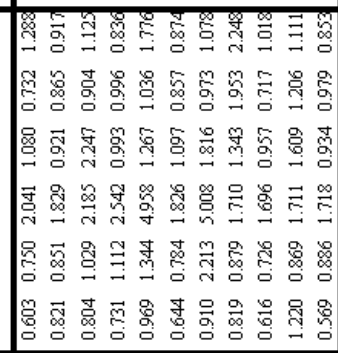 & 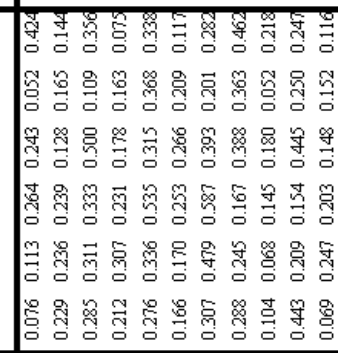 \\
\hline & & & \\
\hline
\end{tabular}




\section{Figure S2}

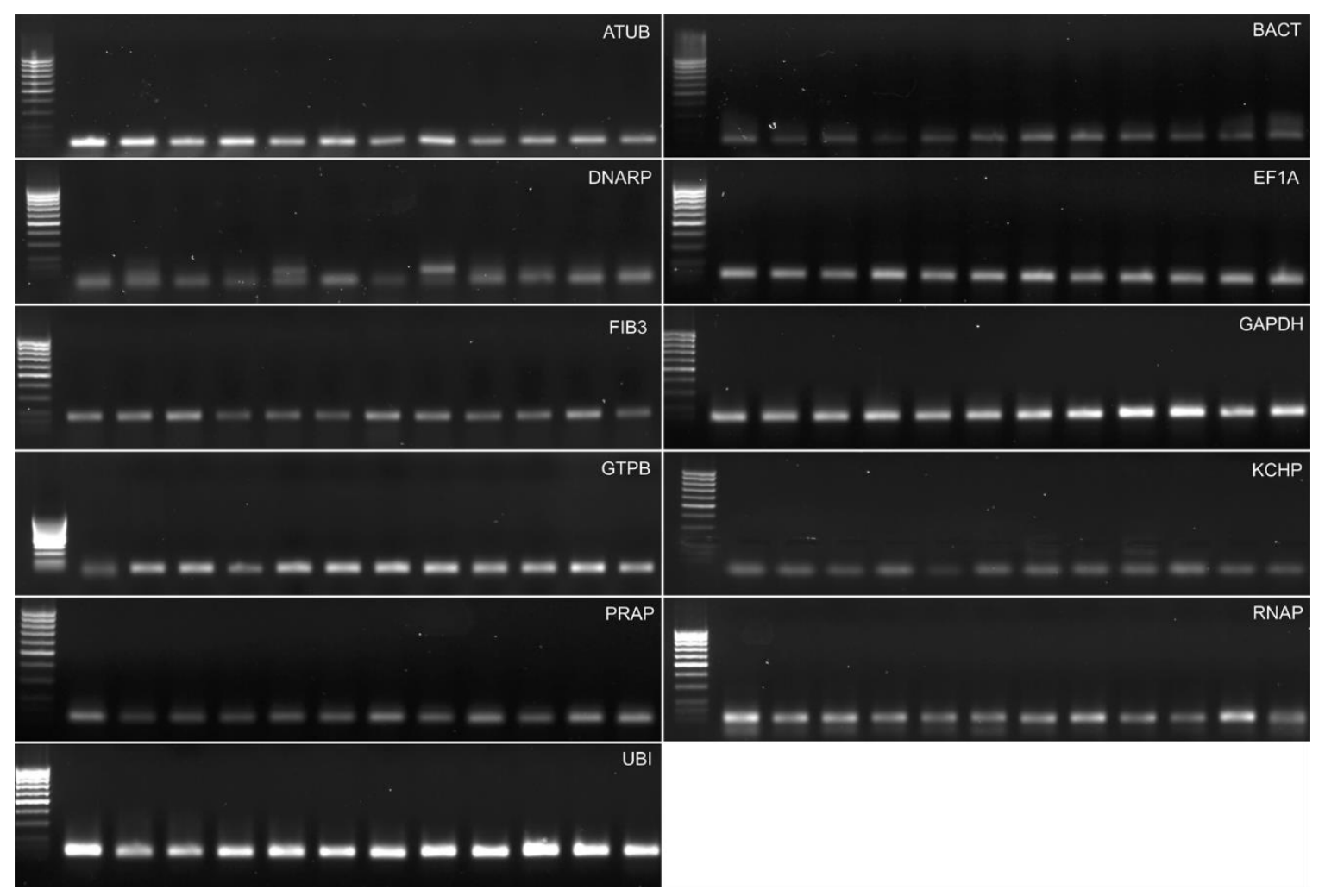


Figure S3

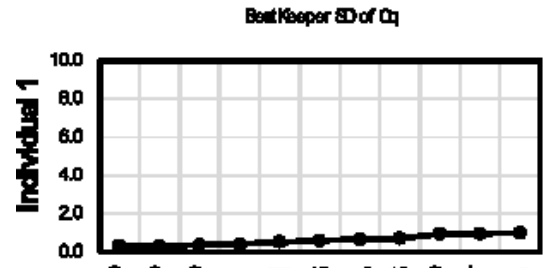

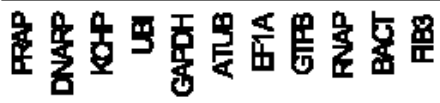

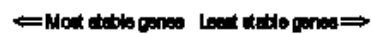

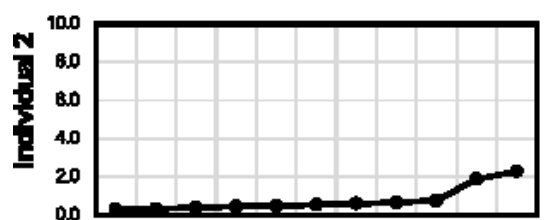

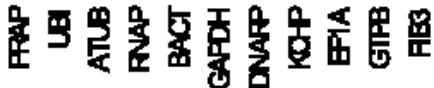

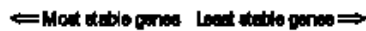

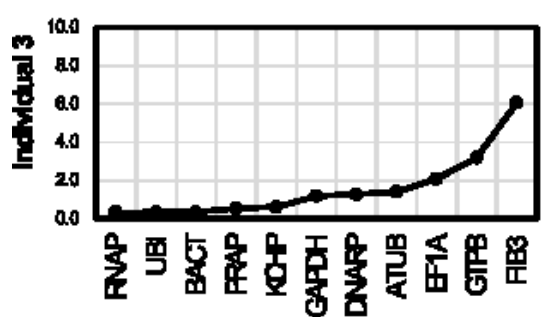

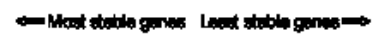

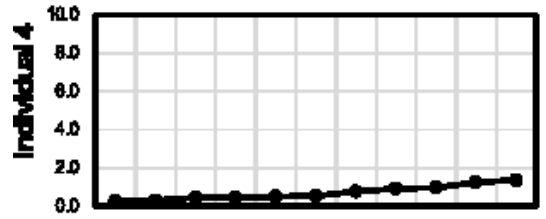

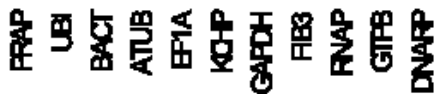

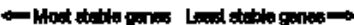

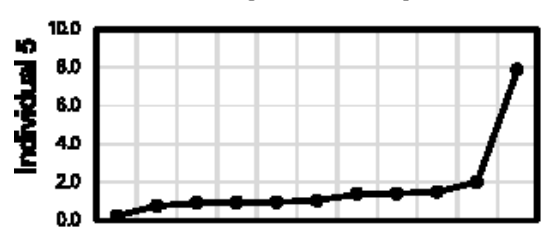

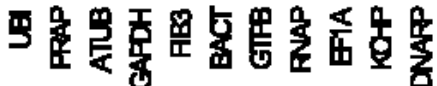

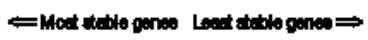

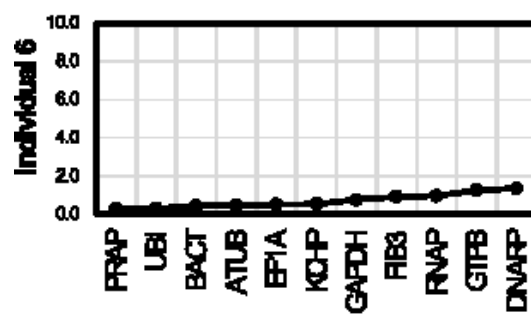

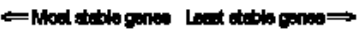

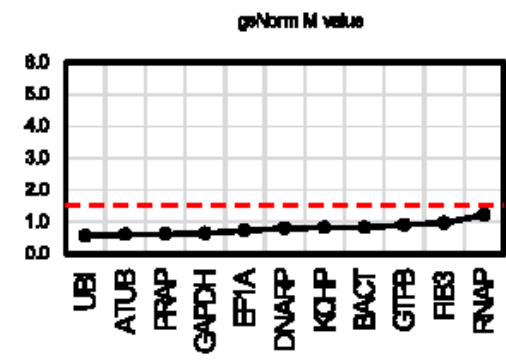

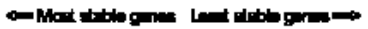

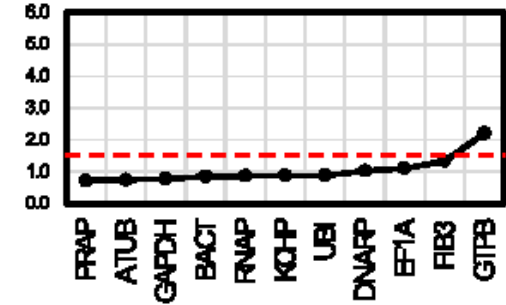

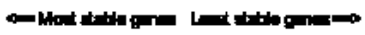

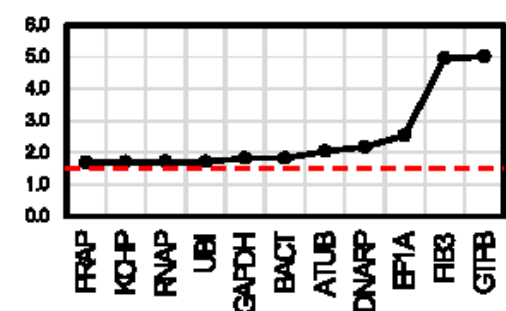

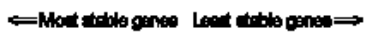

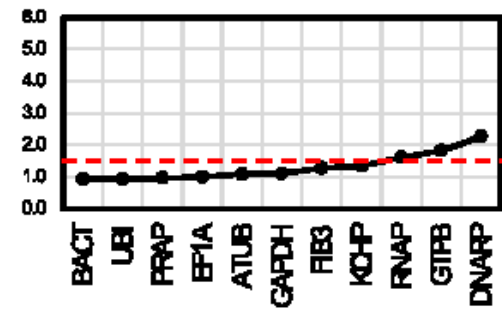

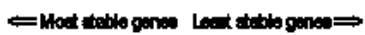

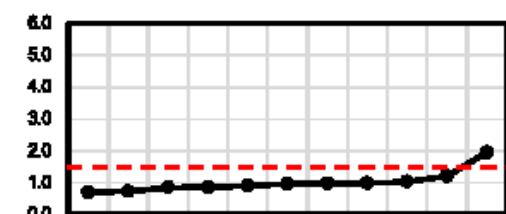

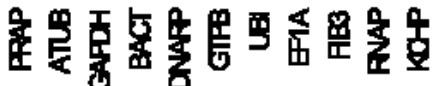

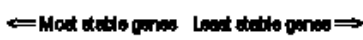

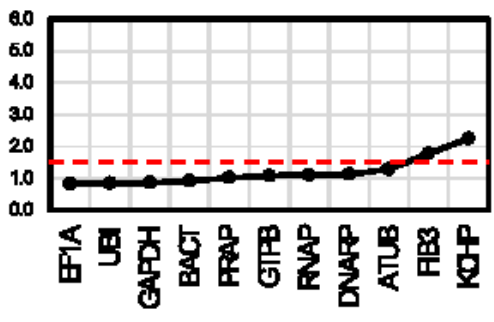

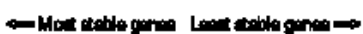

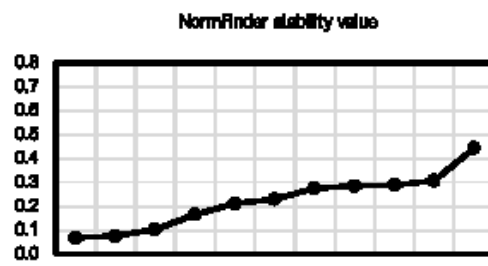

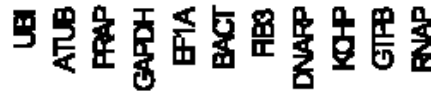

CNat toblegenes lest deble ponese

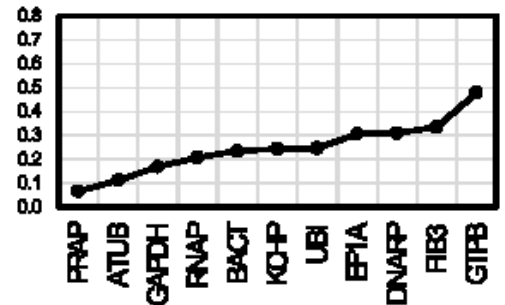

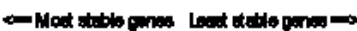
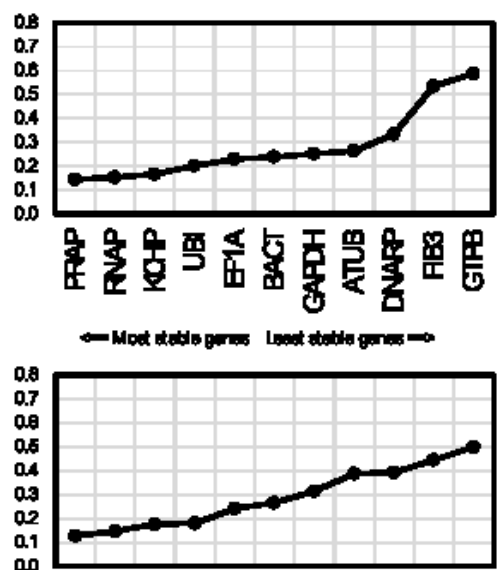

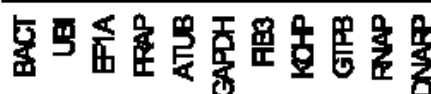

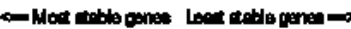

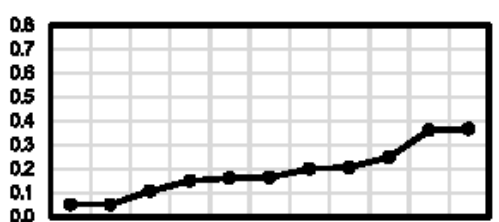

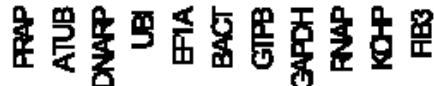

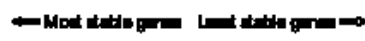

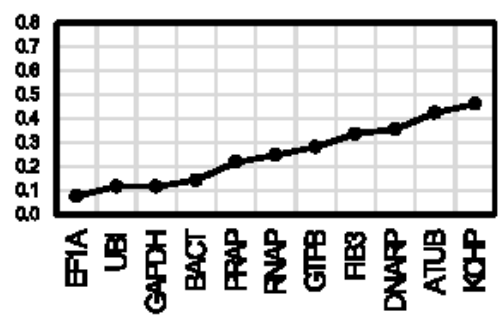

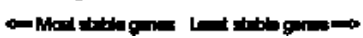

Figure S4 

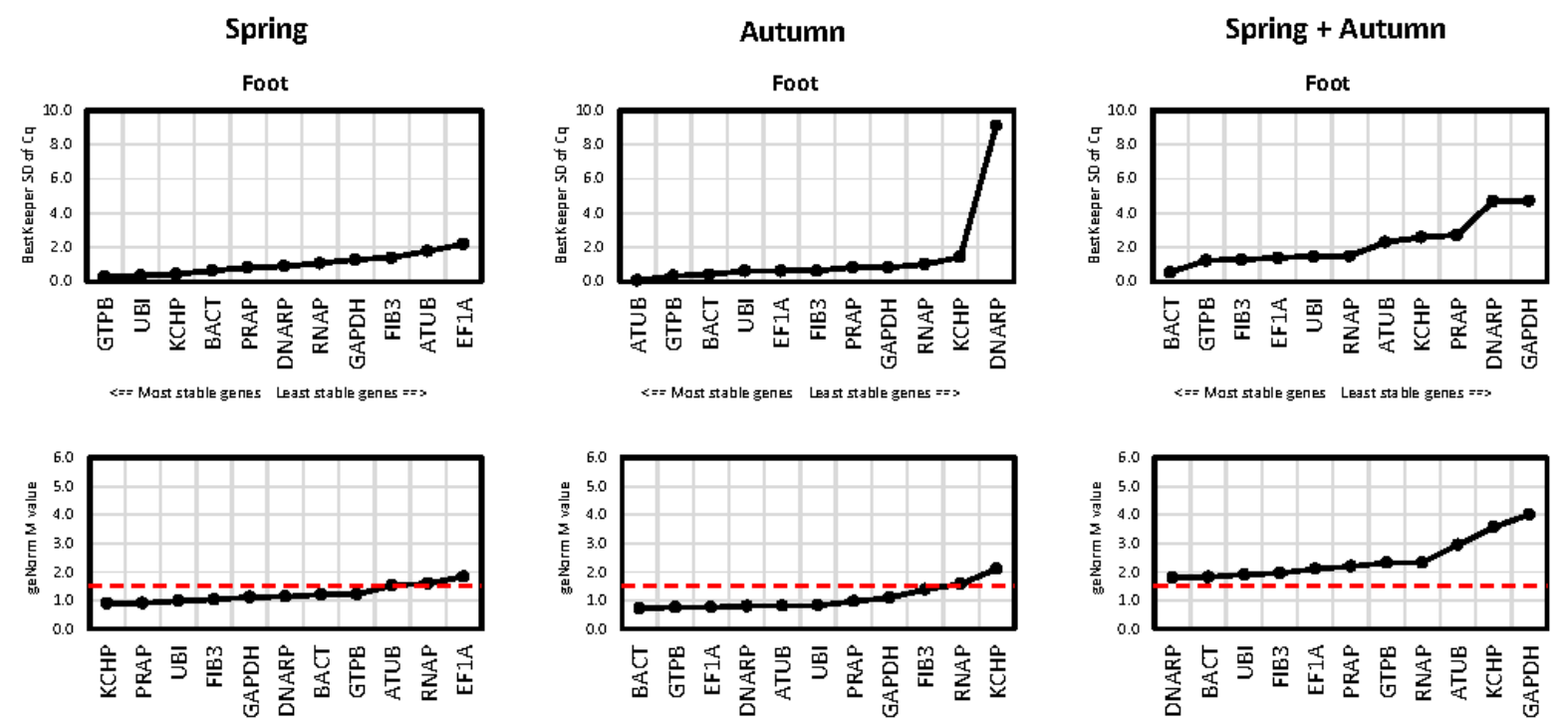

«= Most stable genes Least stable genes =s;
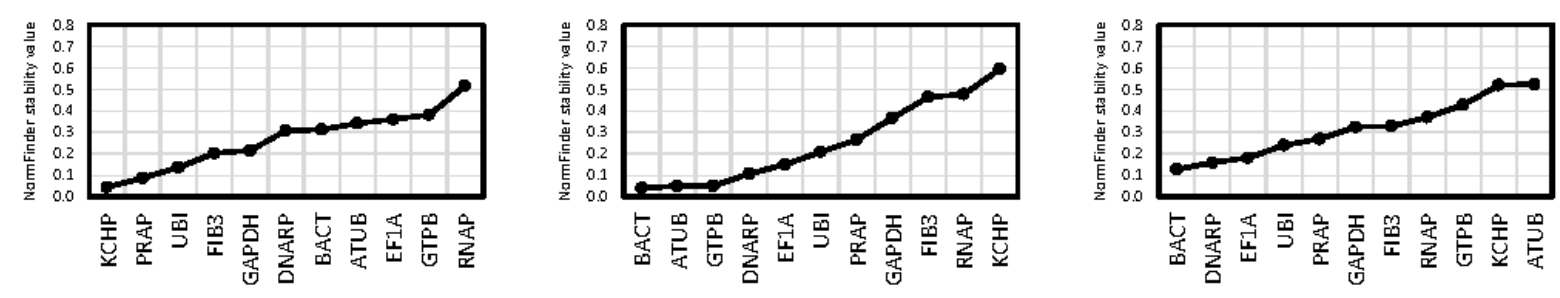

$<==$ Mast stable genes Least stable genes = =>
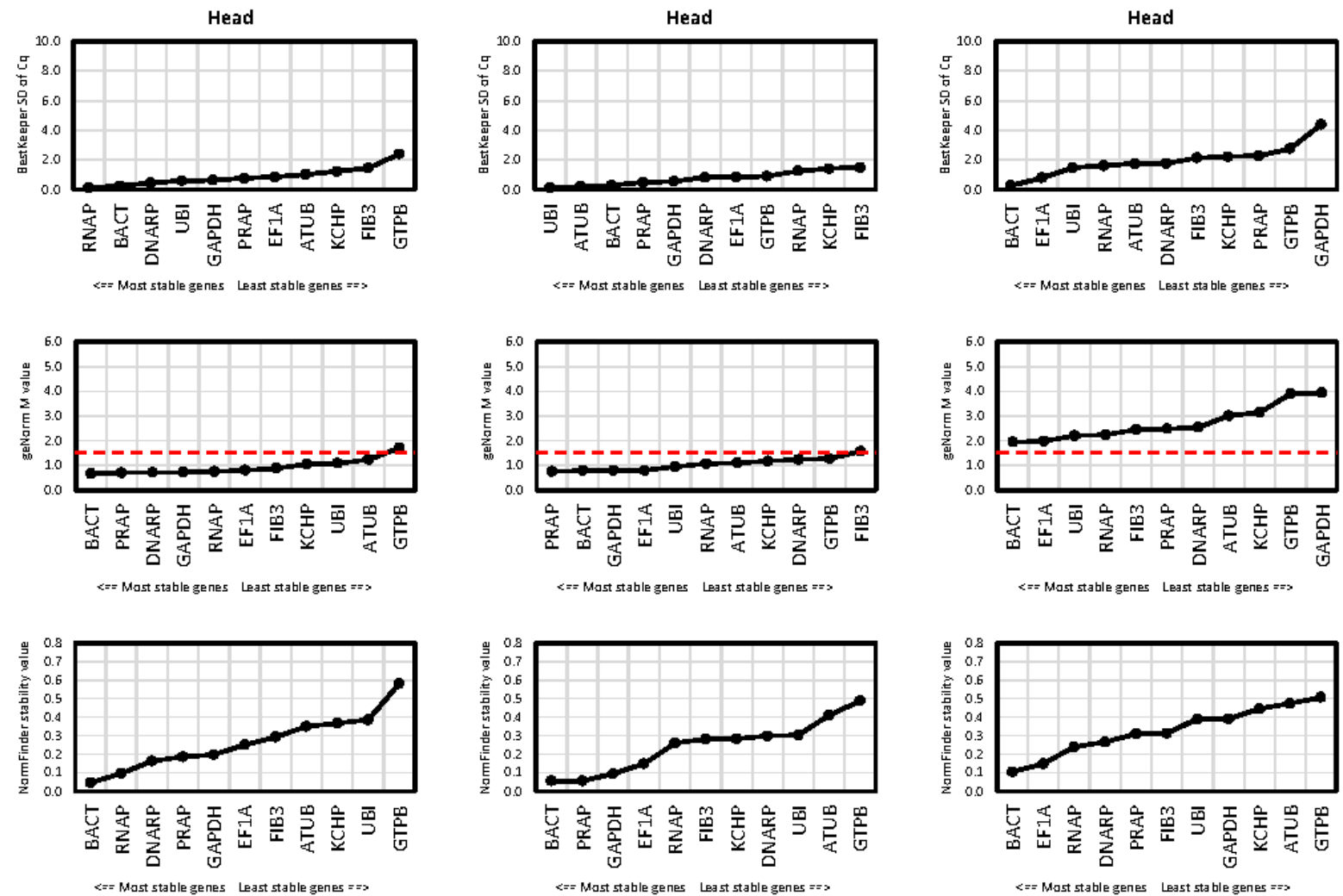

<== Mast stable genes Least sta ble genes =s> 
Figure S5
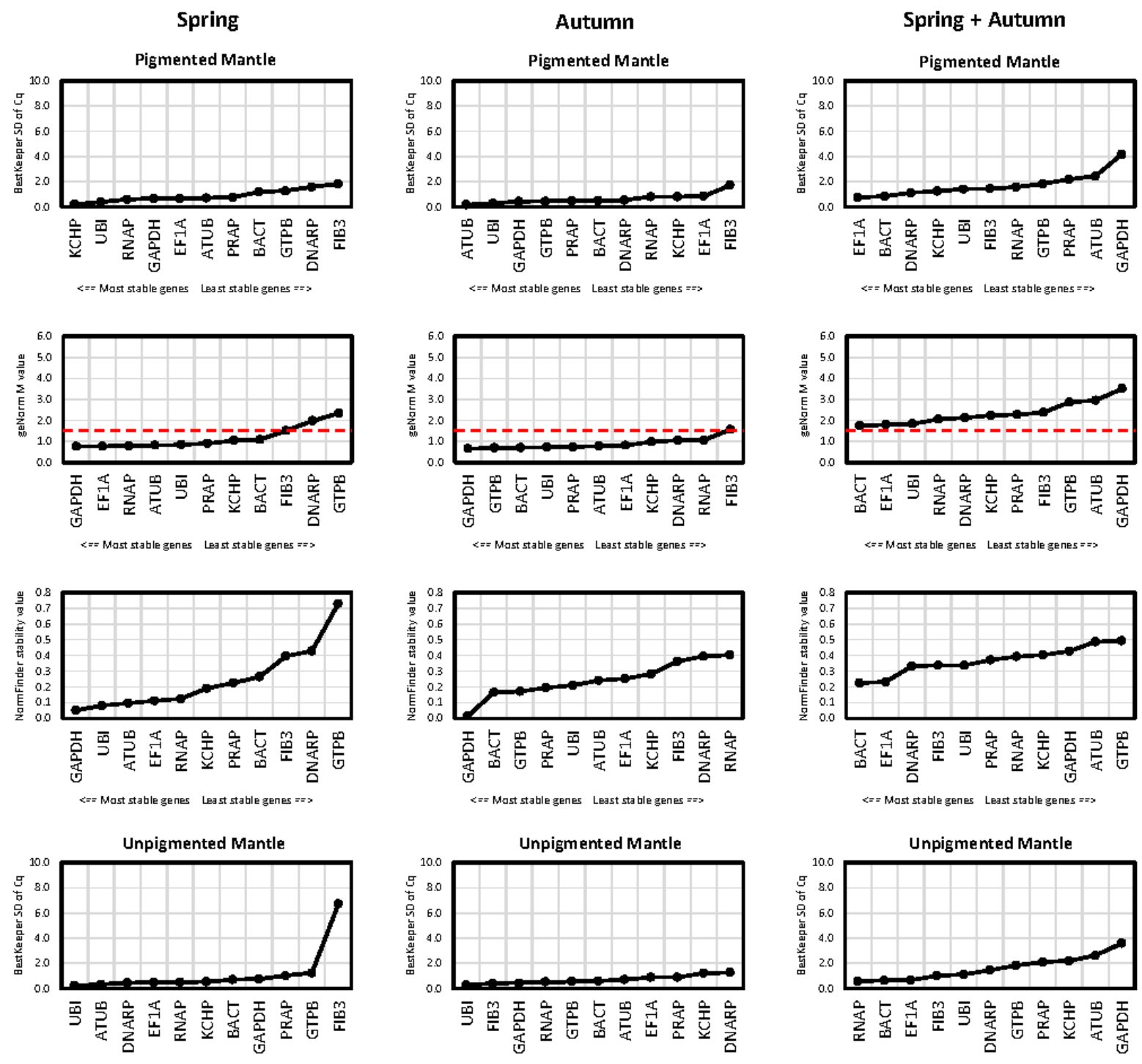

<== Mast stable genes Least stable gener =s>
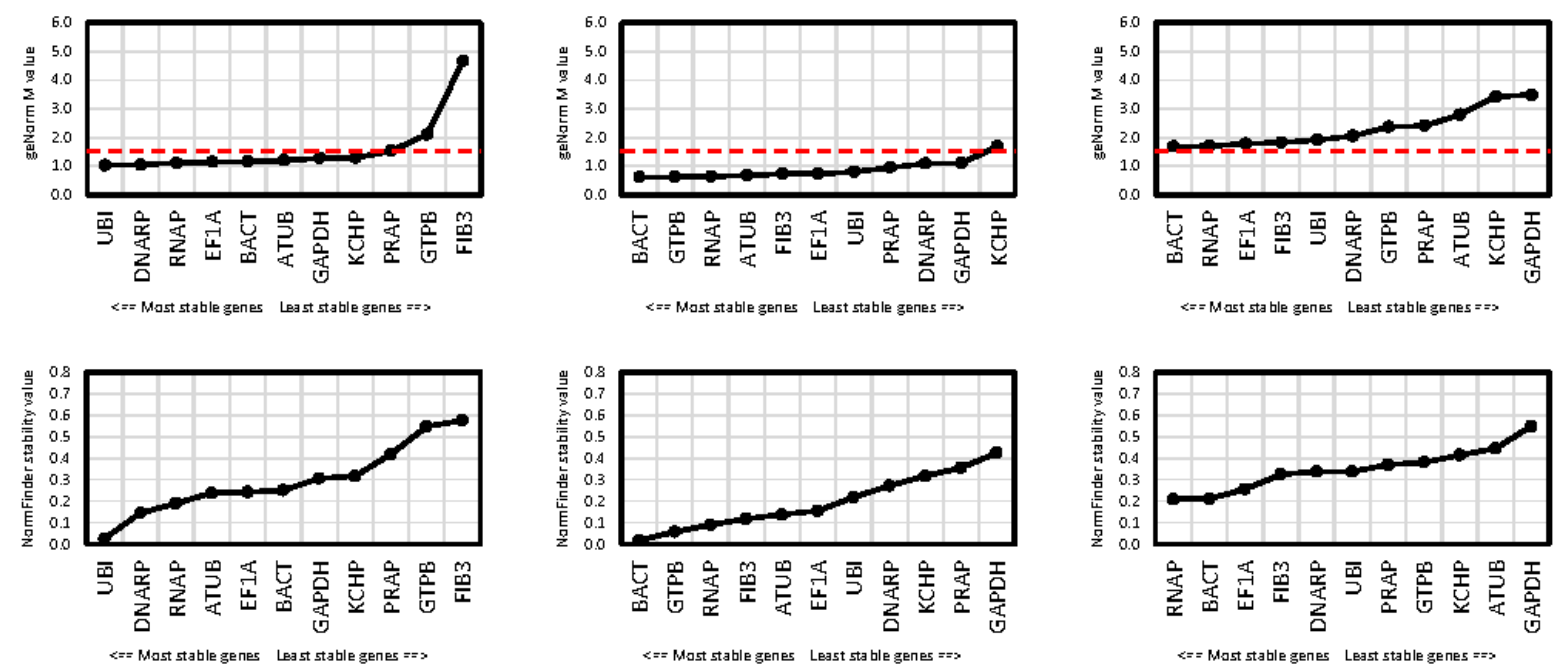
Figure S6

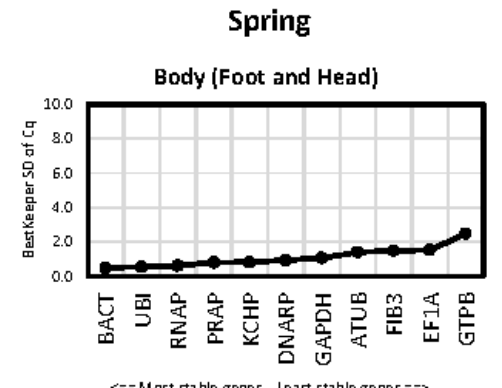

$<==$ Mast sta ble genes Least stable genes $==>$

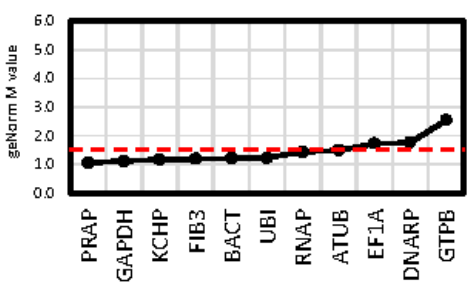

$<==$ Mast stable genes Least stable genes = =>

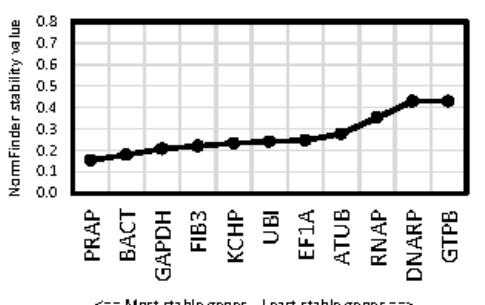

$\Leftrightarrow==$ Mast sta ble genes Least stable genes $==>$

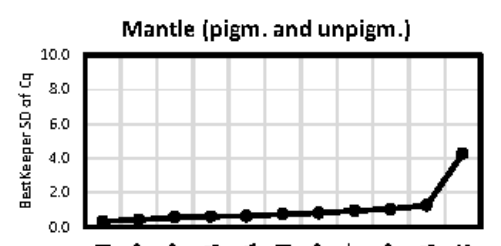

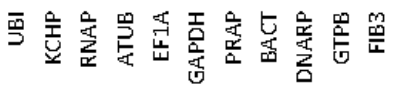

$<==$ Mast sta ble genes Least stable genes $==>$

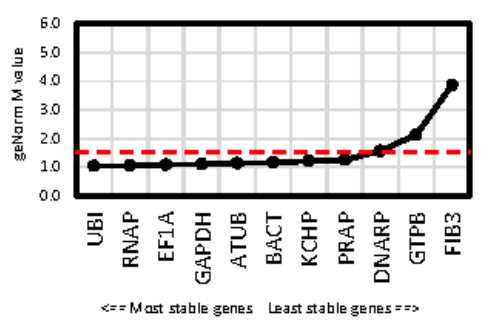

$<==$ Mast stable genes Least stable genes =s

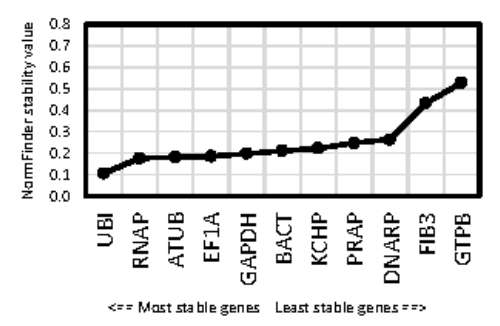

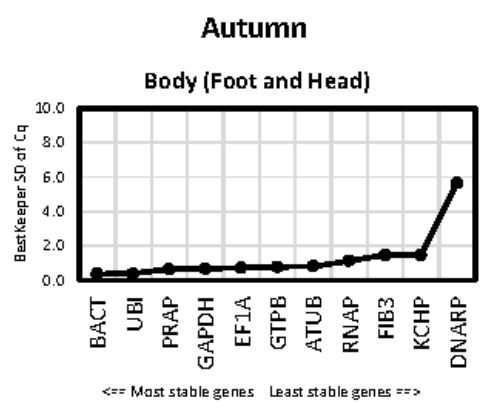
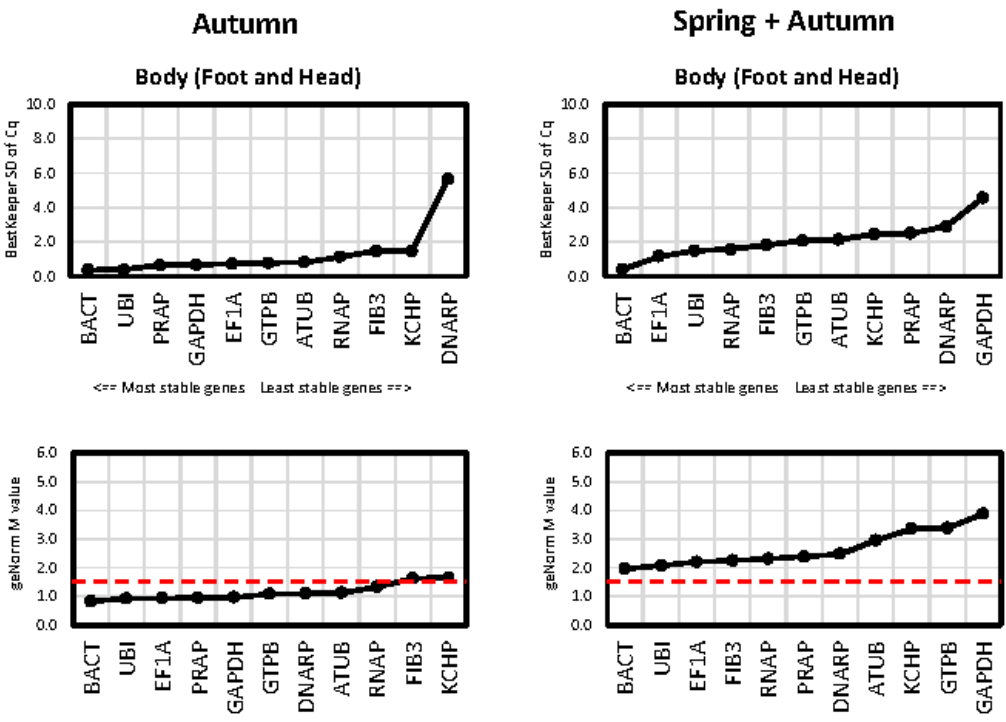

$<==$ Mast stable genes Least stable genes $==>$
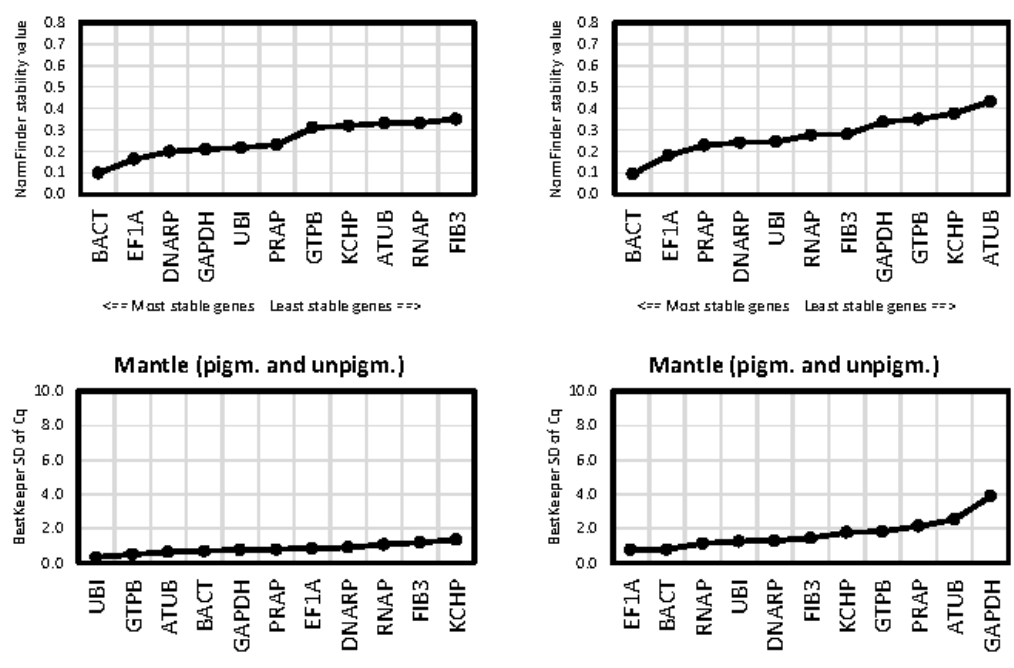

$<==$ Most stable genes Laast stable genes $==>$
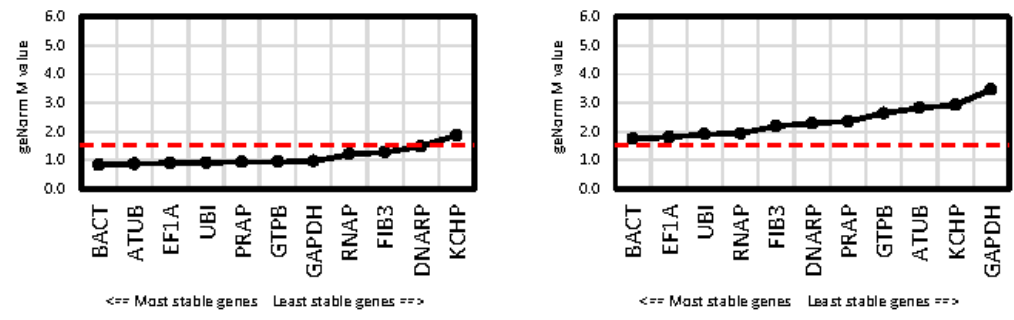

$<==$ Mast stable genes Least stable genes ==>

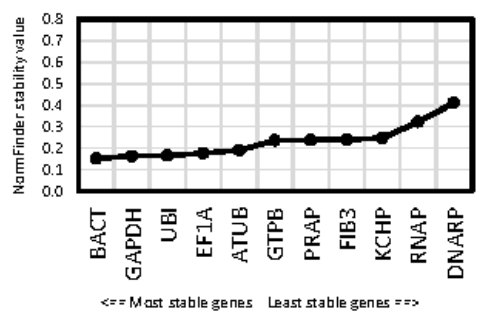


Figure S7

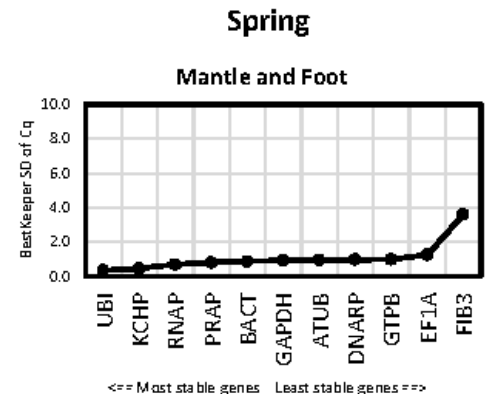

$<==$ Mast sta ble genes Least stable genes $==>$

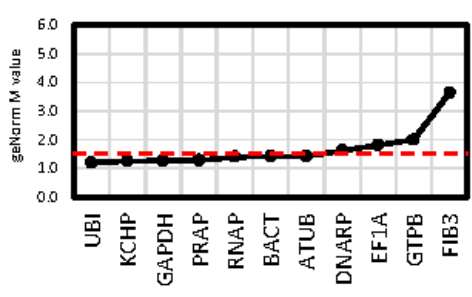

$<==$ Mast sta ble genes Last stable genes $==>$

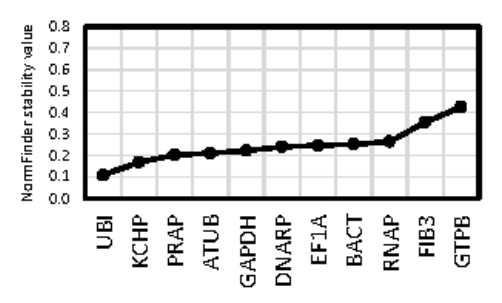

$<==$ Mast stable genes Least stable genes =s

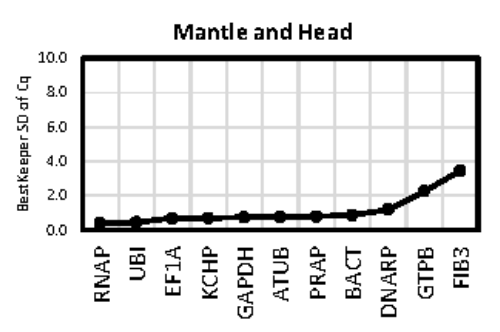

$<=$ Mast sta ble genes Least stable genes =s>

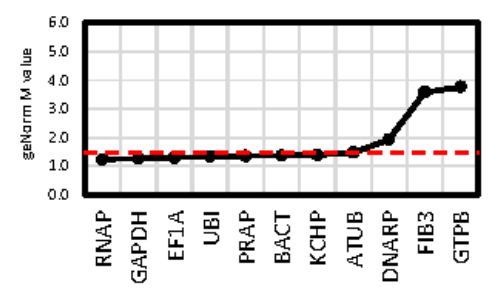

$<==$ Mast stable genes Least stable genes =>>

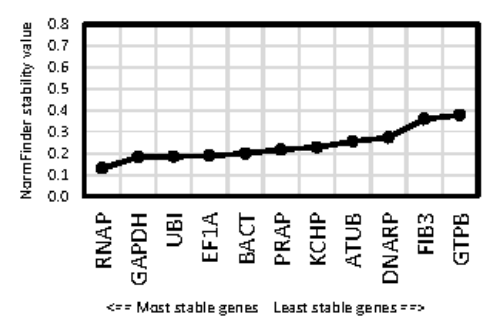

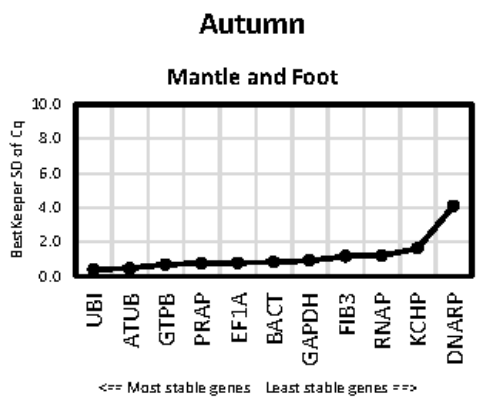

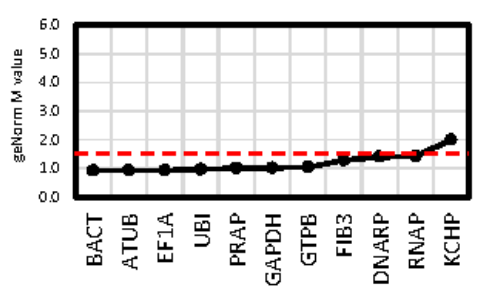

$<==$ Most stable genes Least stable genes $=>$

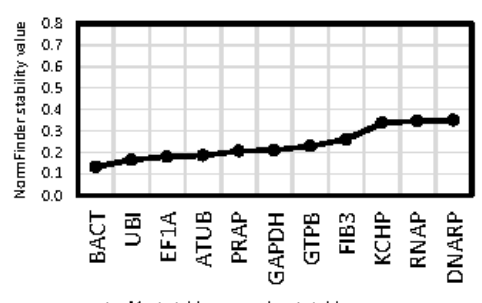

$<==$ Mast stable genes Least stable genes $=>>$

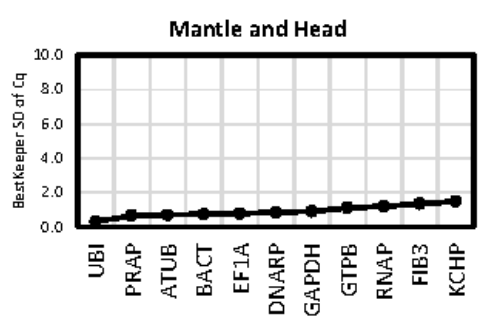

$<==$ Mast stable genes Least stable gener $==>$
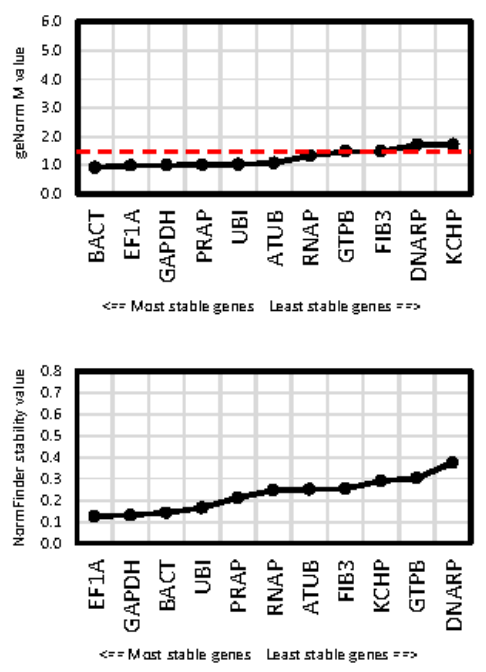

Spring + Autumn

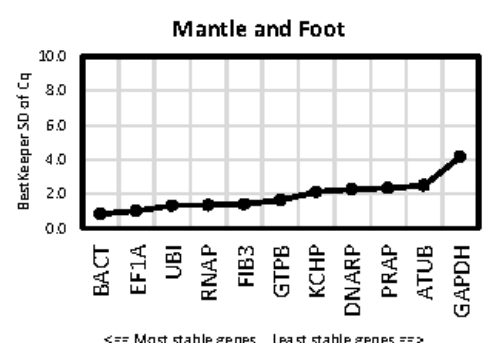

<=- Mast stable genes Last stable genes ==>

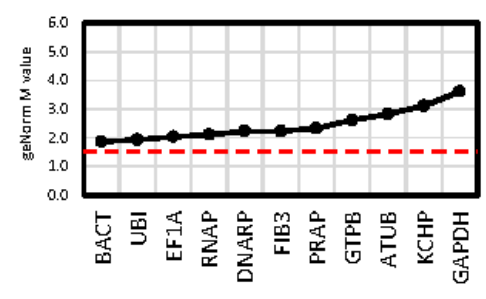

$<==$ Mast stable genes Least stable genes =>>
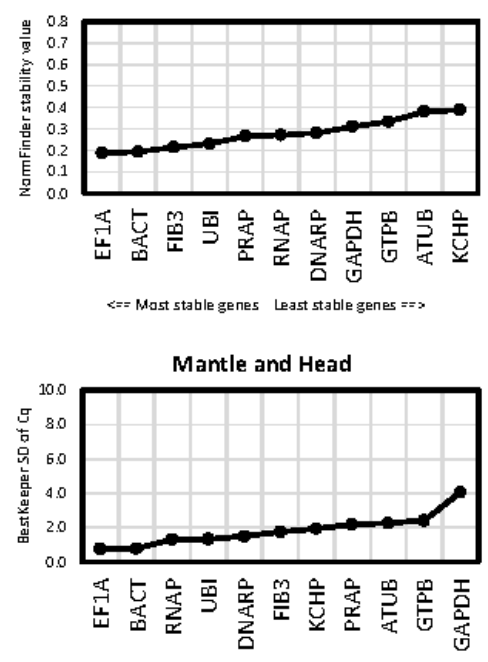

$<==$ Mast stable gener Last stable gener =s>
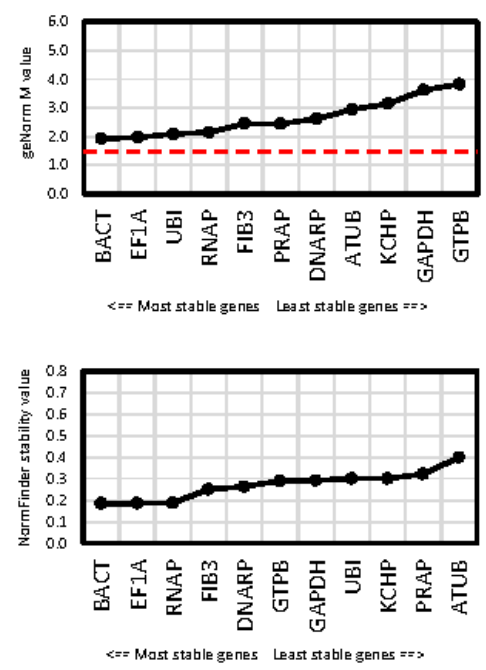
Figure S8
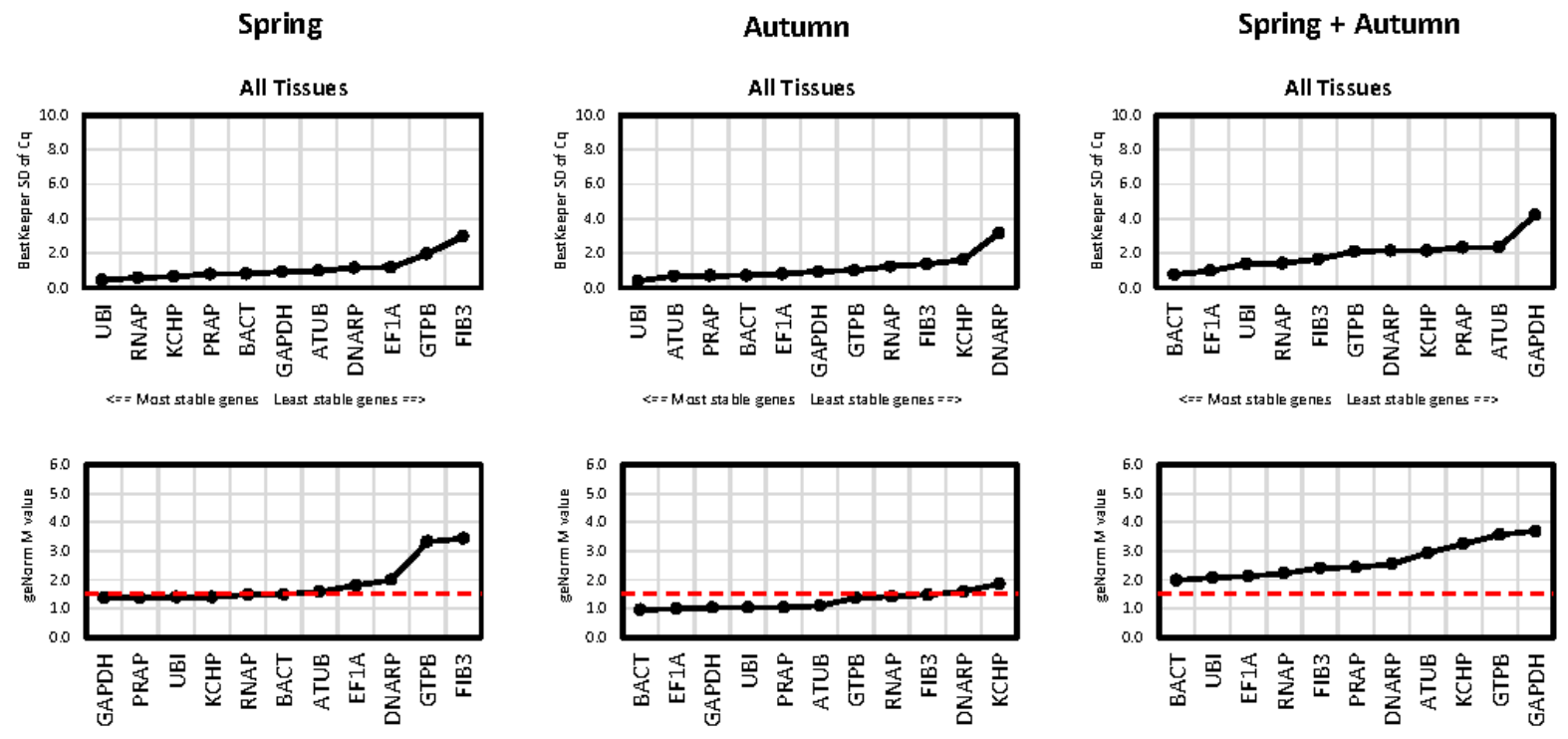

$<==$ Mast stable genes Least stable genes $==>$
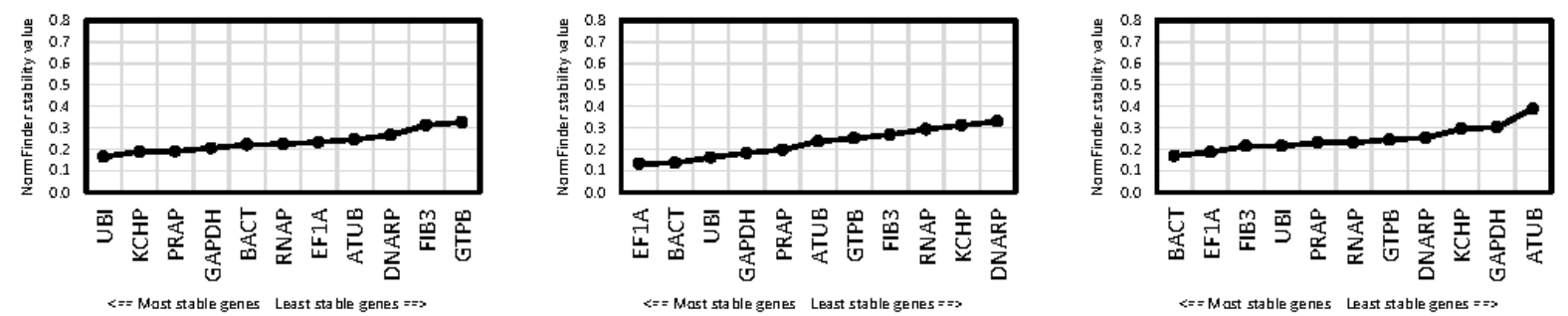

$<==$ Mast sta ble genes Least stable genes $==>$ 


\section{APPENDIX B: SUPPLEMENTARY MATERIAL FOR CHAPTER 4}

\section{Table S1.}

Melanin markers in $\mu \mathrm{g}$ per g shell sample. Limit of quantitation (LOQ) and limit of detection (LOD) were set for each oxidation product as a signal to noise ratio of 10:1 and 3:1 respectively: LOQ $_{\text {PDCA }}=0.08 \mu \mathrm{g} / \mathrm{ml}, \quad$ LOQPTCA $=0.10 \mu \mathrm{g} / \mathrm{ml}, \quad$ LOQ $_{\text {TDCA }}=0.25 \mu \mathrm{g} / \mathrm{ml}, \quad$ LOQ $_{\text {TTCA }}=0.33 \mu \mathrm{g} / \mathrm{ml}$; $\mathrm{LOD}_{\mathrm{PDCA}}=0.03 \mu \mathrm{g} / \mathrm{ml}, \mathrm{LOD}_{\text {PTCA }}=0.04 \mu \mathrm{g} / \mathrm{ml}, \mathrm{LOD}_{\mathrm{TDCA}}=0.08 \mu \mathrm{g} / \mathrm{ml}, \mathrm{LOD}_{\mathrm{TTCA}}=0.10 \mu \mathrm{g} / \mathrm{ml}$.

\begin{tabular}{|c|c|c|c|c|}
\hline Sample & PDCA $(\mu g / g)$ & PTCA $(\mu \mathrm{g} / \mathrm{g})$ & TDCA $(\mu \mathrm{g} / \mathrm{g})$ & TTCA $(\mu g / g)$ \\
\hline \multicolumn{5}{|l|}{ M. edulis } \\
\hline with periostracum & 0.036 & 0.15 & $<\mathrm{LOD}$ & $<\mathrm{LOD}$ \\
\hline without periostracum & $<$ LOQ & 0.046 & $<\mathrm{LOD}$ & $<\mathrm{LOD}$ \\
\hline N. pompilius & 0.011 & 0.025 & $<\mathrm{LOD}$ & $<\mathrm{LOD}$ \\
\hline C. nemoralis & 0.019 & 0.066 & 0.936 & 0.330 \\
\hline C. pharaonius & 0.11 & 0.02 & $<\mathrm{LOD}$ & $<\mathrm{LOD}$ \\
\hline S. adriatica & 0.501 & 0.06 & $<\mathrm{LOD}$ & $<\mathrm{LOD}$ \\
\hline
\end{tabular}




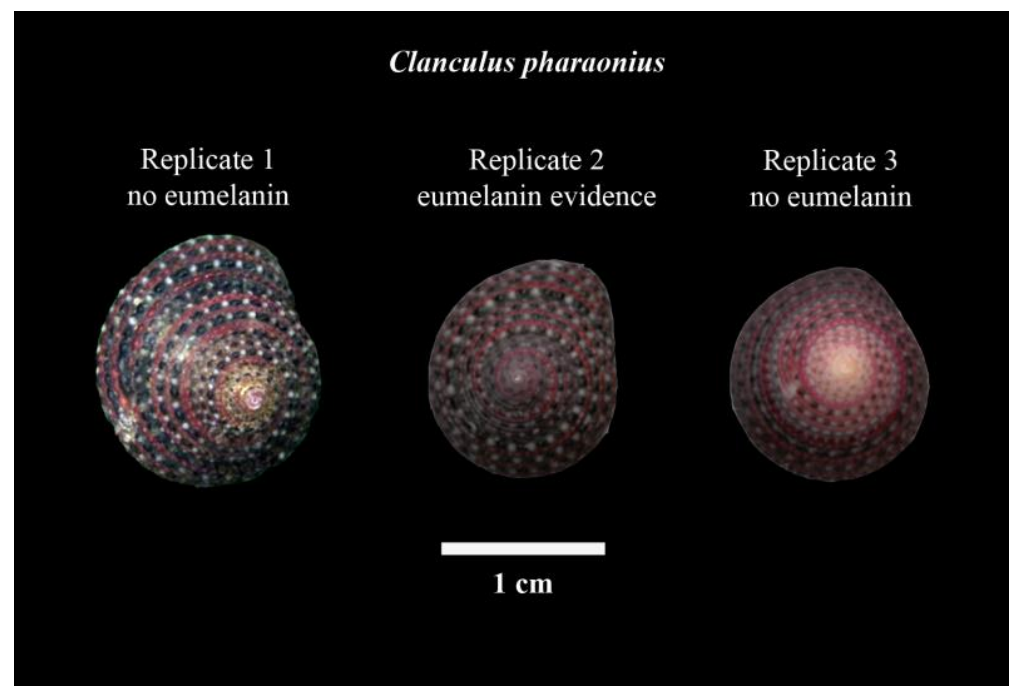

\section{Figure S1.}

The three replicate samples of $C$. pharaonius analysed in this study. 


\section{APPENDIX C: SUPPLEMENTARY MATERIAL FOR CHAPTER 5}

\section{Supplementary Table 1.}

Melanin oxidation product markers in $\mu \mathrm{g}$ per $\mathrm{g}$ shell sample $(\mathrm{n}=3$ for each sample, means \pm standard deviation (SD)). Limit of quantitation (LOQ) was set for each oxidation product as noise to signal ration 1:10 by 9-point dilution series $\left(\mathrm{LOQ}_{\mathrm{PDCA}}=0.08 \mu \mathrm{g} / \mathrm{ml}\right), \mathrm{LOQ}_{\mathrm{PTCA}}=0.10 \mu \mathrm{g} / \mathrm{ml}, \mathrm{LOQ}_{\mathrm{TDCA}}=0.25$ $\mu \mathrm{g} / \mathrm{ml}, \mathrm{LOQ}$ TTCA $=0.33 \mu \mathrm{g} / \mathrm{ml})$

\begin{tabular}{llccc} 
Sample & $\begin{array}{l}\text { PDCA } \\
(\boldsymbol{\mu g} / \mathbf{g}) \pm \mathrm{SD}\end{array}$ & $\begin{array}{c}\text { PTCA } \\
(\boldsymbol{\mu g} / \mathbf{g}) \pm \mathrm{SD}\end{array}$ & $\begin{array}{l}\text { TDCA } \\
(\boldsymbol{\mu g} / \mathbf{g}) \pm \mathrm{SD}\end{array}$ & $\begin{array}{l}\text { TTCA } \\
(\boldsymbol{\mu g} / \mathbf{g}) \pm \text { SD }\end{array}$ \\
\hline $\begin{array}{l}\text { pink morph } \\
\text { background } \\
\text { pink morph }\end{array}$ & $0.031 \pm 0.008$ & $0.060 \pm 0.028$ & $0.311 \pm 0.155$ & $<\mathrm{LOQ}$ \\
$\begin{array}{l}\text { band } \\
\begin{array}{l}\text { yellow morph } \\
\text { background }\end{array}\end{array}$ & $0.051 \pm 0.027$ & $0.083 \pm 0.037$ & $0.356 \pm 0.124$ & $<\mathrm{LOQ}$ \\
$\begin{array}{l}\text { yellow morph } \\
\text { band }\end{array}$ & $0.081 \pm 0.037$ & $0.168 \pm 0.025$ & $1.384 \pm 0.635$ & $0.469 \pm 0.243$ \\
& & $0.148 \pm 0.028$ & $1.653 \pm 0.714$ & $0.736 \pm 0.412$
\end{tabular}




\section{STAR*Methods}

\section{Lead Contact and Materials Availability}

Further information and requests for resources and reagents should be directed to and will be fulfilled by the Lead Contact, Daniel John Jackson (djackso@uni-goettingen.de). Melanin oxidation product standards must be requested from Prof. Shosuke Ito (Department of Chemistry, Fujita Health University School of Health Sciences).

\section{Experimental Model and Subject Details}

\section{Cepaea nemoralis}

Six living animals and approximately 100 empty shells of C. nemoralis were collected at University of Göttingen, Germany (51 33'24.0"N 9 $\left.57^{\prime} 27.3^{\prime \prime E}\right)$. Empty shells were cleaned and dried, then crushed. Shell pieces were sorted according to replicate group and colour fraction. Tissue samples were taken from fresh material by careful dissection of mantle and foot tissue.

\section{Method Details}

\section{Shell Extraction, Melanin Oxidation and LC-MS Analyses}

Two major morphs C. nemoralis (pink banded and yellow banded) were investigated by analysing their colour sorted shell fragments (pink morph background, pink morph band, yellow morph background, yellow morph band; three replicates each, each replicate is comprised of up to 8 shells). 
Testing for eumelanin and pheomelanin oxidation products was carried out as previously described (Affenzeller et al. in prep): Shells were cleaned in deionized water and weighed. Cleaned shell pieces were dissolved in $6 \mathrm{M} \mathrm{HCl}$ and centrifuged at $13000 \mathrm{rpm}$ for $15 \mathrm{~min}$. Residue was washed twice in HPLC grade water and remaining water was carefully removed by pipetting after centrifugation. Samples were treated with Proteinase $\mathrm{K}$ in $1 \mathrm{M}$ Tris- $\mathrm{HCl}$ buffer at $37^{\circ} \mathrm{C}$ for $2 \mathrm{~h}$. Treatment was stopped by acidification with $6 \mathrm{M} \mathrm{HCl}$, samples were centrifuged and washed as described above.

Oxidation reactions for each sample contained $100 \mu \mathrm{L} \mathrm{H}_{2} \mathrm{O}, 375 \mu \mathrm{L} 1 \mathrm{M} \mathrm{K}_{2} \mathrm{CO}_{3}$ and $25 \mu \mathrm{L} 30 \% \mathrm{H}_{2} \mathrm{O}_{2}$ and was carried out for $20 \mathrm{~h}$ at $25^{\circ} \mathrm{C}$ under vigorous shaking. Remaining $\mathrm{H}_{2} \mathrm{O}_{2}$ was decomposed by the addition of $50 \mu \mathrm{L} 10 \% \mathrm{Na}_{2} \mathrm{SO}_{3}$ and mixture was acidified with $140 \mu \mathrm{L} 6 \mathrm{M} \mathrm{HCl}$. The solution was centrifuged at 13000rpm for 40min and supernatant was transferred to a fresh tube.

Samples were desalted via solid phase extraction on Strata-X $33 \mu \mathrm{m}$ Polymeric Reversed Phase columns (200 mg/6 ml Phenomenex, ) under vacuum suction. Columns were conditioned with $5 \mathrm{~mL}$ methanol $(\mathrm{MeOH})$ followed by $5 \mathrm{~mL} \mathrm{H}_{2} \mathrm{O}$. Shell extract was loaded onto the column diluted in $5 \mathrm{ml}$ $0.3 \%$ formic acid and washed twice with $5 \mathrm{~mL} 0.3 \%$ formic acid. Column was dried for $30 \mathrm{~min}$ and elution was carried out with $3 \mathrm{~mL} \mathrm{MeOH}$ followed by $3 \mathrm{~mL}$ Ethyl acetate. Solvents were removed under constant nitrogen stream at $40^{\circ} \mathrm{C}$ and samples dissolved in $200 \mu \mathrm{L} \mathrm{H}_{2} \mathrm{O}$.

Conditions for chromatographic separation were as follows: An aliquote $(10 \mu \mathrm{L})$ of oxidised sample was directly injected into the LC-MS system run with a Gemini C18 column (5 $\mu \mathrm{m}$ particle size, 250x2 mm; Phenomenex, ) at a flow rate of $0.2 \mathrm{~mL} / \mathrm{min}$. The mobile phase of $0.3 \%$ formic acid in $\mathrm{H}_{2} \mathrm{O}$ (eluent A) : $\mathrm{MeOH}$ (eluent B) $(80: 20)$ was run at $45^{\circ} \mathrm{C}$ over 20 min isocratically, followed by a wash step of A : B (5:95) for $10 \mathrm{~min}$ and an equilibration phase to starting conditions for $10 \mathrm{~min}$.

Mass spectrometric measurements were carried out on a Thermo Fisher Scientific (Waltham, USA) Accela LC-MS system containing a Finnigan Surveyor PDA Detector and coupled to an LTQ 
Orbitrap XL mass spectrometer. Ionisation was carried out with an electrospray ionisation (ESI) in negative mode. Scan window was set to $\mathrm{m} / \mathrm{z}=120-220$.

\section{Reverse transcription quantitative PCR (qPCR) of melanin pathway genes in $C$. nemoralis}

Four genes that are known to be involved in melanin synthesis and dark pigmentation were chosen for qPCR testing: tyrosinase (Tyr), tyrosinase related protein (TyrRP), yellow-like gene (Yellow) and laccase 2 (Lacc2). From $C$. nemoralis mantle tissue transcriptome data set (will be published elsewhere) corresponding sequences were extracted based on their alignment score in tblastx application of BLAST ${ }^{\circledR}$. Primer for qPCR were designed with Primer3 (Untergasser et al., 2012). Primer sequences and Genbank accession codes are listed in Data and Code Availability section.

Study design for qPCR experiments followed the protocol described in Affenzeller et al. (Affenzeller et al., 2018): Six sub-adult individuals of C. nemoralis were collected at the University of Göttingen. Total RNA from pigmented mantle (producing the band in the shell), unpigmented mantle (producing background coloured shell) and foot tissue was extracted from each individual using Qiazol (Qiagen) according to the manufacturer's instructions resulting in a total of twelve RNA extractions. These underwent a DNase treatment (RQ1 RNase-free DNase, Promega) according to the manufacturer's instructions. Nanodrop and agarose gel electrophoresis were employed to verify quality and integrity of RNA. Synthesis of cDNA was carried out with $1 \mu \mathrm{g}$ of total extracted RNA per sample using Promega M-MLV reverse transcriptase and oligo dTs. Reaction was run at $42^{\circ} \mathrm{C}$ for $75 \mathrm{~min}$, followed by $15 \mathrm{~min}$ at $70^{\circ} \mathrm{C}$ to inactivate reverse transcriptase. The cDNA was stored at $-20^{\circ} \mathrm{C}$ until further use.

All qPCR runs followed a maximum sample layout, comply with the MIQE guidelines (Bustin et al., 2009) and included no template controls (NTC) for each primer pair and three inter run calibrators (IRC) EFI $1 \alpha$, RNAP and UBI. Samples were run in triplicate, NTC and IRCs were run in duplicate. 
Amplification reactions contained $5 \mu \mathrm{L} 2 \mathrm{x}$ Rotor-Gene SYBR Green PCR Master Mix, $0.4 \mu \mathrm{L}$ cDNA, $1 \mu \mathrm{M}$ final Primer concentration and $4.4 \mu \mathrm{L} \mathrm{ddH}_{2} \mathrm{O}$ to a final volume of $10 \mu \mathrm{L}$. Reactions were run on a Rotor-Gene Q (Qiagen) using Rotor-Gene Q software (version 2.0.2) with the following temperature profile: 5 min initial activation and denaturation at $95^{\circ} \mathrm{C} ; 45$ cycles of $5 \mathrm{sec}$ denaturation at $95^{\circ} \mathrm{C}, 10 \mathrm{sec}$ annealing and extension at $60^{\circ} \mathrm{C}$ (data collection at this step); a final melt curve analysis from $60^{\circ} \mathrm{C}$ to $95^{\circ} \mathrm{C}$ at a rate of $5 \mathrm{sec} / 1^{\circ} \mathrm{C}$.

\section{Quantification and Statistical Analyses}

\section{LC-MS of melanin oxidation products}

Quantitation of melanin oxidation products was carried out by external calibration with standard mixtures (obtained from S. Ito). External calibration was set with 9-point calibration curves. Limit of quantitation (LOQ) was set as 1:10 noise to signal ratio. All manual peak integrations of chromatograms and analyses of mass spectra were done in Xcalibur 2.2 Qual Browser (Thermo Scientific, Waltham, USA). Quantitation was based on areas gained from peak integrations of UV chromatograms in a range of 250-290 $\mathrm{nm}$. Each colour fraction was run for three replicates (comprised of up to eight shells each). Statistical analyses (mean and standard deviation calculations) were carried out in Microsoft ${ }^{\circledR}$ Excel $^{\circledR}$ for Office 365 MSO (16.0.11629.20192).

\section{qPCR}

Raw fluorescence data was baseline and amplification efficiency corrected in LinRegPCR (Ruijter et al., 2009). Inter run correction was performed using Factor-qPCR (Ruijter et al., 2015). So gained corrected cycle threshold $(\mathrm{Cq})$ values were used to calculate the geometric means of technical replicates. Normalisation and relative expression were calculated based on the Pfaffl method (Pfaffl, 
2001) with beta-actin and elongation factor 1 alpha serving as reference genes as previously tested for mantle tissue in C. nemoralis (Affenzeller et al., 2018).

Descriptive statistical analyses (mean and standard deviation calculations) of six biological replicates for each sample set (pigmented mantle, unpigmented mantle, foot) were carried out in Microsoft ${ }^{\circledR}$ Excel $^{\circledR}$ for Office 365 MSO (16.0.11629.20192). Statistical comparisons between pigmented mantle and unpigmented mantle, as well as between all mantle samples and foot tissue, were run in PAST 3.15 (Hammer et al., 2001) as t-tests using Mann-Whitney as a significance measure $(* \mathrm{p} \leq 0.05$, ** $\mathrm{p} \leq 0.01)$

\section{Data and Code Availability}

Primer sequences, amplicon sizes and Genbank accession codes for all genes used for qPCR assessments are available here:

\begin{tabular}{|c|c|c|c|c|}
\hline Gene & Forward Primer (5' to 3') & Reverse Primer (5' to 3') & $\begin{array}{l}\text { Amplicon } \\
\text { Size (Bp) }\end{array}$ & Genbank accession \\
\hline$B A C T$ & CAGAAGCAATGTTCCAGCCA & TGAGCCACCAGACAAGACAA & 137 & $\begin{array}{l}\text { MH035489 } \\
\text { (Affenzeller et al., } \\
2018 \text { ) }\end{array}$ \\
\hline$E F 1 \alpha$ & GTACCGGAGAGTTTGAGGCT & GAGTAAGGTGGAGTGGTGCT & 133 & $\begin{array}{l}\text { MH035491 } \\
\text { (Affenzeller et al., } \\
\text { 2018) }\end{array}$ \\
\hline$U B I$ & AGAATGCCCCAACAAATGCT & AGAATCAGCCTCTTCTCCGG & 121 & $\begin{array}{l}\text { MH035498 } \\
\text { (Affenzeller et al., } \\
\text { 2018) }\end{array}$ \\
\hline Tyr & TCCTACTGGCTTTGGGAGTC & GTATCTTGAAGGGCACTGCG & 121 & $\mathrm{n} / \mathrm{a}$ \\
\hline$T y r R P$ & АССТССААСТССССТСАСТА & CGAGTTCAACATCCGGCATT & 125 & $\mathrm{n} / \mathrm{a}$ \\
\hline Yellow & АССТСТTCTATGGGGCCTTG & CAACCTCGCTTTCAGTGTCC & 117 & $\mathrm{n} / \mathrm{a}$ \\
\hline Lacc2 & CAAGGTCACATCTGGAACGC & TTATCTCTCCTCGTGCGTCC & 133 & $\mathrm{n} / \mathrm{a}$ \\
\hline
\end{tabular}




\section{APPENDIX D}

\section{Differentially Expressed Candidate Genes}

Based on a transcriptome gained from three subadults of Cepaea nemoralis (assembly information see Chapter 2 (1)) differential gene expression analyses were carried out between pigmented and unpigmented mantle tissue. Nine Genes of interest (GOI) were chosen based on p-value score and highest differential expression in pigmented tissue for validation in reverse transcription quantitative polymerase chain reaction (qPCR) and In situ hybridisation.. These genes were identified based on ORF Finder and SmartBlast against SwissProt (https://www.ncbi.nlm.nih.gov/orffinder/) or their tblastx score against Nucleotide Collection (nr/nt) (https://blast.ncbi.nlm.nih.gov/Blast.cgi). Highly expressed mantle genes with low differential expression were chosen as Mantle reference genes for In situ experiments based on previously done proteomic analyses of $C$. nemoralis (2). Gene names and primer sequences for qPCR and In situ hybridisation experiments are listed in Table 1. All primer were designed using Primer3 software (3).

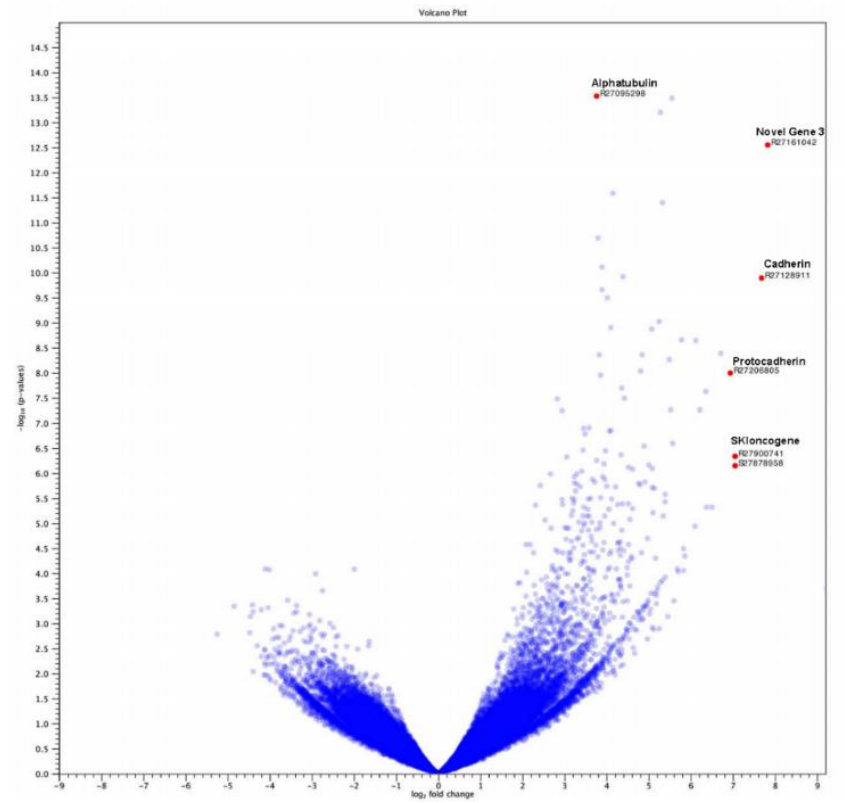

\section{Figure 1.}

Vulcano Plot of C.nemoralis differential gene expression analysis. Left side is unpigmented tissue, right side is pigmented tissue. p-value decreases along the y-axis. Chosen GOI are named and marked with a red dot.

Table 1: GOI names and primer sequences and amplicon lengths are listed for qPCR products and riboprobes used in In situ hybridisation experiments. 


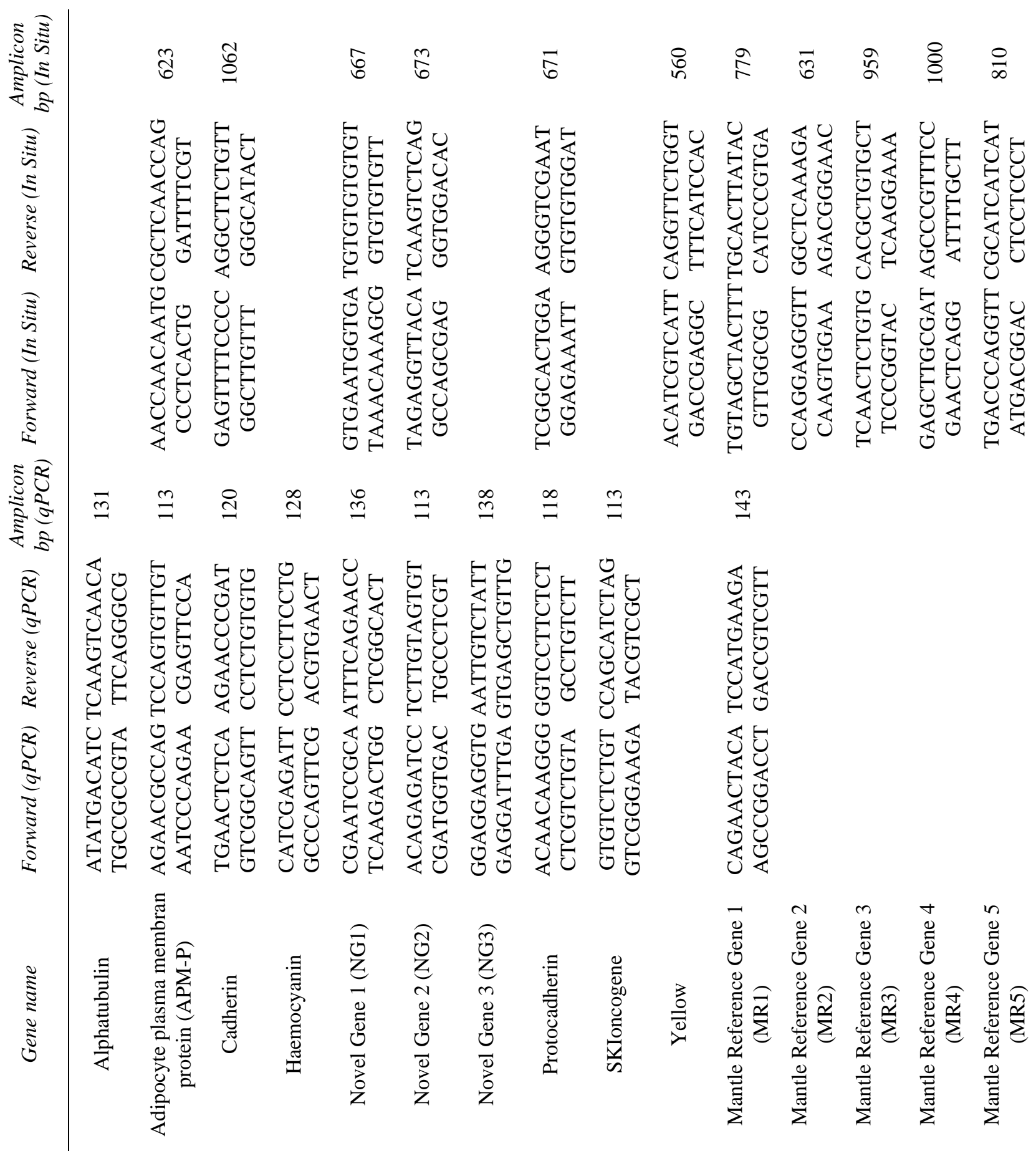


Experimental comparison of GOI between Pigmented mantle tissue and Unpigmented mantle tissue were run as described in Chapter 4. In short: 10 sub-adult individuals of $C$. nemoralis were collected at the University of Göttingen. Total RNA from pigmented mantle (producing the band in the shell), and unpigmented mantle (producing background coloured shell) was extracted from each individual using Qiazol (Qiagen) according to the manufacturer's instructions. All 20 RNA extractions underwent a DNase treatment (RQ1 RNase-free DNase, Promega) according to the manufacturer's instructions. Quality and integrity of RNA were tested via Nanodrop and agarose gel electrophoresis.. cDNA synthesis was carried out with $1 \mu \mathrm{g}$ of total extracted RNA per sample using Promega M-MLV reverse transcriptase and oligo dTs. Each reaction was run at $42^{\circ} \mathrm{C}$ for $75 \mathrm{~min}$, followed by $15 \mathrm{~min}$ at $70^{\circ} \mathrm{C}$ to inactivate reverse transcriptase. The cDNA was stored at $-20^{\circ} \mathrm{C}$ until further use. Following this protocol additional cDNAs were gained for four corresponding Foot tissue samples. Two additional individuals were used to gain two Mantle edge and two Mantle back tissue samples.

Primer pairs used for qPCR are listed in Table 1. All qPCR runs followed a maximum sample layout and the MIQE guidelines (4) and included no template controls (NTC) and three inter run calibrators (IRC) EF 1 $\alpha, R N A P$ and UBI. Samples were run in triplicate, NTC and IRCs were run in duplicate. Amplification reactions consisted of $5 \mu \mathrm{L} 2 \mathrm{x}$ Rotor-Gene SYBR Green PCR Master Mix, $0.4 \mu \mathrm{L}$ cDNA, $1 \mu \mathrm{M}$ final Primer concentration and $4.4 \mu \mathrm{L} \mathrm{ddH}_{2} \mathrm{O}$ to a final volume of $10 \mu \mathrm{L}$. A Rotor-Gene Q (Qiagen) using Rotor-Gene Q software (version 2.0.2) was used with the following temperature profile: 5 min initial activation and denaturation at $95^{\circ} \mathrm{C} ; 45$ cycles of $5 \mathrm{sec}$ denaturation at $95^{\circ} \mathrm{C}, 10$ sec annealing and extension at $60^{\circ} \mathrm{C}$ (data collection at this step); a final melt curve analysis from $60^{\circ} \mathrm{C}$ to $95^{\circ} \mathrm{C}$ at a rate of $5 \mathrm{sec} / 1^{\circ} \mathrm{C}$.

Baseline and amplification efficiency correction of raw fluorescence data was done in LinRegPCR (5). Inter run correction was performed using Factor-qPCR (6). Geometric means of technical replicates were used to gain final corrected cycle thresholds $(\mathrm{Ct})$. Normalisation with beta-actin and 
elongation factor 1 alpha serving as reference genes as previously tested for mantle tissue in $C$. nemoralis (1) and relative expression were calculated based on the Pfaffl method (7).

Statistical comparisons between pigmented mantle and unpigmented mantle, as well as between all mantle samples and foot tissue and between Mantel edge and Mantle back, were run in PAST 3.15 (8) as pairwise t-tests using Mann-Whitney as a significance measure.

Three genes were significantly upregulated in Pigmented Mantle tissue according to qPCR results (Fig. 2). Cadherin shows a 33-fold upregulation and is highly significantly upregulated $(\mathrm{p}<0.01)$. Two genes were significantly upregulated in Pigmented Mantle $(\mathrm{p}<0.05)$ : Adipocyte Plasma Membrane Protein and Novel Gene 1. All other genes did not show significant normalized expression differences between Pigmented and Unpigmented Mantle tissue.

Figure 3: Normalized Relative

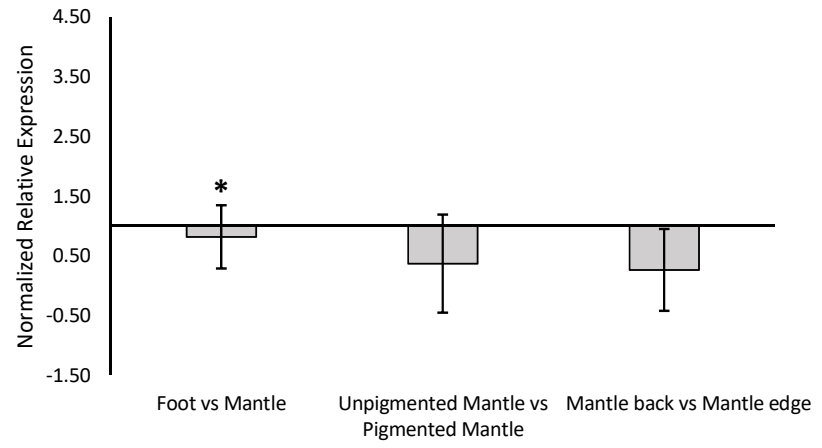
Expression $(\mathrm{ddCt})$ for different tissue samples from qPCRs of Mantle Reference Gene 1. Significant upregulation in Foot tissue was found in Mann-Whitney after pairwise t-tests.

To verify Mantle Reference Gene 1 (MRl)'s upregulation in Mantle tissue qPCR comparisons between Mantle tissue and Foot tissue were run. In addition Mantle edge and Mantle back tissue expression rates were measured as well. Surprisingly $M R l$ was found to be significantly higher expressed in Foot tissue than in Mantle tissue (Fig. 3). No significant expression difference was found between Pigmented Mantle and Unpigmented Mantle, as well as between Mantle edge and Mantle back tissue samples (Fig. 3). 


\section{In situ hybridisation on $C$. nemoralis embryos and sub adult tissue section}

Wholemount In situ hybridisation (WMISH) and tissue section In situ hybridisation (TSISH) for $C$. nemoralis were based on protocols previously established for a limnic gastropod Lymnea stagnalis $(9-12)$.

Individuals of $C$. nemoralis were collected from the University of Göttingen in spring and summer. Sub-adults were fixed for tissue sections as described in detail below. Adults were kept in glass terraria on Cocos substrate mixed with sand and chalk. Terraria were kept humid and snails were fed regularly with salad, cucumber and occasionally carrots. Egg clutches were carefully removed from terraria once spotted and reared in plastic containers with soil under humid conditions.

Observations of mating behaviour and egg clutch development confirmed difficulties in keeping the animals in conditions perfect for mating. Mating only occurred in first season after collection. Keeping individuals over winter with hibernation phase was possible but no further mating occurred. Clutch development seems to be asynchronous and egg capsules are opaque and easily broken when handled, making clutch staging very difficult. WMISH were therefore conducted on young juveniles (max. 5mm shell diameter) exhibiting first signs of shell banding.

Juvenile fixation was carried out in $3.7 \%$ paraformaldehyde (PFA) for 5 min. Samples were then thoroughly washed in PBS (phosphate buffered saline solution) and shells were carefully taken of with forceps and needles. Juveniles were treated in Proteinase K solution $(500 \mu \mathrm{g} / \mathrm{ml})$ for $10 \mathrm{~min}$ and the digestion was stopped with two washes of $0.2 \%$ Glycine. All samples were thoroughly washed in PBS and fixed for $30 \mathrm{~min}$ in $3.7 \%$ PFA. Fixative was washed of with PBS. Pre-hybridisation was carried out at $55^{\circ} \mathrm{C}$ for 15 min. Riboprobes were synthesised from PCR products generated with In situ primer pairs listed in Table 1 following the protocol in (9). Riboprobe concentrations were trialled at 300-500 ng/ml. Hybridisation followed an initial denaturation step of $75^{\circ} \mathrm{C}$ for 15 min and was 
done for approximately $24 \mathrm{~h}$ at $55^{\circ} \mathrm{C}$. Post hybridisation washes and treatment were carried out according to (9) including colour development. Colour development duration varied from 10 min to several hours.

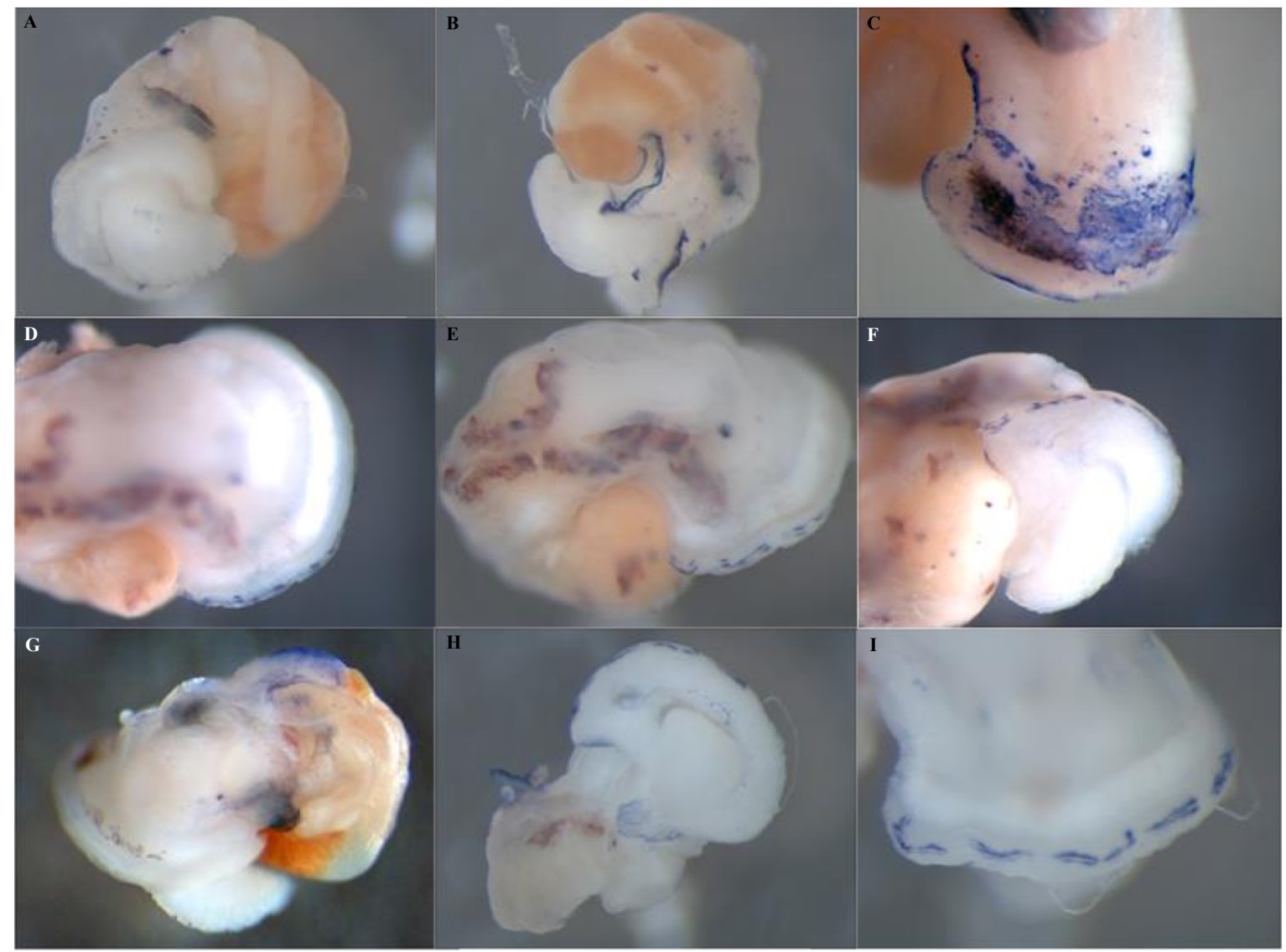

Figure 4: Unspecific WMISH staining of juvenile C. nemoralis A-C Mantle Reference Gene 1 (MRI)

\section{D-F Cadherin G-I Yellow}

WMISH experiments for $M R l$ resulted in only minor unspecific staining along the mantle tissue (Fig. 4 A \& C) and artefact staining at the columella attachment muscle (Fig. 4 B). The GOIs Cadherin and Yellow were also trialled in WMISH, but although staining along the mantle edge could be observed in both genes, this could not be verified as a true signal (Fig. 4 D-I). In addition background signal in the digestive gland, the pneumostome and the columellar muscle was visible (Fig. 4 F-H). The mantle edge signal in both genes also doesn't correspond with the expected banding pattern (one banded juveniles). 
Due to the limitations in individual numbers and difficulties in rearing juveniles further optimisation of a WMISH protocol would be very time intensive and detrimental to population numbers. Finding a good reference gene and overcoming the strengthened skin barrier of this terrestrial gastropod should be the next steps to adjust published protocols for this species.

One approach was switching the experimental set up to In situ hybridisations on sub-adult tissue sections. This allowed us to use larger animals with distinct banding patterns and at the same time provides more experiments per individual. Optimisation of the protocol in (10) and (12) yielded the following adjustments. Four different fixation schemes were trialled: 3.7\% PFA, Carnoy's (60\% ethanol, 30\% chloroform, $10 \%$ glacial acetic acid), Methacarn (60\% methanol, 30\% chloroform, $10 \%$ glacial acetic acid), $100 \%$ ethanol. Snails with slightly damaged shells were left in the respective fixative for $60 \mathrm{~min}$. After thorough washing and removal of the shell, samples were dehydrated through an ethanol series. Each snail was dissected along its midline, allowing a smooth placing in the cassette with a clear cutting start of the mantle edge. Samples were treated to three changes of $100 \%$ xylene and submerged in paraffin overnight. Setting in the cassette was carefully done with forceps and the samples were cooled for at least three hours. Microtome cut sections of $8 \mu \mathrm{m}$ were adhesed to polylysine coated slides overnight at $60^{\circ} \mathrm{C}$. Slides were treated with $100 \%$ xylene and rehydrated before hybridisation treatment. Proteinase K treatment was carried out for 10 min with concentrations of either $50 \mu \mathrm{g} / \mathrm{ml}$ or $100 \mu \mathrm{g} / \mathrm{ml}$. Riboprobe synthesis from PCR products gained form primer pairs in Table 1 was conducted as described above. Hybridisation with probe concentration of $800 \mathrm{ng} / \mathrm{ml}$ was done for 24 hours at $55^{\circ} \mathrm{C}$, followed by washes and blocking as described in (12). Samples were treated with anti DIG antibody conjugated to alkaline phosphatase (concentration 1/10000) for 12 hours. Final washes and colour development were carried out according to the protocol in (12). 


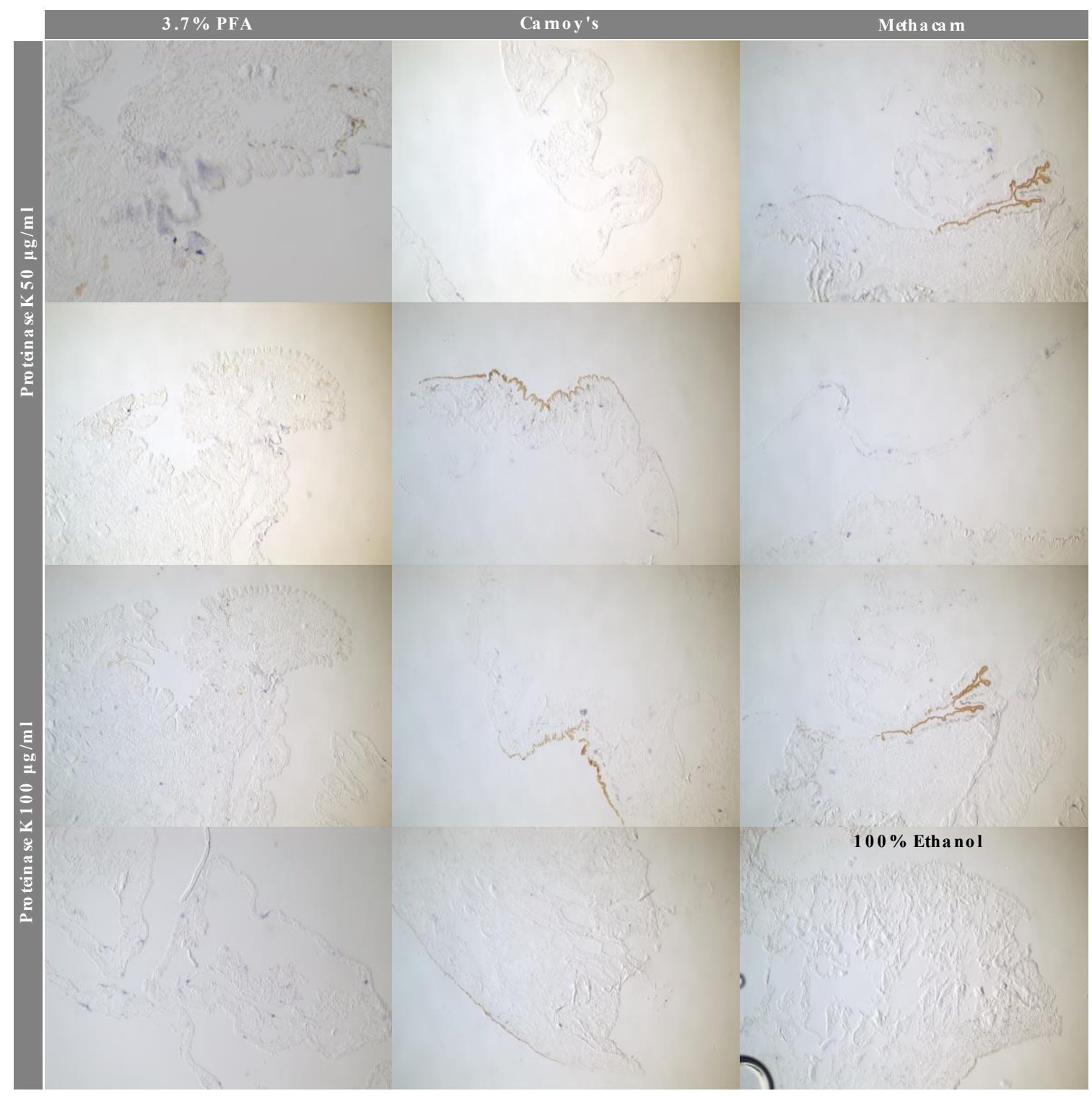

Figure

5: Tissue slide In situ hybridisations of Mantle Reference Gene 1 on sub-adult $C$. nemoralis. Typically unspecific spotted staining independent of fixation and Proteinase $\mathrm{K}$ treatment.

Independent of fixation scheme no clear signal for $M R l$ could be achieved (Fig. 5). In general paraffin penetration in all samples was poor. Some individuals seemed to be severely underfixed. Proteinase K treatment variations didn't have obvious effects on tissue preservation or signal intensity. Further tests with Mantle Reference Genes 2-5 didn't yield any better results (not pictured here). More research and method optimisation is needed to improve this protocol for samples of C. nemoralis. 
Especially tissue penetration should be further researched, as it seems these animals have a much stronger skin barrier than other molluscs. This is unsurprising considering the habitat they are commonly found in is dry and they have to adjust for water loss. It can also not be said with certainty that there are no inhibiting factors influencing these In situ experiments.

\section{References}

1. Affenzeller S, Cerveau N, Jackson DJ. Identification and validation of reference genes for qPCR in the terrestrial gastropod Cepaea nemoralis. PLoS ONE. 2018;13(8):e0201396.

2. Mann K, Jackson D. Characterization of the pigmented shell-forming proteome of the common grove snail Cepaea nemoralis. BMC Genomics. 2014;15(1):249.

3. Untergasser A, Cutcutache I, Koressaar T, Ye J, Faircloth BC, Remm M, u.a. Primer3 — new capabilities and interfaces. Nucleic Acids Research. 2012;40(15):e115-e115.

4. Bustin SA, Benes V, Garson JA, Hellemans J, Huggett J, Kubista M, u.a. The MIQE Guidelines: Minimum Information for Publication of Quantitative Real-Time PCR Experiments. Clinical Chemistry. 2009;55(4):61122.

5. Ruijter JM, Ramakers C, Hoogaars WMH, Karlen Y, Bakker O, van den Hoff MJB, u.a. Amplification efficiency: linking baseline and bias in the analysis of quantitative PCR data. Nucleic Acids Research. 2009;37(6):e45-e45.

6. Ruijter JM, Ruiz Villalba A, Hellemans J, Untergasser A, van den Hoff MJB. Removal of between-run variation in a multi-plate qPCR experiment. Biomolecular Detection and Quantification. 2015;5:10-4.

7. Pfaffl MW. A new mathematical model for relative quantification in real-time RT-PCR. Nucleic Acids Research. 2001;29(9):2002-7.

8. Hammer $\varnothing$, Harper DAT, Ryan PD. PAST: PAlaeontological STatistics softwarre package for education and data analysis. Paleontologia Electronica. 2001;4(1):9.

9. Hohagen J, Herlitze I, Jackson DJ. An optimised whole mount in situ hybridisation protocol for the mollusc Lymnaea stagnalis. BMC Developmental Biology. 2015;15(19):13.

10. Herlitze I, Marie B, Marin F, Jackson DJ. Molecular modularity and asymmetry of the molluscan mantle revealed by a gene expression atlas. Gigascience. 2018;7(6):1-15.

11. Jackson DJ, Herlitze I, Hohagen J. A Whole Mount In Situ Hybridization Method for the Gastropod Mollusc Lymnaea stagnalis. J Vis Exp. 2016;(109).

12. Herlitze I. Molecular characterisation of biomineralising genes in the freshwater pond snail Lymnea stagnalis. Georg-August-Universität Göttingen; Göttingen. 2017. 


\section{ACKNOWLEDGEMENTS}

My gratitude is due to Daniel John Jackson for affording me the opportunity to keep working on my passion for molluscs during my $\mathrm{PhD}$ research.

I would like to thank Gregor Bucher and Klaus Wolkenstein for their supervision and support. Furthermore I would like to thank Volker Thiel, Christoph Bleidorn, Sven Bradler and Nico Posnien for spending time and effort on my committee.

Nicholas Cerveau deserves thanks for fruitful discussions, explanations when needed and inspiring coffee breaks. I thank Anne Geissler for her support, knowledge on snails and laughs when I most needed them.

I would like to thank Ines Herlitze, Juliane Germer and Eva-Maria Sadowski for their encouragements and sharing their wisdom on PhD life. Alexander Schmidt I thank for mentoring and allowing me to develop my teaching skills.

For sound advise and a push of motivation when needed I thank Elisabeth Haring and Gerhard Steiner, as well as Lisa-Maria Schmidt and Hannah Schmidbaur.

Without the unwavering support, repeated reminders not to give up and a steady tea supply my thesis would probably not be what it is now: Many thanks are due to Leyla Seyfullah!

Regardless of distance and minor and major catastrophes my family always supported me. I am deeply grateful to them for their understanding and encouragements.

I dedicate this thesis to Thomas: You take my crazy phases with a laugh and my desperate ones with a warm hug. Thank you for always reminding me that "Aufgebn tuat ma nur an Briaf" 


\section{CURRICULUM VITAE}

\section{Susanne Affenzeller}

Date of Birth: 3.8.1990

\section{Work experience:}

2016 - 2019 Research associate, Georg-August-University Göttingen, Geobiology: Evolution of the Metazoa group

2014 - 2016 Scientific Collection Management, University of Vienna: Mollusca (Collection SalviniPlawen)

2014 - 2016 University Lecturer, University of Vienna: Basic Course in Phylogenetics 2012 - 2014 University Tutor, University of Vienna: Basic Practical Course in Zoology (Baupläne) Formal Education:

2016 - 2019 PhD (Geoscience) Georg-August-University Göttingen Supervisor: Daniel J. Jackson 2013 - 2015 M.Sc. (Zoology) University of Vienna Supervisor: Gerhard Steiner 2009 - 2013 B.Sc. (Biology) University of Vienna

Nonformal Education:

2009 - 2018 Scout Leadership Training to Woodbadge Level at Pfadfinder und Pfadfinderinnen Österreichs

2017 Workshop "Business Competence and Basic Accounting for Scientists"

2016 Lehrgang Gene Technology, Biosafety and Biosecurity nach $\S 15$ GenTSV, Medizinische Hochschule Hannover 
Affenzeller, S., Cerveau, N., Jackson, D.J. 2018. Identification and validation of reference genes for qPCR in the terrestrial gastropod Cepaea nemoralis. PloS One, 13(8), e0201396.

Affenzeller, S., \& Steiner, G. 2017. Catalog of taxa introduced by Luitfried Salvini-Plawen (1939-2014). Zootaxa, 4337(1), 73-90.

Affenzeller, S., Haar, N., \& Steiner, G. 2017. Revision of the genus complex Gibbula: an integrative approach to delineating the Eastern Mediterranean genera Gibbula Risso, 1826, Steromphala Gray, 1847, and Phorcus Risso, 1826 using DNA-barcoding and geometric morphometrics (Vetigastropoda, Trochoidea). Organisms Diversity \& Evolution, 17 (4), 789-812.

\section{Conference Contributions and Prizes:}

Affenzeller, S., Wolkenstein, K., Cerveau, N., Jackson, D.J. 2018. A Colourful mystery: Insights into the Cepaea nemoralis banding pattern mechanism. Abstracts Abstracts $111^{\text {th }}$ Annual Meeting German Zoological Society, Sept. $10^{\text {th }}-15^{\text {th }} 2018$ Greifswald, Germany

Affenzeller, S., Haar, N. Steiner, G. 2016. Species delineation: Comparing the powers of shell morphometrics and DNA-barcoding in the trochid gastropod genus Gibbula. Abstracts $19^{\text {th }}$ International Congress of UNITAS MALACOLOGIA, July $18^{\text {th }}-24^{\text {th }} 2016$, Penang, Malaysia

Affenzeller, S. 2015. Morphometric approaches to species delineation and characterisation in the trochid Genus Gibbula (Gastropoda). Abstracts Biosystematics from Past to Present 9. Jahrestagung NOBIS, Nov. 27 ${ }^{\text {th }}-28^{\text {th }}$ 2015 Eggenburg, Austria

Affenzeller, S., Haar, N., Steiner, G. 2015. Species delineation: Comparing the powers of DNA-barcoding and shell morphometrics in the trochid gastropod genus Gibbula. Abstracts $108^{\text {th }}$ Annual Meeting German Zoological Society, Sept. $9^{\text {th }}-12^{\text {th }} 2015$ Graz, Austria

Frontiers of Zoology Prize 2015 for Best Student Short Talk in Systematics Symposium: Affenzeller, S., Haar, N., Steiner, G. 2015. Species delineation: Comparing the powers of DNA-barcoding and shell morphometrics in the trochid gastropod genus Gibbula. $108^{\text {th }}$ Annual Meeting German Zoological Society, Sept. $9^{\text {th }}-12^{\text {th }} 2015$ Graz

NOBIS-Preis für herrausragende Forschung 2015: Affenzeller, S. 2015. Morphometric approaches to species delineation and characterisation in the trochid Genus Gibbula (Gastropoda). Abstracts Biosystematics from Past to Present 9. Jahrestagung NOBIS, Nov. $27^{\text {th }}-28^{\text {th }} 2015$ Eggenburg, Austria 
